\title{
WestVirginiaUniversity
}

THE RESEARCH REPOSITORY @ WVU

Graduate Theses, Dissertations, and Problem Reports

2010

\section{Mandatory Reporting in the Context of Home Visitation Programs}

Danielle Marie Davidov

West Virginia University

Follow this and additional works at: https://researchrepository.wvu.edu/etd

\section{Recommended Citation}

Davidov, Danielle Marie, "Mandatory Reporting in the Context of Home Visitation Programs" (2010).

Graduate Theses, Dissertations, and Problem Reports. 3197.

https://researchrepository.wvu.edu/etd/3197

This Dissertation is protected by copyright and/or related rights. It has been brought to you by the The Research Repository @ WVU with permission from the rights-holder(s). You are free to use this Dissertation in any way that is permitted by the copyright and related rights legislation that applies to your use. For other uses you must obtain permission from the rights-holder(s) directly, unless additional rights are indicated by a Creative Commons license in the record and/ or on the work itself. This Dissertation has been accepted for inclusion in WVU Graduate Theses, Dissertations, and Problem Reports collection by an authorized administrator of The Research Repository @ WVU.

For more information, please contact researchrepository@mail.wvu.edu. 


\title{
Mandatory Reporting in the Context of Home Visitation Programs
}

\section{Danielle Marie Davidov}

Dissertation submitted to the

School of Medicine

at West Virginia University

in partial fulfillment of the requirements for the degree of

\author{
Doctor of Philosophy \\ in \\ Public Health Sciences
}

\author{
Jeff Coben, MD \\ Lesley Cottrell, PhD \\ Carole Harris, PhD \\ Susan Jack, PhD, RN \\ Ruth Kershner, EdD, RN \\ Department of Community Medicine
}

\author{
Morgantown, West Virginia \\ 2010
}

Keywords: Intimate Partner Violence, Child Maltreatment, Mandatory Reporting, Home Visitation, Secondary Qualitative Analysis, Survey Research

Copyright 2010 Danielle M. Davidov 


\section{ABSTRACT \\ Mandatory Reporting in the Context of Home Visitation Programs}

\section{Danielle Marie Davidov}

Each year in the United States, 4.8 million physical assaults and rapes are committed against 1.5 million women by an intimate partner. An estimated 3.3 to 10 million children are exposed to some form of intimate partner violence (IPV) in their own homes annually. Although mandatory reporting laws regarding child abuse and/or neglect are implemented in all 50 U.S. states, the extent to which these laws are appropriate for IPV between adults and children exposed to IPV is undetermined. A comprehensive examination of the perspectives of those required to report abuse is critical, as their roles as mandated reporters often pose legal, practical, moral and ethical questions. Even so, the perspective of the mandated reporter is often overlooked. Very few studies have examined the perspective of the mandated reporter with regard to reporting of IPV and children exposed to IPV. Even less research has been dedicated to mandated reporters who work outside of clinical settings, such as public health nurses, who engage in home visitation with clients. The main objective of this project was to enhance our understanding of mandatory reporting issues with regard to IPV and children's exposure to IPV within the context of home visitation programs. In the first study, a secondary analysis of qualitative data was employed to examine community stakeholders', clients', and home visiting nurses' perspectives of mandatory reporting of IPV and children's exposure to IPV within the context of the Nurse-Family Partnership (NFP) home visitation program. Findings demonstrated that issues surrounding reporting in these instances are salient and warrant further investigation with the population of home visitors, as nurses in the focus groups revealed wide variability and uncertainty with regard to their reporting obligations. In the second study and third studies, a web-based survey was administered to NFP nurses in order to quantify the emergent themes found in the qualitative study. The results of the second study revealed that nurse home visitors generally support mandated reporting of IPV, yet exhibited varied attitudes with regard to the impacts of reporting. Furthermore, many nurses revealed uncertainty with regard to reporting duties when managing clients experiencing IPV. The third study assessed home visitors' perceptions of mandated reporting of children's exposure to IPV. Results of this study demonstrated that the majority of our sample believed reporting IPV perpetrated in the presence of a child can help the battered woman and protect her children, but can also result in negative repercussions on the nurse-client relationship, such as limiting the disclosure of abuse to the home visitation provider. Furthermore, nurses were more likely to endorse reporting of children's exposure to IPV when the child was at greatest risk for being physically injured as a result of the IPV between adults. The results of these three studies highlight the need for comprehensive guidelines for providers managing clients and children exposed to IPV that routinely interact with abused women and their children, but may not provide medical treatment, as a substantial proportion of home visitors were uncertain about their obligations to report IPV towards women or perpetrated in the presence of a child. This research demonstrates the importance of examining the perspective of the mandated reporter with regard to managing IPV in home visitation settings. Our findings support and enhance previous research about mandated reporting and demonstrate the need for training, education, and intervention in order for health care providers to appropriately support women and children exposed to IPV. 


\section{DEDICATION}

I proudly dedicate this dissertation to my mother, the strongest and smartest women I've ever known. 


\section{ACKNOWLEDGEMENTS}

I would like to express my deepest gratitude to my advisor, Dr. Jeff Coben, who has provided me with invaluable guidance and supervision over the past three years. His faith in my abilities gave me the confidence to successfully carry out this project even when I doubted myself. Thank you, Dr. Coben, for always being available even though you are one of the busiest people I have ever known. Thank you for your responsiveness to my questions and concerns and for always pushing me to do my very best.

I would also like to acknowledge my committee members-Dr. Lesley Cottrell, Dr. Carole Harris, Dr. Susan Jack, and Dr. Ruth Kershner for their guidance and support in this process. I would like to extend a special thanks to Dr. Jack who shared her incredible skills and knowledge of conducting and analyzing qualitative research with me. I would also like to thank Dr. Kershner for her continual support and inspiration.

My thanks go out to the faculty and staff in the Department of Community Medicine, whose doors were always open, and to Dr. Keith Zullig, Director of the Public Health PhD program, who has worked so hard to develop a strong foundation for the program. I would also like to thank Dr. Rob Pack for recruiting me into the PhD program and providing me with encouragement, guidance, and support when the field of public health was foreign to me. For his consultation regarding statistical methods, I would also like to thank Dr. Matt Gurka.

It is a pleasure to thank the faculty and staff at the Injury Control Research Center, especially Bonnie Grimm, Mike Furbee, Dave Fulaytar, and Becky Shingleton, who were always warm and welcoming, and made going to work every day a fun and never boring experience. I am also grateful to Steve Davis who was always available to answer my IRB-related questions.

I also wish to thank all of my fellow graduate students in the $\mathrm{PhD}$ program, especially Penney Baughman, Ekta Choudhary, Stephanie Frost, and Traci Jarrett. It has been a pleasure sharing doctoral life with each of you and I feel honored to know such an amazing group of woman. I would also like to thank Mike Nadorff in the Department of Psychology for his assistance with manuscript preparation and statistical procedures.

I would also like to recognize and thank the Nurse-Family Partnership Intimate Partner Violence Research Team. I am humbled and honored to have been a part of this group of incredible researchers. I am especially grateful to Dr. Harriet Macmillan and Dr. David Olds. Special thanks go out to Mariarosa Gasbarro who helped facilitate my primary data collection. I would also like to acknowledge the women, home visiting nurses, and community stakeholders that participating in the current research and made the completion of my dissertation possible.

Last, I would like to thank my family and friends for their unconditional love and support, and my wonderful boyfriend, James, for his encouragement and patience. 


\section{TABLE OF CONTENTS}

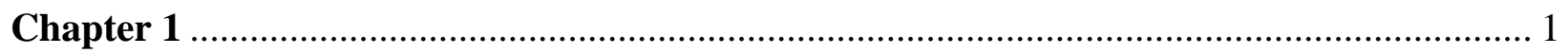

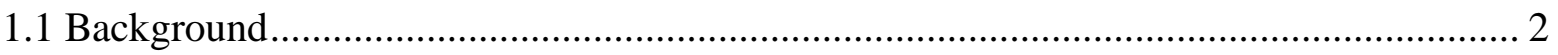

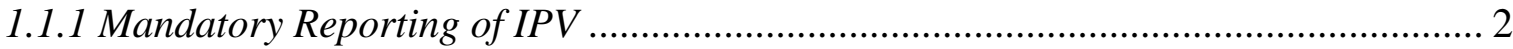

1.1.2 IPV and Child Maltreatment............................................................................... 5

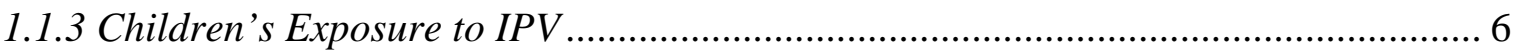

1.1.4 Mandatory Reporting of Children's Exposure to IPV ................................................ 7

1.2 Current Gap in the Literature........................................................................................ 9

1.2.1 Home Visitation Programs .................................................................................... 10

1.2.2 Nurse Family Partnership Program ..................................................................... 11

1.3 The Purpose of the Current Research ............................................................................ 12

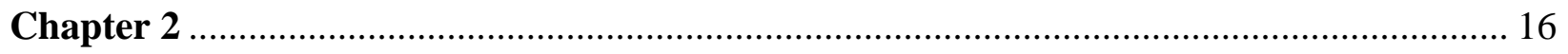

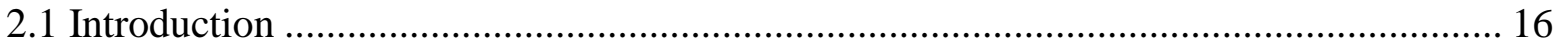

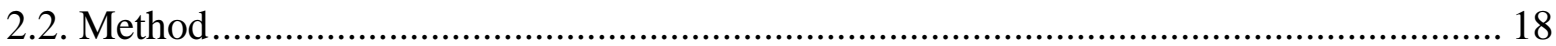

2.2.1 Participants and Procedures .................................................................................. 18

2.2.2 Secondary Data Analysis .................................................................................... 20

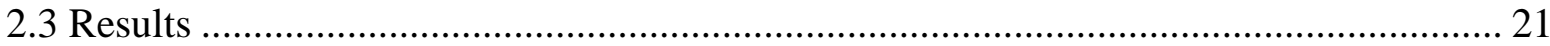

2.3.1 Mandatory Reporting of IPV and Children's Exposure to IPV ................................ 21

2.3.2 Clients' Fears of Losing Custody of Children ........................................................... 23

2.3.3 Experiences with Child Protective Services ............................................................. 25

2.3.4 Strategies Nurses Can Use to Ease Clients’ Fears.................................................... 26

2.3.5 Nursing Skills and Knowledge Required for Effective Reporting............................ 28

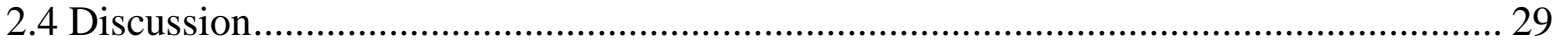

2.4.1 Strengths and Limitations .................................................................................... 32

2.4.2 Implications for Research, Practice, and Policy ....................................................... 33

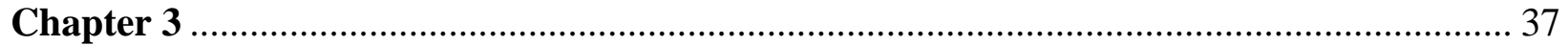

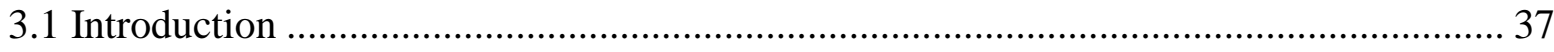

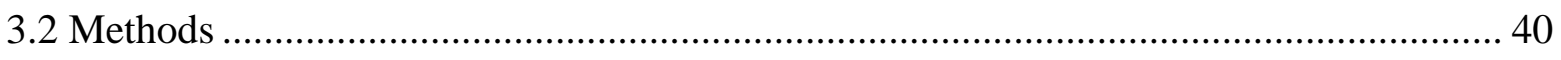

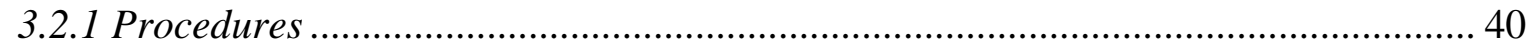

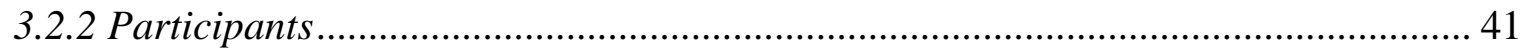




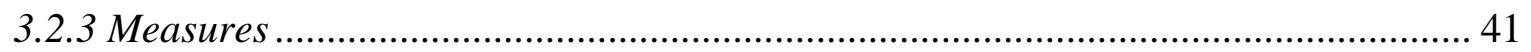

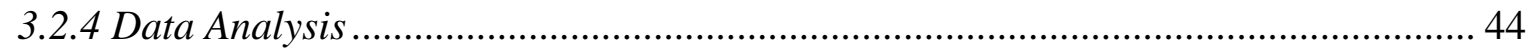

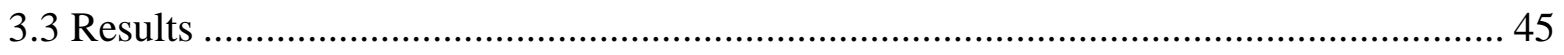

3.3.1 Attitudes, Perceived Awareness, and Intended Reporting Behavior ........................ 45

3.3.2 Logistic Regression Analyses................................................................................... 47

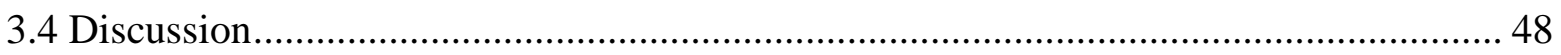

3.4.1 Strengths and Limitations .................................................................................. 51

3.4.2 Conclusion ……………………......................................................................... 53

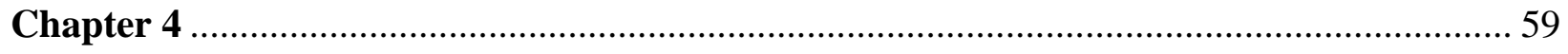

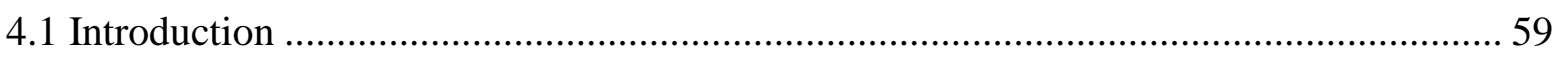

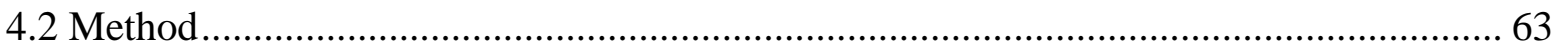

4.2.1 Participants and Procedures ............................................................................ 63

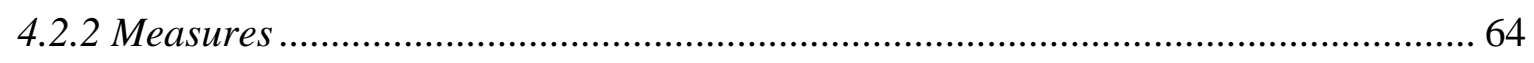

4.2.3 Data Analysis ...................................................................................................... 66

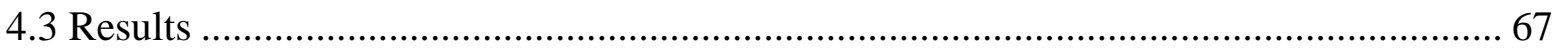

4.3.1 Demographic Characteristics .............................................................................. 67

4.3.3 Home Visitation Scenarios..................................................................................... 68

4.3.4 Logistic Regression Analyses............................................................................ 69

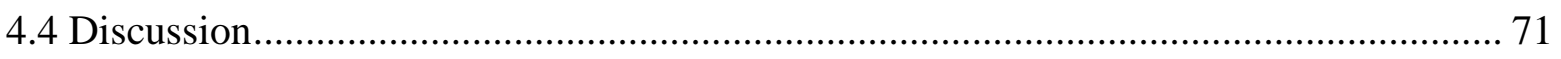

4.4.1 Strengths and Limitations ……………………….......................................... 75

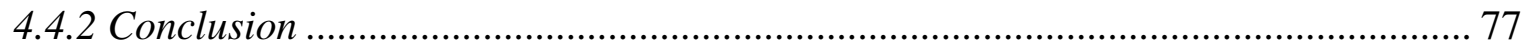

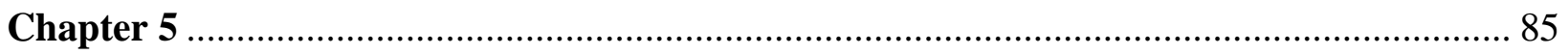

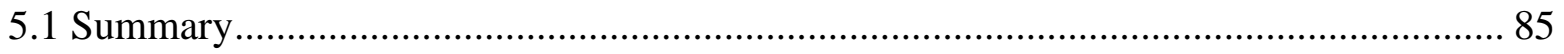

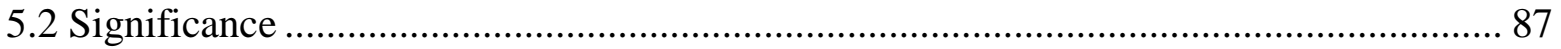

5.3 Strengths and Limitations ............................................................................................... 88

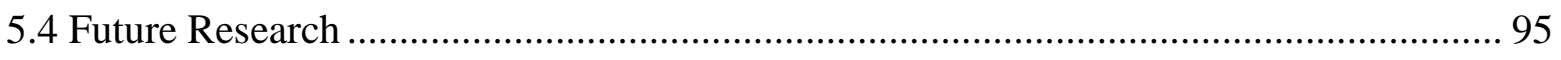

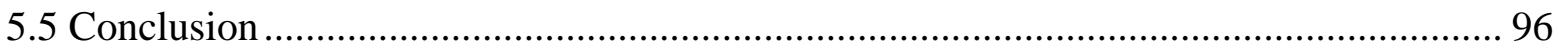

Appendix A: Home Visitation Scenarios................................................................................... 98

Appendix B: Comparisons of Sample Characteristics with Population ………………................. 99

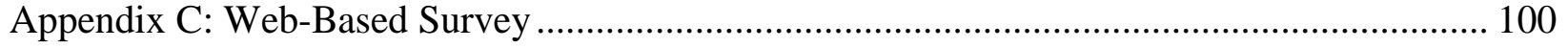

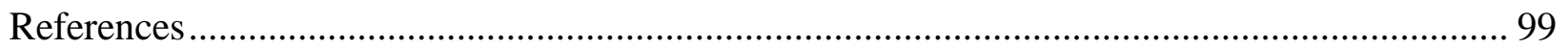




\section{Chapter 1}




\section{Chapter 1}

\subsection{Background}

Intimate Partner Violence (IPV) is defined by the Centers for Disease Control and Prevention (CDC) as "physical, sexual, or psychological harm by a current or former partner or spouse". ${ }^{1}$ The vast majority of violence against women is committed by an intimate partner, with 1.5 million being physically assaulted and/or raped each year in the United States. ${ }^{2}$ The lifetime prevalence estimates of IPV fall between $25 \%$ and $30 \%$, and it is estimated that between $2 \%$ and $12 \%$ of women in the U.S. experience IPV annually. ${ }^{2}$ IPV is associated with deleterious consequences to a woman's health. ${ }^{3-5}$ The physical health effects for female victims of IPV include, but are not limited to, severe injuries, stress and pain, digestive problems, eating disorders, neurological damage, and reproductive health problems. ${ }^{4-7}$ Women who have been physically or sexually abused by an intimate partner are more likely to engage in high-risk sexual behaviors ${ }^{5,6}$ and are at greater risk for sexually-transmitted infections, ${ }^{5,8}$ unintended pregnancy, 9, 10 and induced abortions. ${ }^{5}$ Psychological consequences include depression, anxiety, posttraumatic stress disorder (PTSD), insomnia, social dysfunction, and substance abuse. ${ }^{7,11-13}$ IPVrelated injuries ranging from gunshot wounds, stabbings, broken bones and internal injuries to injuries from sexual assault, bruises, cuts and/or swelling often require medical treatment for the victim. $^{2}$

\subsubsection{Mandatory Reporting of IPV}

Primary health care facilities, such as emergency departments, are often the first place victims turn to as a result of acute or chronic consequences of IPV. ${ }^{13-15}$ Appropriate medical intervention strategies are needed to safely and effectively meet the needs of victims of IPV. ${ }^{2}$ One currently debated strategy is the legal requirement of health professionals who may 
routinely interact with individuals exposed to violence to report instances of abuse to proper authorities—making them mandated reporters. Examples of mandated reporters include, but are not limited to, physicians, mental health specialists, dentists, nurses, social workers and other caretakers. Instances of abuse and/or neglect to vulnerable populations, such as children and the elderly, are routinely reported to the police. ${ }^{16,17}$ In addition, most states legally mandate health care workers to report patients with injuries resulting from illegal acts, such as use of a gun, knife or other weapon, sexual assaults, and injuries resulting from criminal activity to law enforcement authorities. ${ }^{16,18,19}$ These mandatory reporting laws potentially apply to injuries sustained as a result of IPV $;{ }^{20}$ however, the extent to which these laws are appropriate for IPV between adults and children exposed to IPV is undetermined. ${ }^{18}$ Currently only six states specifically mention in their statutory law that health care providers are to report instances of IPV to the criminal justice system, ${ }^{15,21}$ the laws of which are summarized in Table 1.

Table 1: Mandatory Reporting Laws Specifically Mentioning IPV

\begin{tabular}{|l|l|}
\hline State & Mandatory Reporting Law \\
\hline California & $\begin{array}{l}\text { Health care providers are mandated to report to the police if they have reasonable } \\
\text { suspicion that the injury was caused by IPV. }\end{array}$ \\
\hline Colorado & $\begin{array}{l}\text { Physicians are mandated to report to the police if they attend to an injury resulting from a } \\
\text { criminal act or caused by a weapon, including IPV. }\end{array}$ \\
\hline Kentucky & $\begin{array}{l}\text { Health care providers are mandated to report to the Cabinet of Human Resources (which } \\
\text { reports to the police) if they have suspicions that an adult is the victim of abuse, neglect } \\
\text { or exploitation. }\end{array}$ \\
\hline Hampshire & $\begin{array}{l}\text { Health care providers treating gunshot wounds or other injuries caused from a criminal } \\
\text { act, including IPV, are mandated to report (unless the patient is a victim of sexual } \\
\text { assault/abuse, is > 18 years of age and objects to the report). }\end{array}$ \\
\hline New Mexico & $\begin{array}{l}\text { Health care providers are mandated to report injuries caused by deadly weapons and IPV } \\
\text { for data collection purposes. }\end{array}$ \\
\hline Rhode Island & \begin{tabular}{l} 
Health care providers are mandated to report IPV instances to the police. \\
\hline
\end{tabular}
\end{tabular}

Note. Table modified from References 15 and 21. 
As can be seen in Table 1, wide variability is observed within the wording of these laws and each state has its own distinct reporting procedures, definitions of abuse, and designations regarding who is considered a mandated reporter. Beyond these statutory legal requirements, health care providers may be under the impression that they are mandated to report IPV as a result of publicized and/or agency reporting requirements. ${ }^{21}$ Thus, inconsistencies with regard to mandatory reporting may emerge at the agency or state level, and the decision to report is often left open to interpretation by the mandated reporter, raising professional and ethical questions. ${ }^{22}$

As a result, the mandatory reporting of IPV between adults has become a controversial issue. ${ }^{23}$ Specifically, a mandatory reporting law may pose ethical concerns for health care professionals as well as infringe upon the victim's safety. ${ }^{24}$ This controversy is exacerbated by the lack of evidence regarding the mandatory reporting of IPV in reducing the risk of violence against women. ${ }^{25}$ Those in favor of mandatory reporting of IPV argue that such a law will lift the burden of reporting IPV off of the victim, ${ }^{19}$ hold the perpetrator legally accountable for the violence, ${ }^{19,20}$ as well as facilitate perpetrator prosecution. ${ }^{23}$ These advocates feel that mandatory reporting of IPV sends a clear message to society that violence will not be tolerated. ${ }^{15,18,20}$ Opponents of mandatory reporting of IPV feel that reporting requirements for incidents of IPV may disrupt provider-patient confidentiality, ${ }^{15,18,20}$ may deter victims from seeking medical care, ${ }^{16,18,19}$ undermine patient autonomy, ${ }^{15,18,20}$ and may limit victim disclosure of IPV. ${ }^{25}$ Importantly, those opposed to mandatory reporting of IPV feel it can potentially put the victim at risk for greater retaliation by the abuser. ${ }^{16,18}$

It is understood that victims’ perspectives, experiences, and policy preferences should be considered before support or opposition for mandatory reporting laws should be given. ${ }^{16,20,25}$ Hence, a substantial amount of research has been dedicated to examining IPV victims' attitudes 
toward mandatory reporting laws regarding IPV ${ }^{16,17,19,23,25-29}$ as well as the opinions of female patients in clinical settings ${ }^{19,23,26,27}$ and individuals in the general population. ${ }^{16}$ The results of these studies show that the majority of the general population, clinic samples and even recently or currently abused women support mandatory reporting laws. ${ }^{16,17,19,23,25-29}$ Even with this support, several studies found that abused women who report current, recent, or lifetime IPV support mandatory reporting laws significantly less than women who have not been victims of IPV. ${ }^{16,25,26}$ Furthermore, a substantial proportion of participants in most studies, especially victims of IPV, felt that a mandatory reporting law may increase the risk of perpetrator retaliation. The authors of these studies as well as several medical organizations caution the interpretation of these results without further research on the risks and benefits of mandating IPV reporting, ${ }^{16}$ illustrating that the controversy and debate surrounding the mandatory reporting of IPV is far from resolved.

\subsubsection{IPV and Child Maltreatment}

The aforementioned review of the literature focuses on the adult female victim of IPV; however, children in homes where IPV is perpetrated often experience co-occurring child maltreatment. ${ }^{30}$ Rates of overlap between IPV and child maltreatment fall between $30 \%$ and $60 \%$ in the general population. ${ }^{31,32}$ Child maltreatment encompasses both child abuse and/or neglect. Mandatory reporting of child maltreatment is considered good care ${ }^{16}$ and has been in place in all 50 U.S. states since the passage of the Child Abuse Prevention and Treatment Act (CAPTA) in 1974. While CAPTA provides a foundation for the definition of child maltreatment, it does not provide specific definitions of what constitutes physical abuse, emotional abuse, or neglect. Therefore, each state is responsible for providing its own definition of these forms of maltreatment as well as describing the circumstances that obligate reporting of known or 
suspected child abuse and deciding which forms of child maltreatment should be criminally punishable. $^{33}$

Consequently, wide variability in specific definitions of child maltreatment exists throughout the U.S. In 1998, Appel and Holden found 15 different definitions of child abuse used within 31 reviewed studies of child maltreatment and IPV. ${ }^{32,34}$ The majority of these studies focused on physical child abuse; however, research shows that children living in families

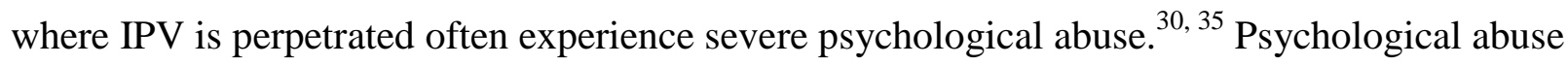
may include mental abuse, ridiculing, threats of physical abuse, as well as emotional and mental neglect. ${ }^{35}$ Furthermore, there has been increasing concern among researchers and policymakers that the witnessing of IPV by children can be considered a form of psychological child abuse in and of itself. ${ }^{30,34}$ The debate surrounding whether children's exposure to IPV in the home should be considered a form of child maltreatment is extremely complex. ${ }^{30}$

\subsubsection{Children's Exposure to IPV}

Annual estimates of children exposed to IPV fall between $10 \%$ and $20 \%{ }^{36,37}$ with a commonly cited estimate ranging from 3.3 to 10 million children exposed to IPV each year. ${ }^{37-40}$ Furthermore, it has been projected that anywhere from 25\% to one-third of all children are exposed to IPV at some point during childhood. ${ }^{37,41}$ Children can be exposed to IPV in several ways other than visually witnessing violence between adults. Exposure can include overhearing violent conflicts, intervening in the incidents, or seeing the after-effects of the violence, such as destruction of furniture or observing bruises or injuries of the adult. ${ }^{37,42}$ Similar psychopathology is found between children who have been exposed to IPV and those who have been victims of physical abuse themselves. ${ }^{43}$ Infants and toddlers may display excessive irritability, sleep

disturbances, emotional distress, ${ }^{44,45}$ disrupted feeding patterns and poor weight gain, ${ }^{46}$ as well 
as regression with regard to toilet-training, ${ }^{45,47}$ thumb-sucking, ${ }^{47}$ and language development. ${ }^{45}$ An integrative review of the literature by Sox revealed that increased aggression and conduct disorder, depression, anxiety, low self-esteem, poor school performance and impaired social skills were significantly more prevalent among children exposed to IPV than children who were not. ${ }^{48}$ Children exposed to IPV in the home are also at an increased risk for developing PTSD ${ }^{47-49}$ as well as greater lifelong psychopathology than children not exposed to IPV. ${ }^{50}$ Twin studies have shown that witnessing IPV can suppress a child's Intelligence Quotient (IQ) by as much as 8 points. ${ }^{51}$ Furthermore, childhood exposure to IPV is linked to negative health outcomes later in life, as children exposed to IPV are at greater risk for unintended pregnancy, ${ }^{52}$ sexuallytransmitted infections, ${ }^{53,54}$ substance abuse, ${ }^{54}$ smoking, ${ }^{55}$ and suicide. ${ }^{56}$ Studies have also shown that sons who observe IPV between adults in childhood have an increased risk for perpetrating IPV in adulthood, ${ }^{40,57}$ with a recent study estimating an increased risk of $56-63 \%$, depending on the severity of abuse witnessed during childhood. ${ }^{58}$

\subsubsection{Mandatory Reporting of Children's Exposure to IPV}

Taking into account the aforementioned negative short and long-term consequences of exposure to IPV, it is not surprising that some health care providers, researchers, and policymakers feel it is appropriate to consider childhood exposure to IPV a form of child maltreatment. Since child maltreatment is a reportable condition in all 50 U.S. states, equating exposure with maltreatment would require all suspected or verified instances of IPV in homes where children are present to be reported to proper authorities. Given the implications of such a law, an intense debate currently exists about whether or not mandatory reporting of children's exposure to IPV is necessary. 
Proponents of mandatory reporting feel that expanding the definition of child maltreatment to include exposure to IPV is necessary to bring at-risk children to the attention of child welfare agencies in order to prevent long-lasting damage to children in violent homes. ${ }^{59}$ Opponents to this expansion feel that it may unnecessarily overwhelm an already overburdened, underfunded system of child protection agencies (CPS). ${ }^{60,61}$ The possibility of charging the abused victim with "failure to protect" her child from harm, as well as the removal of the child from the home may also revictimize both mother and child. ${ }^{59,62}$ Those against the expansion also posit that it may discourage women from seeking police protection or medical care out of fear that they will lose custody of their children. ${ }^{59,61,62}$ Furthermore, not all children experience adverse consequences from exposure to IPV and mandated reporting may be inappropriate and possibly damaging in these instances. ${ }^{59}$

Currently, Alaska is the only state whose child maltreatment statute clearly defines IPV perpetrated in the presence of a child as a form of child abuse within its juvenile code, making it a reportable condition to CPS. ${ }^{62}$ Alaska's statute asserts that conditions created by parents or guardians, such as crimes of assault or sexual assault between adults, that result in mental injury or substantial risk of mental injury to the child, are to be reported. ${ }^{62}$ Several other states also use language such as "substantial risk" or "mental injury" in their definitions of child abuse or reporting statutes, but the descriptions are state-specific, vague, and left up to the interpretation of the health care provider. ${ }^{62}$ In 1999, Minnesota expanded its definition of child neglect to include IPV within "sight or sound of the child". The change was considered a "modest expansion" of the current definition, yet it resulted in a $50-100 \%$ increase in reports of child maltreatment to CPS. ${ }^{63}$ The change significantly increased CPS agency workloads in the majority of Minnesota's counties and the legislation impacted some children who were in 
desperate need of help, but also affected other children who were not. In addition, no specific funding was set aside for the new definition and resulting implications, leading social service administrators to call the change an "unfunded mandate". In 2000, Minnesota repealed the definition change. Policymakers learned from Minnesota's experience the importance of coupling definitional changes with significant changes in practice as well as adequate resources for implementation. ${ }^{63}$

\subsection{Current Gap in the Literature}

In the complex debate surrounding mandatory reporting of IPV and of children's exposure to IPV, policymakers and researchers have recognized the need for collaborations between CPS, IPV victim services, and the criminal justice system as well as the importance of victims' perspectives. ${ }^{59,60,63}$ However, less attention has been given to the mediating step in the process of reporting - the mandated reporter. As individuals mandated to report abuse often face legal, practical, moral and ethical dilemmas in their professions, the perspective of the mandated reporter is imperative, but often overlooked. ${ }^{22}$ The extreme variability in statutory and agencyspecific reporting laws translates into serious implications for mandated reporters. Failing to report an instance of child maltreatment or IPV where doing so is mandated is considered a misdemeanor and the mandated reporter can face substantial fines and possible time in jail. ${ }^{22,63}$ Thus, it is it crucial that mandated reporters are aware of their states' laws with regard to mandatory reporting of IPV and child exposure to IPV—an awareness that may be difficult to ascertain, given the wide variability in mandatory reporting laws in each state. Lastly, it is crucial that mandatory reporting legislation be practical, effective, and realistic for mandated reporters to carry out in clinical and real-world settings ${ }^{63}$ Most research involving mandated reporters’

perspectives of mandatory reporting focuses on reporting child abuse, ${ }^{64-66}$ although most of these 
mandated reporters are generally aware of their reporting duties with regard to child maltreatment. ${ }^{22}$ Less research has been conducted about the mandatory reporting of IPV and significantly less about the mandatory reporting of children’s exposure to IPV.

\subsubsection{Home Visitation Programs}

Most mandated reporters work in clinical settings and attend to patients and clients who travel to the primary care facility to access services. However, one group of mandated reporters, public health nurses, is often responsible for providing services inside their clients' homes. This allows nurses to build a therapeutic relationship with the client that is unlike one that may develop in clinical settings. ${ }^{67-69}$ Nurses in these situations are more likely to become aware of the full range of experiences these families share than mandated reporters who work in clinical settings. Specifically, home visitation may encourage or discourage the disclosure of IPV. Not only do home visiting nurses screen for abuse, they are actually in a position to witness IPV. Home visiting nurses who are aware of instances of child maltreatment are legally required to report to CPS.

Furthermore, research suggests differences lie in child maltreatment reporting between those professionals involved in home visitation and those working in clinical settings. ${ }^{70-72}$ Specifically, studies show that professionals involved in home visitation are significantly more likely to report incidents of maltreatment to CPS, resulting in a surveillance bias between home visited families where maltreatment is present and those families with maltreatment that do not receive home visitation services. ${ }^{70-72}$ This suggests that nurse home visitors' experiences with women and children exposed to domestic violence are likely to be different from those in clinical settings; however, this populations' perspectives regarding mandatory reporting of IPV and children's exposure to IPV remain unexplored. 


\subsubsection{Nurse Family Partnership Program}

The Nurse-Family Partnership (NFP) is an evidenced-based, home-visiting program for first-time, disadvantaged mothers. The program's mission is to improve the health and wellbeing of mothers and their children by providing education and services through nurse home visitation, beginning in the pre-natal period and extending through the child's second birthday. ${ }^{73}$ Currently, the NFP program is serving clients in 385 counties throughout 32 U.S. states and over 1,000 NFP nurse home visitors are working to support the 21,494 families presently enrolled in the program. ${ }^{74}$ The NFP program has been rigorously tested in three prior randomized controlled trials. ${ }^{75-79}$ These trials demonstrated that the NFP has consistent and enduring program effects for both mother and child; ${ }^{76-81}$ most notably, a 15-year follow-up of one randomized trial showed that families who were visited by a nurse during pregnancy and until the child was two years of age experienced a 50\% reduction in state-verified reports of child maltreatment versus the comparison group. ${ }^{79}$

The majority of women enrolled in the NFP program are young (median age $=19$ years), unmarried (84\%), and possess lower levels of education (median education $=11$ years) and income (median annual income $=\$ 13,500){ }^{82}$ These risk factors that make a client eligible for enrollment in the NFP program are also associated with an increased likelihood of experiencing IPV. ${ }^{83}$ A study conducted by Eckenrode and colleagues revealed that a sample of NFP clients reported IPV at a rate twice as high as in the general population. ${ }^{84}$ Thus, it is likely that NFP nurses will home visit with women exposed to IPV in the course of their home visitation schedules, and they may face additional challenges when working with families where IPV and children's exposure to IPV is occurring. 


\subsection{The Purpose of the Current Research}

Before interventions for IPV (such as mandatory reporting laws) can be put into place, it is crucial that their practicality, applicability, feasibility, relevance, and efficacy be properly measured. In the same vein, it is critical that those individuals who deliver these interventions (mandated reporters) feel that the intervention is practical, applicable, feasible, and relevant to the populations with which they work. Because of the close relationship that develops between nurses and clients as well as the nurses' proximity to potentially violent situations, issues surrounding mandatory reporting may be problematic for nurses involved in home visitation services. This research seeks to address the current gap in the literature by focusing on the perspective of the mandated reporter — a population that has been overlooked and understudied in research about mandated reporting of IPV. Home visiting nurses' perspectives of mandatory reporting of IPV between adults and of mandatory reporting of children's exposure to IPV are likely to be informative and may highlight some of the risks and benefits of enacting mandatory reporting laws. The NFP program, the most efficacious ${ }^{85}$ and rigorously tested ${ }^{86}$ home visiting program in the U.S. provides an ideal setting to explore this issue.

The study described in Chapter 2 uses secondary analysis of qualitative data to examine mandated reporting in the context of home visitation services within the NFP program. Qualitative data collected from NFP nurses, NFP clients, and community stakeholders were analyzed in order to obtain an in depth understanding of issues related to 1) mandatory reporting of IPV between adults and 2) mandatory reporting of children's exposure to IPV. The results of this analysis complement other findings in the literature about abused women's reluctance to disclose abuse to health care providers and their fears losing their children due to involvement with law enforcement or CPS. This qualitative study also provided a solid foundation for the 
development of a survey that was used to examine nurse home visitors’ perspectives of mandatory reporting, which is described in Chapters 3 and 4.

The studies described in Chapters 3 and 4 extend our understanding of the perspective of the mandated reporter (i.e., the nurse home visitor). A web-based questionnaire was administered to nurse home visitors in the NFP program in order to capture their perceived awareness of reporting requirements, attitudes towards mandated reporting, and intended reporting behaviors. Chapter 3 focuses on these issues with regard to mandated reporting of IPV between adults, while Chapter 4 explores nurse home visitors’ perspectives of reporting children's exposure to IPV.

It is important to note that one of our original aims was to collect data on home visiting nurses' own history of abuse and examine the influence of this past history on the respondents' support or non-support for mandatory reporting of IPV and children's exposure to IPV, as well as nurses' intended reporting behaviors. However, due to restrictions placed on the survey questions by the NFP's Research and Publication Communication Committee (RAPCOMM), we were unable to ask nurses about their personal history of abuse. The studies described in Chapters 3 and 4 provide a descriptive overview of nurse home visitors' perspectives of mandated reporting, and this information was used to predict support for mandated reporting and intended reporting behavior.

In summary, there is a paucity of research that explores the perspectives of mandated reporters with regard to reporting IPV and children's exposure to IPV. Research that has focused on mandated reporting in these instances, especially children's exposure to IPV, has referred to this issue as a "gray zone" or "gray area". ${ }^{60,87}$ As mandated reporting can result in legal and ethical consequences for those mandated to report, it is crucial that mandated reporters be aware 
of the instances that require reporting of IPV and of children's exposure to IPV, yet little information is available that sheds light on mandated reporters' current knowledge, attitudes, and practices regarding these two controversial issues. The results of these three studies will advance scientific knowledge by examining the uncovered perspectives of public health home visiting nurses regarding mandatory reporting laws. 
Chapter 2 


\section{Chapter 2}

Mandatory Reporting in the Context of Home Visitation Programs: Intimate Partner Violence and Children's Exposure to Intimate Partner Violence. Accepted for publication in Violence Against Women. ${ }^{103}$

\subsection{Introduction}

The mandatory reporting of intimate partner violence (IPV) has become a controversial issue among health care practitioners, victims of IPV and victim advocates. ${ }^{23} \mathrm{As}$ children in homes where IPV is perpetrated often experience co-occurring abuse and/or neglect, the controversy surrounding mandatory reporting of IPV is intensified..$^{30}$ Rates of overlap between IPV and child maltreatment fall between $30 \%$ and $60 \%$ in the general population. ${ }^{31,32}$ Mandatory reporting of child maltreatment is legally mandated in all 50 U.S. states. However, each state provides its own definition of what constitutes maltreatment, describes the circumstances that obligate reporting, and decides which forms of maltreatment should be criminally punishable. ${ }^{33}$ Consequently, wide variability in specific definitions of child maltreatment exists between states. ${ }^{32}$ There is increasing concern that children exposed to the abuse of their mother constitutes a form of psychological abuse at the most basic level..$^{30,34}$ Since child maltreatment is reportable in all 50 U.S. states, equating exposure to IPV with child maltreatment would require all suspected or verified instances of IPV in homes where children are present to be reported to child protective service (CPS) agencies.

The limited amount of previous research concerning IPV reporting has focused on the perspectives of IPV victims, ${ }^{19,25,88}$ female patients in clinical settings, ${ }^{20,23,26}$ and the general population, ${ }^{16}$ with even less research capturing the perspective of the mandated reporter. In addition, most previous research concentrates on mandatory reporting in clinical settings, such as the emergency department. Some groups of mandated reporters, such as public health nurses or 
social workers, often provide services inside their clients' homes through home visitation programs. Home visiting programs have emerged as a primary intervention for improving the health and well-being of pregnant mothers and families with newborns and young children, particularly among disadvantaged populations. These home visiting programs vary considerably in regards to program content, initiation, frequency, and termination of visits, as well as educational and skill level of the home visitor. ${ }^{89}$

The Nurse-Family Partnership (NFP) program is an evidence-based home visitation program for young, first time-disadvantaged mothers that has been rigorously evaluated in three randomized controlled trials. ${ }^{75-77,86}$ Most women enrolled in the NFP program are unmarried $(84 \%)$ and report low income (median annual income $=\$ 13,500) .^{82}$ The risk indicators for client eligibility to enroll in the NFP are similar to indicators associated with abuse exposure. ${ }^{83}$ It is probable that clients enrolled in the NFP program are more likely to experience IPV than women in the general population. In fact, a sample of NFP clients in a study conducted by Eckenrode and others reported IPV at a rate twice as high as in the general population. ${ }^{84}$

Home visiting nurses have opportunities to develop trusting therapeutic relationships with their clients over time which may facilitate their ability to identify and respond to their clients' exposure to IPV. ${ }^{67-69}$ Trying to balance clients’ wishes, confidentiality, and privacy with their legal duty as mandated reporters for child maltreatment may pose legal and ethical dilemmas for nurses. This dilemma is especially pertinent to health care professionals involved in home visitation, because of the therapeutic relationship that develops between client and home visitor. ${ }^{68,69,}{ }^{90}$ As a result, when working in homes where IPV or child maltreatment is occurring, home visitors are likely to face challenges that medical professionals in clinical settings may not encounter. ${ }^{69}$ Being fully aware of local mandated reporting duties, including the mandated 
reporting of IPV or reporting children's exposure to IPV, is as crucial for those who work in home settings as those who work in clinical settings. The perspectives of those involved in home visitation services are likely to be informative and may highlight some of the risks and benefits of enacting mandatory reporting laws. The NFP program provides an ideal setting to explore this issue. The purpose of this secondary qualitative analysis study was to identify and describe issues related to mandatory reporting within the context of home visitation. This analysis will focus on (a) the mandatory reporting of IPV between adults, and (b) the mandatory reporting of children's exposure to IPV.

\subsection{Method}

The current study is a secondary analysis of data collected from NFP clients, nurses, and community stakeholders for the qualitative phase of a larger, 5-year project aimed at developing an intervention for IPV in the context of the NFP program. The sample of NFP sites $(N=4)$ was purposefully selected from a sampling frame of all NFP sites that (a) have graduated at least one cohort of NFP clients, (b) have nurses who are home visiting women exposed to IPV, (c) exhibit low levels of nurse attrition, and (d) have a high percentage of nurses who have provided home visitation services for more than two years.

\subsubsection{Participants and Procedures}

\subsubsection{Interviews with NFP Mothers}

At each of the four NFP sites, clients who reported exposure to moderate or severe levels IPV within the past one year on the abuse assessment administered as part of the NFP program, were 16 years of age or older, and were English-speaking were invited to participate in two faceto-face interviews. Clients were recruited into the study until the point of saturation. A total of 20 women participated in the first interview and 16 returned for a follow-up interview six months 
later. Participants were given a \$30 gift certificate and were reimbursed for travel and child care expenses for each interview. The mean age of the clients was 21.3 years. The clients were racially diverse—50\% were White, 25\% Black, and 15\% Hispanic—and the majority (90\%) reported being single or never married. Twelve of the women (60\%) currently had a partner and seven (35\%) were pregnant during the first interview. Their mean number of years of school completed was 11.7 and $80 \%$ reported a total income less than $\$ 24,000$.

\subsubsection{Focus Groups with NFP Nurses}

NFP nurses who reported home visiting abused NFP clients were invited via email to participate in two focus group interviews. Two 90- to 120-minute focus group interviews were conducted at each of the four selected NFP sites ( $N=8$ focus groups), with the same sample of nurses from each site participating in the first and second focus groups. Each focus group was comprised of four to seven NFP nurses to ensure maximum interaction and participation from participants, resulting in 23 nurses attending the first series of focus groups and 25 nurses

participating in the second round of focus group interviews. The mean age of the nurses was 46.2 years and 92\% held a bachelor's degree or more education. Their mean number of years of nursing experience was 19.7 (range $=5$ to 38 years) and the mean number of years as a nurse home visitor in the NFP program was 4.4 years.

\subsubsection{Interviews with Community Stakeholders}

Interviews with NFP program stakeholders were conducted in order to understand community stakeholders' roles in supporting women exposed to IPV as well as to identify facilitators and barriers these stakeholders face in responding to IPV within the community. Local research assistants at each site, NFP personnel, and study investigators worked to identify relevant key informants in each of the four communities. Ten (45\%) community stakeholders 
were employed in shelter services, six (27\%) worked in law enforcement or legal agencies, four (18\%) worked in a hospital or in public health services, and two (9\%) were involved in education. Stakeholders reported working in their current positions for a mean of 9.2 years. Their mean age was 50.5 years.

The semi-structured interview guides focused on facilitating an in-depth analysis of current practices, needs, and challenges associated with identifying and responding to IPV in a home visiting context. Informed consent, parental assent (if the participant was younger than 18 years of age), and permission to record the interviews was obtained from each study participant. This study was approved by the NFP's Research and Publication Communication Committee, Hamilton Health Sciences/Faculty of Health Sciences Research Ethics Board (McMaster University), and West Virginia University’s Institutional Review Board.

\subsubsection{Secondary Data Analysis}

Data available for secondary analysis included all 87 transcripts from NFP clients, nurses, and community stakeholders as well as field notes and demographic information. Issues related to mandatory reporting emerged in 44 of the transcripts. Thus, the specific type of secondary analysis used in the current study was "retrospective interpretation", which involves using existing textual data to develop themes that emerged but were not thoroughly examined by the original research study. ${ }^{91}$ Audiotapes were transcribed verbatim and all identifying information was removed. NVIVO 8.0 qualitative analysis software was used to facilitate all aspects of data management, searching, coding, and categorization. Conventional content analysis was used to analyze chunks of data relevant to the study objectives. Content analysis is the established means for secondary analysis of textual data. ${ }^{91}$ and is often used within a study whose aim is to gather more information on a phenomenon about which theory or research literature is limited. ${ }^{92} \mathrm{~A}$ 
thorough reading of all data was followed by preliminary selective coding of data relevant to issues surrounding the mandatory reporting of IPV and the reporting of children's exposure to IPV. These codes were created to the point of saturation, that is, where no new variation in the data emerged with review of new transcripts. Once all transcripts had been coded, the codes and categories were reviewed and organized into a hierarchical structure resulting in emergent themes. ${ }^{92}$ Coding rules were established for each category and after a training session with the second coder, a final set of main categories was agreed upon. Cohen’s kappa statistic was assessed after all transcripts were independently coded by the primary investigator and second coder. Acceptable reliability for each category or theme was indicated by a kappa statistic of .80 to $1.0 .^{93}$ If the kappa was below .80 for any category, the coders met to remedy any discrepancies and disagreements in data organization and coding until a consensus was reached and an acceptable kappa statistic was attained (See Table 2). This process of peer debriefing with the second coder increases the study's credibility and overall trustworthiness. ${ }^{94}$

\subsection{Results}

\subsubsection{Mandatory Reporting of IPV and Children's Exposure to IPV}

Although the purpose of the original qualitative study was not to specifically examine mandatory reporting issues, a considerable amount of important information emerged regarding both mandatory reporting of IPV and reporting of children's exposure to IPV. There was consensus among NFP clients, nurses, and community stakeholders that home visitors are not mandated to report IPV between adults to the police department or adult protective services. One nurse revealed, "We don’t have to report anything that happens to an adult.” However, several community stakeholders, especially those involved in law enforcement, discussed that nurses should use their own professional judgment to decide whether or not to involve the police when 
they become aware that a client is in an abusive situation. One police officer explained that although home visiting nurses may not have a legal duty to report IPV, they have a "moral mandate" to mitigate the harm caused by IPV.

Among all study participants, less agreement and more confusion emerged with regard to the mandatory reporting of children's exposure to IPV to CPS (also referred to as Children's Services, Child Services Bureau, Social Services, or Department of Family and Child Services throughout the interviews and focus groups). Clients expressed awareness of home visiting nurses' reporting duties involving child abuse, and many thought a disclosure of IPV and children's exposure to IPV would require the nurse to report to CPS as well. As one client shared:

I tell her [the nurse] about the verbal abuse but I wouldn't tell her if he hit me or stuff like that, especially if he was doing it in front of the son or the kid because she's mandatory to go and tell Social Services. She's mandatory, mandated to report it, to tell them. ... I know that and she'd have to and it'd be right because it's obvious you know you're endangering the child. He shouldn't be witnessing that.

This belief was pervasive among nurses and stakeholders as well, as one community stakeholder said, "If there's abuse in the home and there’s a child present then it’s reportable." A nurse explained, "See, we're mandated reporters for the child, not for the mom. . . I I think if it's happening in front of the child you are mandated to report it.” Conversely, there were also participants who were adamant that notifying CPS in such an instance is unnecessary. One stakeholder involved with both CPS and IPV services explained:

Domestic violence cannot be the reason why children are removed. There needs to be abuse and neglect identified to the children.... Yes domestic violence is a concern but 
that can't be the only reason that children are removed because mom is failing to protect in their eyes because of domestic violence.

For other participants, the disclosure of IPV in the household was perceived to be an opportunity to dialogue with the client about the impact of IPV exposure on child health and development and to frame it for the client as a form of child abuse. As one stakeholder commented:

If they start talking about domestic violence then at that point engage them in the discussion about, "Well do you realize that that is a form of child abuse? Not that I'm going to report you today or anything but I want you to be aware of that.”

\subsubsection{Clients' Fears of Losing Custody of Children}

Clients' fears of losing custody of their children while enrolled in the home visitation program emerged as a major theme throughout this qualitative study. Clients, nurses and community stakeholders explained that clients are fearful that their abusive relationships may be reported to CPS and their children will be removed from their home. A client expressed:

Yeah because you don’t want Social Services you know because they can go and report you because they're mandatory and you're trying your best. If they're going to go tell Social Services, you don't want your kids taken away. You definitely, you know if you're a good mom you don’t want your son taken away from you or your daughter.

Nurses' roles as mandated reporters and clients' fears of losing their children emerged as major factors in clients not disclosing their personal experiences of IPV to their nurses. One client said that if mandatory reporting was not an issue, she would tell her nurse everything about the abuse in her relationship. A client's quote shows how these fears can limit the disclosure of IPV: 
I say “No" [when my nurse asks me if I am experiencing abuse] because that's how you play the game. People are afraid of Social Services. They do not want Social Services to come.... That’s my biggest fear is Social Services.

In addition to limiting the disclosure of abuse, it appears that the fear of losing children can also result in clients' attrition from the home visitation program, ranging from cancelling visits with nurses or stopping the schedule of home visitation altogether. One client spoke of a friend in the program who avoids her nurse:

Like I was saying about my friend, the reason she don't [disclose abuse to her nurse] is because she thinks that the nurse is going to call Children Services into the whole situation. And so some people might be scared of that. And my friend she just don't want Children Services to get involved with her ... so she, yeah, she avoids her nurse a lot. One nurse revealed that she was aware of clients' fears of losing custody of their children and how this fear impacted the nurse-client relationship:

And it's not that I want to report. It's not like because I'm out there to try to get them but then I lose that lack of trust and respect with my clients also.... I had relatives wanting to basically kick me out of the home because they saw me as being a spy there for Children Services whose one task in life is to take their child away. Participants thought help-seeking behavior was limited by abused clients' fears of losing their children. One nurse discussed that although reporting children's witnessing of IPV is meant to benefit women, it can actually prevent her from calling for help when she is in danger:

We now have the thing where the police are calling Children's Services. Well that prevents the mom from calling the police now because now she becomes the victim twice — "Not only have I been hit, now you might take my children because he hit me.” 
And so it's something that looked like it was going to work goes in the other direction...

. It helps mothers get empowered but it also makes mothers not call for help.

\subsubsection{Experiences with Child Protective Services}

Another major theme that emerged was the fear and mistrust associated with CPS due to the agency's role in removing children from homes. Many participants indicated that distrust of CPS is common among abused women. Conversations involving clients' fears of CPS and losing their children often led to debates about the legitimacy of such fears. An IPV victim advocate expressed that fears of losing custody are pervasive among abused women and are often legitimate:

One of the most frequent things you hear is that they will lose custody of their children or that Children Services will become involved and jeopardize their custody. It can be [a legitimate fear], especially if they [Children’s Services] find out that there's a batterer that's living in their home.

The qualitative data establish the legitimacy of abused women's fears of losing custody of their children, as nurses and stakeholders described circumstances in which clients have been involved with CPS and accused of "failure to protect" their children by staying in abusive relationships. One nurse expressed:

If you're going through domestic abuse and you get yourself out of that situation, Children Services is less likely to take that child from you. Unfortunately, many people do know somebody who's had a child taken away from them by Children Services ... and the clients we deal with, I guarantee you they know at least two or three people have lost their children. ... You know how are you going to get back that trust? You can't. 
Several community stakeholders involved with CPS and IPV services discussed situations where women they knew have been accused with failing to protect their children and have been subsequently threatened with the loss of their child, as can be seen in the following comment by a community stakeholder:

What has happened, and I've heard from Department of Child and Family Services, is that if she returns from shelter to that abusive situation she’s putting her children in danger and DCFS may intervene and accuse her of endangering her children by returning to an abusive partner. And unfortunately I've seen that happen.

\subsubsection{Strategies Nurses Can Use to Ease Clients’ Fears}

Although clients' fears of mandated reporting and losing their children seem to act as barriers within the home visitation program, especially with regard to establishing trust between nurse and client and the disclosure of abuse, participants suggested different strategies home visiting nurses can employ within the program to reduce clients’ fears. Clients, nurses, and stakeholders all mentioned the importance of reassuring the client that the purpose of home visits is to support the mother in developing skills to effectively parent. Participants agreed that to increase clients' trust and comfort level with their home visitors, nurses are recommended to emphasize that they are non-judgmental and that their goal is not to take charge of the clients' lives or tell them what to do. Nurses stressed the importance of asking the client what she wanted to do after a disclosure of IPV was made. The following comment shows one client's suggestions:

Another thing that makes me feel comfortable about her is the fact that none of that information will get out to other people that can possibly you know try to take charge of 
your life and you know try to take your kid from you ... that's one of the first things they should just suggest—no information gets out ... and to state they're not judgmental. Stressing the strict confidentiality between client and nurse was another tactic mentioned to help clients feel at ease within home visitation programs. In addition, participants expressed that making clients aware of the nurses' duties as mandated reporters at the first home visit was very important. One client stated, "Make sure that they [nurses] do not make them [clients] feel like Social Services are going to come. Put them at ease right away.” However, it was discussed that if a nurse does need to contact CPS, they should notify the client prior to making the report so that the nurse and client can make the call together. One nurse stated, "I always tell mine I'm not going to go behind their back and turn them in even if I do see something... I would tell them we're going to go call this in now."

Another tactic mentioned to help reduce clients' fears of mandated reporting and losing their children was for nurses to provide education about CPS and other services that abused women might access. The importance of educating clients that CPS can be used as a positive resource and that their mission is not to remove children from the home was emphasized. One stakeholder involved with CPS and IPV services mentioned:

There's already a lot of anxiety if you know talk about Children Services. ... Hopefully [CPS] could be seen as more of a positive support for this mom and the children.... One thing is just to educate and talk to moms about what role Children Services can play, and seeing it more as a positive not just a negative experience. ... Educate that, you know, Children Services is here to help, Children’s Services isn’t here to remove your kids. 


\subsubsection{Nursing Skills and Knowledge Required for Effective Reporting}

In order to support women experiencing IPV while fulfilling their legal duties as mandated reporters, nurses stated that they needed state-specific, up-to-date, detailed information about mandated reporting policies and procedures. One nurse suggested:

I think you need to have in your literature about mandated reporting because, as nurses, we are mandated reporters and we need to know, again, with that role it needs to be spelled out very clearly because in a court of law that's what would be thrown at us, if we have fulfilled our responsibilities in what way.

Nurses were correct in their assumptions that they did not have to report the abuse of an adult woman, as the focus groups were conducted in states where reporting of IPV by health care providers is not mandated. Furthermore, children's exposure to IPV is also not considered a form of child maltreatment in these states, yet nurses were uncertain of their reporting duties for children exposed to abuse. Nurses wanted to know what constitutes children's exposure to IPV and under what circumstances it should be reported to CPS. One nurse raised the following question:

And if you know that it is violent and the baby's there, how far do you go or how do you ... you let this to go if you know that baby can get in the middle of it or ... and they tell you that he hit her but she didn't call the police. So then we come, what do we do with that? Do we let it go? Or do we ... are we supposed to report if he hit her?

Another nurse commented:

For instance, the father hit the mom in the mouth with the baby in her arms, or he choked her with the baby in her arms. Is that abuse to the baby? I mean that's a call that I have to 
make. You know was he threatening that child? So you know as a healthcare provider I may be obligated to report that.

\subsection{Discussion}

The results of this secondary analysis of qualitative data indicate that issues surrounding mandatory reporting of IPV between adults and mandatory reporting of children's exposure to IPV in the context of home visitation are salient and warrant further investigation. Previous

research on these two issues has focused on reporting in clinical settings, ${ }^{20,23,26}$ but the results of this study show that these mandated reporting issues transcend clinical care and have significant consequences for abused women and health care professionals in other settings. Although most participants did not endorse IPV reporting to police or adult protective services, knowledge, attitudes, and opinions differed with regard to reporting children's exposure to IPV to CPS. As home visiting nurses are mandated reporters of child abuse, it is crucial that they are aware of the specific circumstances that constitute child maltreatment and those that do not. The qualitative data indicate that many nurses are not confident in their knowledge of this distinction. Some participants in the present study equate children's exposure to, or witnessing of, IPV to child maltreatment, while others clearly stated that IPV cannot be the sole reason to call CPS or remove children from homes. It became apparent that mandatory reporting policies and procedures regarding children's exposure to IPV were not the same at each NFP site, as clients, nurses and community stakeholders as a whole were not entirely in agreement about which instances nurses should report to CPS. The lack of consensus is not surprising; the delineation between children's exposure to IPV and child maltreatment has often been referred to as a complex and complicated gray area in research on this topic. ${ }^{60}$ 
Several themes that emerged in this study have been documented in other qualitative studies examining abused women's perspectives on mandated reporting. Abused women's fears of losing custody of their children are barriers to service delivery and help-seeking behaviors. ${ }^{95}$, ${ }^{96}$ Other studies have documented abused women’s fears of police or CPS involvement serving as barriers to seeking acute care and/or disclosing abuse in clinical settings. ${ }^{16,25}$ Our study shows abused women's reluctance to fully engage in a home visitation program (e.g., cancellation of visits) and disclose abuse to home visiting nurses. This shows that it may not be the particular setting (e.g., emergency department, clinic, client’s home), but any interaction with an individual who is perceived to be a mandated reporter, which elicits fear in these women.

The theme Experiences with CPS clarifies whether or not the fears that women hold about losing their children are realistic or legitimate. The data shows that not only are these fears prevalent among the abused clients in our study, but they are indeed justified. Nurses and stakeholders shared real-life experiences about the ways in which abused women have been accused of failing to protect their children and how CPS has threatened women with the loss of their children if they do not leave their batterers. Douglas and Walsh conducted focus groups with community workers who support mothers in order to gain insight into the workers' perceptions of how CPS responds when mothers experience IPV. ${ }^{88}$ As in our study, the community workers claimed that CPS has often presented abused women with ultimatums about leaving their batterers or losing their children. Based on their experiences supporting abused women and navigating CPS systems, the community workers concluded that abused women's fears of CPS are indeed reasonable. In addition, Sullivan \& Hagen used a qualitative framework to examine abused women's experiences with mandatory reporting and state that participants' fears of CPS involvement are "not an idle threat but a stark reality" ${ }^{96(\mathrm{p} 354)}$ English, Edleson, \& 
Herrick add that there is evidence that these fears can be accurate, specifically mentioning a lawsuit against New York City’s CPS agencies for unconstitutionally removing children from homes solely because their mothers were victims of IPV (see Jackson, 2005). ${ }^{97,98}$ Although English, Edleson, \& Herrick conclude that a CPS referral alone is very unlikely to lead to removal of children from the home, ${ }^{97}$ it is important to note that mere contact with CPS opens up the possibility of child removal and this is surely a legitimate fear for abused women.

Thus, addressing NFP clients' fears of losing their children and mistrust of CPS is critical, as these fears have the potential to negatively impact the nurse-client relationship and the mission and goals of home visitation programs. The current study indicates that nurses' duties as mandated reporters coupled with clients' fears of losing their children can hinder the nurse-client relationship. Fortunately, the study participants offered myriad suggestions and tactics that NFP nurses can use with clients to reduce fears of mandated reporting, removal of children, and other issues with CPS. However, before home visiting nurses can demystify any stigma or mistrust associated with CPS for their clients, they must receive training and education on issues regarding mandatory reporting and CPS referrals themselves. Nurses need state-specific guidelines about mandatory reporting of IPV and children's exposure to IPV as well as detailed information about which circumstances require a CPS report and which do not. Therefore, it would be beneficial if individuals working within law enforcement, CPS, and IPV shelters could play an active role in training home visiting nurses on their duties as mandated reporters and system navigation. Participants mentioned initiatives where local service agencies have worked with the NFP program to reduce confusion and improve the relationship between CPS and IPV services, demonstrating that this important collaboration has already begun at several NFP sites. 


\subsubsection{Strengths and Limitations}

These findings should be viewed with regard to the study's strengths and weaknesses. According to Thorne, the fit between the original data and new research question posed by the secondary analyst is critical when determining the appropriateness of secondary analysis. ${ }^{91}$ Because one aim of the original study was to explore NFP nurses' responses to IPV within the context of home visitation, and mandatory reporting was frequently mentioned as a response to disclosure of IPV, the data from the original study provided an appropriate and rich data source that was ideally suited for secondary analysis. ${ }^{99}$ Furthermore, the use of multiple data sources (i.e., NFP clients, nurses, and community stakeholders) from multiple sites allows for data triangulation which aids in ensuring that a complete and credible understanding of the issues surrounding mandatory reporting in home visitation has been obtained, strengthening the accuracy of research findings and increasing the study's confirmability. ${ }^{100}$ Furthermore, the detailed description of the original research methods, participants, and analysis process and rich description of the results of the current analysis addresses the current study's transferability from one context to another. ${ }^{94,100}$

There are several limitations to the present study. Because this study is a secondary analysis of qualitative data, the data reflect the perspectives and research questions proposed by the original study. The purpose of the original study was not to specifically examine mandatory reporting of IPV or reporting of children's exposure to IPV to CPS, and thus conducting a secondary analysis of this data precluded our ability to gather additional information on our topic of interest. Therefore, an important limitation of the current study that is inherent to secondary data analysis is that further sampling and probing techniques could not be utilized and the 
emergent themes examined by this secondary analysis may not have achieved adequate saturation. $^{99}$

\subsubsection{Implications for Research, Practice, and Policy}

Despite these limitations, the current study has important implications for future research as well as practice and policy. This study shows that issues related to mandated reporting of IPV and mandated reporting of children’s exposure to IPV to CPS are not limited to clinical care settings. Further research should be conducted with the specific purpose of examining these mandatory reporting issues in the context of home visitation, as the current study indicates that health care professionals involved in home visitation are not unaffected by the issues related to mandated reporting in these two controversial instances. Future research must be carried out on a larger scale to determine if the emergent themes found in this study apply to nurse home visitors at other NFP sites or in other home visitation programs. Furthermore, several participants in the current study recommended that home visitors use their own judgment with regard to IPV reporting. One police officer stated that home visiting nurses have a "moral mandate” to report IPV regardless of state laws. Although prior research has examined the perspectives of mandated reporters in clinical settings, little is known about home visitation providers' attitudes toward mandatory reporting of IPV or children's exposure to IPV. Future research capturing home visitors’ opinions toward mandatory reporting in these instances in conjunction with their knowledge of reporting policies is needed to fill the current gap in literature.

At the practice level, this study has implications for the ways in which home visiting nurses and other service agencies interact with women in abusive relationships. Mandated reporting duties of health care professionals in conjunction with the mistrust of CPS and service agencies in general can negatively affect the relationship between abused women and those who 
can offer help, leading women in need of the most care to avoid seeking help. The current study offers suggestions for enhancing the nurse-client relationship, including reassurance and education early in the visitation schedule, in order to reduce fears that abused women in home visitation programs might face. Ideally, easing clients’ fears and strengthening the therapeutic relationship between nurse home visitor and client will lead to more disclosures of IPV and more opportunities for women and children exposed to IPV to receive help.

Lastly, this comprehensive examination of clients, nurses, and community stakeholders at several home visitation sites illustrates that despite the presence or absence of IPV and children’s exposure to IPV reporting laws in each state, the public perception of these policies has a significant impact on home visitation practice. Thus, when policies related to mandatory reporting of adult IPV or children's exposure to IPV as a form of child maltreatment are created and put in place, it is important to consider the impact these policies will have on patients and health care professionals outside of clinical settings. Policymakers should specify reporting duties for health care professionals that routinely interact with patients, but do not necessarily provide clinical treatment, such as social workers and home visitation providers. Furthermore, those individuals involved in creating mandatory reporting policies should be aware of the impact that these laws have on the disclosure of abuse and help-seeking behavior for victims of IPV. 
Table 2: Kappa Coefficients Representing Agreement between Two Raters

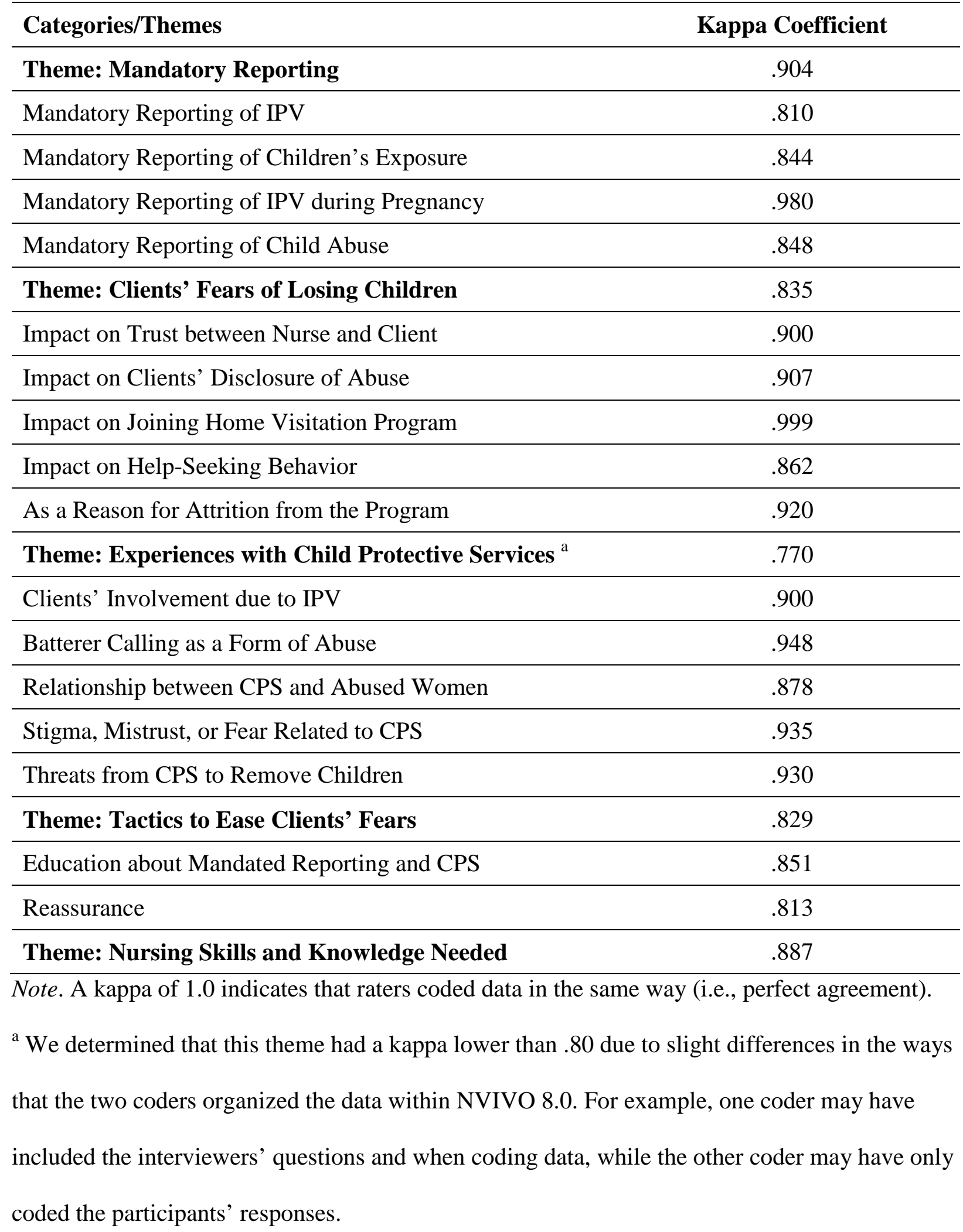




\section{Chapter 3}




\section{Chapter 3}

\subsection{Introduction}

Each year in the United States, 4.8 million physical assaults and rapes are committed against 1.5 million women by an intimate partner. ${ }^{2}$ Intimate partner violence (IPV) is associated with deleterious short- and long-term consequences for female victims of abuse. ${ }^{4,5}$ In many jurisdictions, there is an ongoing debate about legally requiring health care professionals to report women who are exposed to IPV to law enforcement agencies.

Those in support of IPV reporting laws argue that mandatory reporting will hold the abuser legally accountable for the violence and facilitate prosecution. ${ }^{19,}$ 20, 23 Furthermore, proponents envision that identification and treatment for victims of IPV as well as data collection of IPV-related incidents will improve if health care workers are mandated to report abuse. ${ }^{18,65}$ Those opposed to mandated reporting laws argue that reporting IPV undermines patient autonomy and privacy, ${ }^{22,34,37}$ may negatively affect the patient-provider relationship, ${ }^{15,18,20}$ and may limit victim disclosure of IPV. ${ }^{25}$ In addition, there is also concern that mandating health care professionals to report instances of IPV may deter victims of abuse from seeking medical care and put the victim at greater risk of harm or retaliation by the perpetrator. ${ }^{16,18}$

Even with this debate, six states have instituted laws specifically mandating health care

providers to report instances of IPV to the legal authorities. ${ }^{21}$ These laws exhibit wide variability, even though they are implemented in only a few states. Furthermore, each state is responsible for determining the procedures for reporting abuse and which health care professionals should be mandated to report IPV. Differences in agencies that receive reports, methods to identify and treat victims of IPV, and referral options for the victim often differ as well. This variability is 
compounded by any potential requirements, policies, and practices of individual agencies to report, regardless of the presence of a statutory mandatory reporting law. ${ }^{101}$

Previous research focusing on mandatory reporting of IPV has shown that the majority of participants recruited from clinical populations, ${ }^{20,23,26,27}$ women in the general population, ${ }^{16}$ and even women with a history of experiencing IPV ${ }^{16,19,20,23,25, ~ 26, ~} 28$ generally support mandatory reporting laws. It should be noted, however, that several of these studies found that women reporting a history of IPV support mandated reporting of IPV significantly less than women who have not been victims of IPV. ${ }^{16,23,25,26}$

Although policymakers and researchers have recognized the importance of examining victims' perspectives when weighing the pros and cons of mandated reporting laws, these laws also have significant implications and consequences for the individuals who are mandated to report. Health care providers who fail to report IPV when they are mandated to do so can face substantial fines and even time in jail. ${ }^{22}$ On the other hand, inappropriately breaking confidentiality by reporting non-mandated offenses may leave the reporter vulnerable to legal and ethical issues. Thus, is it crucial that mandated reporters are aware of laws and policies regarding mandatory reporting of IPV — an awareness that may be difficult to ascertain, given the wide variability in mandatory reporting laws in each state.

Research that has addressed mandated reporters’ perspectives of IPV reporting has focused on health care providers working in clinical settings, such as the emergency department or physicians' offices. ${ }^{65}$ Research is scarce on the IPV reporting perspectives of health care professionals who routinely interact with patients, but do not necessarily provide medical treatment, such as public health home nurses or social workers. Freed and Drake suggest that public health home nurses need to be informed of the IPV reporting laws in their states, as these 
laws can significantly affect the nurse-client relationship as well as the nursing strategies they utilize in home visitation practice. ${ }^{22}$ In our previous work with abused women and nurses in a large home visitation program, ${ }^{102}$ participants revealed how home visitors' duties as mandated reporters can create mistrust between a client and her nurse, limit the disclosure of abuse, and cause attrition from the home visitation program. In addition to reporters' awareness of IPV reporting laws, mandated reporters' attitudes toward reporting policies are likely to affect health care practice. Practitioners that agree with mandated reporting of IPV may feel that reporting alone takes care of the problem and might consequently relinquish responsibility for the continued care of the abused woman. ${ }^{17}$ Conversely, providers that hold negative attitudes towards IPV reporting may not adequately screen patients for abuse, depriving abused women of the opportunity to obtain help. ${ }^{17}$ Evanson asserts that research focusing on home visiting nurses’ roles in IPV prevention and intervention is relatively new and that home visitors' duties and practices must be thoroughly investigated and understood in order to advance research in the area. ${ }^{68}$

To the best of our knowledge, no study has examined home visiting nurses’ perspectives regarding mandatory reporting of IPV on a large scale. The purpose of the current study was to build upon our prior qualitative work with nurse home visitors in the Nurse-Family Partnership (NFP) home visitation program ${ }^{102}$ in order to determine nurse home visitors' perspectives about the mandatory reporting of IPV. Specifically, the current study focuses on assessing NFP nurses' (1) attitudes toward reporting IPV, (2) perceived awareness of IPV reporting requirements, and (3) intended reporting behavior. This information has the potential to fill a significant gap in the mandatory reporting literature by adding the unique perspectives of home visiting nurses. 


\subsection{Methods}

\subsubsection{Procedures}

This study was approved by the NFP Research and Publication Communication Committee, the West Virginia University’s Institutional Review Board (IRB), and the Oklahoma State Department of Health IRB. A quantitative, cross-sectional research design was employed to assess nurse home visitors’ perceived awareness of an IPV reporting requirement, attitudes toward mandatory reporting of IPV, and IPV reporting practices. Recruitment e-mails containing an explanation of the study, information about incentives, and a link to an electronic survey were sent to each nurse home visitor in the NFP program whose e-mail address was on file with the NFP National Service Office. Nurses who wished to participate in the survey were instructed to click the link embedded in the e-mail and were automatically directed to a webpage within the online survey system displaying the consent form for the study. After reading the consent form, nurses were able to click a button on the bottom of the webpage directing them to a separate, secure webpage displaying the survey questions. Nurses who did not wish to participate in the study after reading the consent form were instructed to close their web browsers or click an “Exit” link on the page. Once participants submitted their survey responses, they were directed to a separate page where they were able to enter contact information to claim incentives. The first 200 participants to complete the survey were offered a \$10.00 gift card and \$250.00 gift cards were given to two participants chosen from a random drawing of all participants. The deadline for completion of the survey was set at two weeks after the first email was sent and a reminder email was sent to all nurses who had not yet completed the survey after one week. The state of Oklahoma required separate approval for nurses in the NFP program to participate in the study and consequently did not allow nurses to receive incentives for survey participation. The 
recruitment e-mail, consent form, and survey that were sent to the nurses in this state did not contain any language regarding incentives. Response rates between Oklahoma and other states where the survey was administered were not significantly different.

\subsubsection{Participants}

The target population for this study included all NFP nurses from 355 NFP sites across the United States whose e-mails were on file with the NFP National Service Office. The recruitment e-mail containing the link to the electronic survey was sent to 1,119 nurse home visitors. Of these, 26 were returned as “undeliverable” and therefore a total of 1,093 surveys were sent to valid email addresses. The number of surveys returned was 534, representing a response rate of $49 \%$. Due to large amounts of missing data, two surveys were discarded and therefore 532 surveys were used for analysis in the current study.

\subsubsection{Measures}

In our previous focus groups with nurse home visitors in the NFP program, nurses were asked about the language and terminology that they used when discussing IPV between adults or intimate partners. Nurses revealed that among their colleagues in the NFP program and with clients in home visitation practice, they most often use the term "domestic violence" to describe instances of violence between intimate partners. Due to nurses' use of and comfort with the term, “domestic violence” was used in place of “intimate partner violence” or "IPV” throughout the survey; however, nurses were asked to focus specifically on domestic violence that occurs between intimate partners (e.g., between a client and her current partner).

As there were no existing measures that capture home visitation providers’ perspectives with regard to mandatory reporting of IPV, a new survey instrument was developed based on previous literature. A reviewer with expertise in the areas of IPV and family violence was 
consulted throughout all stages of survey development and the final instrument was found to be acceptable by the reviewer. In order to assess the readability and clarity of the survey questions and survey as a whole, a paper-and-pencil version of the survey was pilot tested in a group of nurses and social workers from the Right from the Start home visitation program in West Virginia. The mission and goals of the Right from the Start program are similar to those of the NFP program. Surveys were sent to nine nurses and social workers in the Right from the Start program and they were asked to complete the survey and provide feedback. Specifically, participants involved in this pilot-testing phase were asked whether 1) the questions in each section of the survey were understandable, 2) whether the answer choices were adequate, and 3) if the questions lead to only one response. Nurses and social workers were also given the opportunity to provide general feedback about the survey. Five nurses returned completed surveys and feedback and their comments and suggestions were incorporated into the final survey.

Support for mandatory reporting of IPV within the context of home visitation services was measured by presenting participants with the following statement: "I should be required to report instances of domestic violence.” The response set for this item was a scale ranging from 1 (never) to 5 (always).

In order to measure nurse home visitors’ attitudes towards mandatory reporting of IPV, a 16-item attitudinal scale containing two subscales was created. The first subscale contained twelve items assessing the perceived impact that mandatory reporting of IPV can have on abused women and their children (Cronbach's alpha $=.84$ ). The statements used in this subscale have been used in other studies of mandated reporting of IPV ${ }^{16,25,28}$ and child abuse ${ }^{103}$ and were modified to increase relevance to home visitation practice. Participants were asked to respond to 
each statement on a 5-point Likert scale ranging from 1 (strongly agree) to 5 (strongly disagree). Positively worded items were reversed scored. The possible range was 12 to 60, with higher scores indicating that nurses believe mandatory reporting of IPV can have a negative impact on abused women and their children.

The second subscale consisted of four items measuring the perceived impact that mandatory reporting of IPV can have on nurse home visitors themselves (Cronbach's alpha = .65). The response set for these items ranged from 1 (never) to 5 (always) and positively worded items were reverse scored. The possible range was 4 to 20 , with higher scores signifying the perception that mandatory reporting of IPV can negatively impact nurse home visitors. The statements used in this subscale were modified from the CANNQ — a survey measuring nurses' attitudes toward and knowledge of reporting child abuse and neglect. ${ }^{66}$ The entire attitudinal scale (Cronbach's alpha $=.85$ ) had a possible range of 16 to 80, with higher scores representing more negative attitudes towards mandatory reporting of IPV. The items used in the attitudinal scale can be seen in Table 3.1.

In order to measure home visiting nurses’ perceived awareness of IPV reporting laws and intended reporting behavior, participants were presented with a scenario that they might encounter during a home visitation session (See Appendix A). The scenario describes the abuse of a woman who is pregnant, as home visiting nurses in the NFP program visit with women who are either pregnant or have infants and young children under two years of age. After reading the scenario, participants were asked, "Would you report this case?” and were asked to respond with "yes”, “no”, or "I don’t know”. If participants answered that they would report the case, they were asked to whom they would report. Possible responses include "law enforcement”, "child 
protective services”, “adult protective services”, “NFP supervisor”, and “other”. Participants were able to select more than one answer for this question.

To capture home visitors’ perceived awareness of IPV reporting requirements, participants were asked, “To the best of your knowledge, is there a requirement mandating you to report this case?” with answer choices “yes”, “no”, and “I don’t know”. Participants who responded that they were required to report were asked which entity or agency requires them to report the case presented in the scenario. Again, response choices included "law enforcement”, “child protective services”, “adult protective services”, “NFP supervisor”, and “other” and participants could choose more than one answer. Demographic information including age, state, years in nursing practice, years in the NFP program, and number of children were also included in the survey.

\subsubsection{Data Analysis}

Analyses were conducted using STATA 10.0 software. Preliminary analyses revealed that no more than $5 \%$ of the data were missing for any variable. Given that all missing data

techniques yield similar results when less than $5 \%$ of data are missing, ${ }^{104}$ mean substitution was utilized to estimate missing values. Descriptive statistics (i.e., frequencies, percentages, means, and standard deviations) were used to describe demographic and study variables. For logistic regression analyses, responses to the statement measuring support for IPV reporting were dichotomized into “always” and “often” versus “some of the time”, “rarely”, and “never”. Responses to the scenario that captured home visitors' perceived awareness of reporting requirements and reporting behavior were dichotomized into “yes” versus “no” and "I don’t know”. Separate multiple logistic regression analyses were used to predict two outcome measures: support for mandatory reporting of IPV and intended reporting behavior after reading 
the scenario. Odds ratios and 95\% confidence intervals are presented to show the magnitude and strength of associations between variables. Predictor variables included perceived awareness of an IPV reporting requirement, support for IPV reporting, and both attitudinal subscales. Nurse age, years as a nurse, years in the home visitation program, and number of children were also entered into each regression model separately in a stepwise fashion to assess for confounding. Any demographic variable that was not significantly predictive of the outcome variable and did not display evidence of confounding was dropped from the final regression model. Statistical significance was set to alpha $<.05$ for all analyses.

\subsection{Results}

All nurse home visitors were female, and had a mean age of 44 years $(S D=10.30)$. Home visitors reported being in nursing practice for a mean of 17.85 years $(S D=10.86)$ and had been involved in home visitation services with the NFP program for a mean of 4 years $(S D=3.13)$. The average number of children that nurse home visitors reporting having was two $(S D=1.17)$.

\subsubsection{Attitudes, Perceived Awareness, and Intended Reporting Behavior}

In terms of support for mandatory reporting of IPV in the context of home visitation services, 40\% (212) of nurse home visitors thought that they should "always" be required to report instances of domestic violence, while 15\% (79) thought they should be required to report “often”. Approximately one-third of participants (180) agreed with reporting "some of the time”, 6\% (33) responded that they should "rarely" report, and 5\% (28) thought that they should “never” be required to report domestic violence.

Home visitors’ attitudes towards mandatory reporting of IPV can be found in Table 3.1. The mean attitudinal score for the twelve-item subscale measuring the perceived impact that reporting IPV has on abused women and their children was $34.04(S D=6.77)$ with a range of 13 
to 56. The second subscale measuring the perceived impact that reporting IPV has on nurse home visitors' had a mean of $9.22(S D=2.44)$ and ranged from 4 to 18 . The entire attitudinal scale had a mean of $43.26(S D=8.08)$ and range of 18 to 67 .

Almost two-thirds of the sample agreed that mandatory reporting can damage the relationship between nurse and client and would make it less likely that a client would tell them about the abuse. Furthermore, half of the sample agreed that reporting can put women at greater risk of being abused or hurt. Conversely, two-thirds of the sample thought mandatory reporting of IPV would make it easier for abused women to get help and protect children. The majority of participants disagreed that reporting IPV can traumatize children or damage a woman’s chances of custody of her children. Furthermore, Table 3.1 shows that the majority of nurse home visitors believes mandatory reporting of IPV "some of the time”, "rarely”, or "never” causes problems for nurse home visitors.

With regard to intended reporting behavior, almost half of the participants indicated that they would report the case described in the scenario (Table 3.2). Of the 236 participants that indicated they would report the case, almost half (115) indicated that they would report to law enforcement, 56\% (131) would report to child protective services, $20 \%$ (48) would report to adult protective services, and the majority (89\%) indicated that they would report the case to their supervisor in the home visitation program. An additional 8\% (18) selected "other" and typed in their answers. The answers ranged from reporting to domestic violence shelters, agencies, and hotlines to contacting the abused woman's obstetrician. Several respondents explained that whether or not they would report the case depends on the age of the client. If the client was a minor, some participants explained that they would report to child protective services and if the client was an adult, they would call law enforcement authorities. 
Participants' perceived awareness of an IPV reporting requirement can be seen in Table 3.2. Of the 139 home visitors who thought they were required to report the case, 53\% (74) thought they were mandated to report to law enforcement and 60\% (84) indicated that they should report to child protective services. Another 19\% (27) responded that they were to report to adult protective services, and 77\% (107) indicated that they were required to report to their supervisor in the home visitation program. Additionally, 7\% (10) listed "other" options, including being mandated to notify the abused woman's physician and contact local domestic violence agencies.

\subsubsection{Logistic Regression Analyses}

The demographic variables (nurse age, years in nursing practice, years in the NFP program, and number of children) were not independently predictive of the outcome variables and did not display evidence of confounding; hence, they were not included in either regression model. As can be seen in Table 3.3, perceived awareness of an IPV reporting requirement as well as both attitudinal subscales were statistically predictive of support for mandatory reporting of IPV within home visitation services. Specifically, nurse home visitors who thought there was a requirement to report IPV were almost four times more likely to support IPV reporting than nurses who thought there was no reporting requirement $(O R=3.95, p<.001)$. Nurse home visitors that thought reporting abuse can negatively impact abused women and their children were significantly less likely to support IPV reporting $(O R=0.86, p<.001)$. Furthermore, participants that thought reporting abuse can have negative consequences for home visitors were also significantly less likely to support mandatory reporting of IPV (OR $=0.85, p<0.01)$.

Perceived awareness of an IPV reporting requirement and support for mandated reporting of IPV were also statistically predictive of whether or not home visitors would report the case 
described in the scenario, as were beliefs about the consequences of reporting on abused women and children (Table 3.4). Those nurse home visitors who thought there was a requirement to report the abuse described in the scenario were significantly more likely to respond that they would report the scenario $(O R=13.30, p<.001)$. Additionally, nurse home visitors who indicated greater support for mandated reporting of IPV were almost twice as likely to say that they would report the abuse described in the scenario $(O R=1.89, p<.01)$. Furthermore, participants who thought reporting IPV can have negative consequences for abused women and children were significantly less likely to indicate that they would report the abuse in the scenario $(O R=0.96, p<.05)$. Participants who thought reporting IPV can have negative consequences for home visiting nurses were less likely to indicate that they would report the abuse in the scenario; however, this result did not achieve statistical significance.

\subsection{Discussion}

The results of the current study indicate that the majority of home visiting nurses we surveyed support reporting of IPV and these attitudes are predictive of their intended reporting behaviors. We also found that home visitation providers have mixed beliefs about the impact that mandatory reporting can have on abused women and their children. General support for the mandatory reporting of IPV has been previously demonstrated, as the majority of samples of the general population, physicians, and abused women have been found to support IPV reporting. ${ }^{16,}$ 19, 23, 25-28 However, contradictory opinions about the risks and benefits of mandated reporting have also been reported in prior research with healthcare providers (See Rodriguez et al., 1999). ${ }^{65}$ The authors of this study cite the complexity of handling IPV in clinical settings as the basis for physicians' mixed attitudes regarding IPV reporting. Addressing IPV in the context of home visitation settings can be equally as difficult, as home visiting nurses deliver care within 
the family system, and this framework can also present challenges to maintaining the fine balance between legal responsibility and confidentiality issues. ${ }^{22}$

Examining participants’ specific beliefs about IPV reporting suggests that home visitation providers have mixed perceptions about the impact that mandatory reporting of IPV can have on abused women and their children. The majority of nurse home visitors agreed that reporting IPV can damage the relationships with their clients, put battered women at greater risk for being abused or hurt, and can limit the disclosure of abuse to the nurse. These concerns have been documented in other studies ${ }^{16,65}$ as well as in our previous focus groups with nurse home visitors. ${ }^{102}$ These focus groups also revealed that home visitors’ perceive that mandatory reporting laws may prevent women from seeking help; however, almost two-thirds of the current sample of home visitors thought reporting IPV would make it easier for abused women to get help. Furthermore, when it came to the impact of mandatory reporting of IPV on children of abused women, the majority of home visitors thought reporting would be beneficial. Most respondents indicated that reporting would offer protection, and disagreed that reporting could further traumatize children and damage a woman’s changes of custody.

Almost half of the sample of nurse home visitors indicated that they would report a case of IPV, yet only $27 \%$ of participants thought there was a legal requirement mandating them to report. This suggests that home visitors might report instances of IPV even when they believe there is no mandate to do so. This is of some concern given the potential negative consequences of mandated reporting of IPV, especially since home visitors agreed that reporting can put battered women at greater risk of being hurt or abused. Hyman, Schillinger, and Lo posit that providers who report IPV without first being educated about how to properly handle such cases can further endanger abused women. ${ }^{17}$ However, among our sample, it is possible that the nurses 
may consider reporting instances of IPV to their supervisors in the home visitation program, even when they believe there is no legal mandate that requires a report to an outside agency, such as to the police. This explanation is supported by the fact that the majority of participants in the study who stated they would report the IPV described in the scenario also revealed that they would report the case to their supervisor. Reporting IPV within the confines of the home visitation program may be beneficial, as nurse home visitors can work with their supervisors to figure out the best course of action to take when supporting a client who is experiencing IPV.

Logistic regression analyses revealed that, in addition to perceived reporting requirements, nurse home visitors’ attitudes toward IPV reporting play a significant role in predicting their support for mandatory reporting of IPV. Specifically, beliefs about the impact of reporting on abused women and their children as well as beliefs about the impact of reporting on nurse home visitors were significantly predictive of whether or not home visitors felt they should be mandated to report instances of IPV. Furthermore, as would be expected, those nurses that thought there was a legal requirement to report the case presented in the scenario were much more likely to indicate that they would report abuse described in the scenario. This suggests that home visitors' perceptions of IPV reporting requirements have a major impact on their intentions to report IPV. This is not surprising, as child abuse reporting research has shown reporters’ perceptions of legal requirements to be strongly related to the likelihood of reporting. ${ }^{105,106}$ Thus, this finding highlights the importance of home visitors' knowledge and perceptions about their states' laws surrounding IPV reporting and as well as their specific reporting duties as health care professionals in home visitation programs. Furthermore, approximately one-fifth of the current sample did not know if they would report the abuse described in the scenario and were 
unsure if there was a legal requirement mandating a report, suggesting that home visitation providers may require additional education about IPV reporting requirements.

\subsubsection{Strengths and Limitations}

The large sample of nurses from a home visitation program serving clients in 32 states is a strength of the current study. This study expands on our previous qualitative work that assessed home visitors' experiences with mandated reporting. To the best of our knowledge, this is the first quantitative study to examine the perspectives' of home visitation providers with specific regard to mandatory reporting of IPV. This study adds the perspective of the home visitation provider to the current IPV reporting literature—a population that has been overlooked and understudied. ${ }^{68}$

However, the current study is not without limitations. Our results represent the perspectives of less than half of the target population of nurse home visitors in the NFP program,

as the response rate was $49 \%$, which is typical of internet survey response rates. ${ }^{107,}{ }^{108}$ Appendix B displays comparisons between the characteristics of the current sample and those of the population of NFP home visitors as a whole. Analyses revealed that the sample of home visitors contained significantly fewer nurses under the age of 40 (sample 36\% vs. population 47\%; $p<$ .001 ) and significantly more nurses over the age of 40 (sample 64\% vs. population 53\%; $p<$ .001). Furthermore, the current sample contained home visitors who reported being in nursing practice for significantly longer than the overall population (sample 18 years vs. population 14 years; $p<.001)$. However, it should be noted that data from the overall population of nurses is reflective of age and years in nursing practice upon entry into the NFP program, while the current study assessed age and number of years in nursing practice at the time of survey completion. This may explain the differences found between the sample and population. 
It is important to note that respondents answering "no" and "I don’t know” were grouped together for the logistic regression analyses. The sample contained a substantial proportion of participants indicating that they were unsure of their attitudes towards reporting, their perception of a reporting requirement, and intended reporting behavior. Consequently, grouping participants in this manner may have influenced the result of the current study, particularly if those participants who were “undecided” or who answered “I don’t know” differ significantly from those who agreed, disagreed, or indicated “yes” or "no” responses. Table 5.1 and Table 5.2 in Appendix D characterize participants who were undecided with regard to their attitudes towards mandatory reporting of IPV. Although participants that were undecided about the perceived impacts that reporting IPV might have on abused women and their children did not differ significantly from the rest of the sample with regard to demographic variables (Table 5.1), this group did exhibit significantly higher levels of support for mandatory reporting of IPV than participants who agreed that reporting can damage the relationship between nurse and client and held significantly lower levels of support for IPV reporting than participants who agreed that reporting can protect children and make it easier for abused women to get help and those who either agreed or disagreed with the statements (Table 5.2).

Another limitation of the current study is that we did not include the age of the client in the scenario. Several participants indicated that where they send an IPV report would depend on the age of the client. It would have been interesting to examine nurses' attitudes, perceived awareness, and intended reporting behavior of a situation involving a client who was a minor as well as over the age of majority. Furthermore, we were only able to measure home visitors' perceived awareness of reporting requirements as opposed to actual knowledge of IPV reporting laws. Our inability to assess knowledge of reporting laws was constrained by the lack of 
comprehensive information about IPV reporting laws and policies for health care professionals in home visitation settings. Statutory IPV reporting laws focus mainly on reporting requirements for physicians or health care professionals in clinical settings ${ }^{17}$ and do not necessarily apply to health care providers in home visitation settings. Future research should focus on compiling state-specific, up-to-date requirements for providers in home visitation settings in order to compare providers' intended reporting behavior with state laws.

\subsubsection{Conclusion}

The current study suggests that there is wide variability and uncertainty with regard to home visiting nurses’ perceived awareness of reporting obligations, intended reporting behaviors, and attitudes towards mandated reporting of IPV. This uncertainty might translate into home visiting nurses being unsure of the proper course of action to take when supporting a woman who is experiencing IPV. To address this issue, we recommend additional education about the positive and negative impacts that IPV reporting can have on abused women and their children as well as on home visitation practice. Comprehensive information about the risks and benefits of IPV reporting should be made available to health care providers in home visitation settings, as well as methods for managing complexities inherent to being a mandated reporter, such as balancing patient confidentiality with legal responsibility. Further, as the results of this study demonstrate that home visitors’ perceptions of legal requirements to report are highly predictive of intentions to report IPV, it is essential that supervisors and home visitors are fully informed of IPV reporting requirements mandated by the state as well as those policies and procedures delineated by the home visitation program itself. To this end, accurate and up-to-date information about legal reporting requirements for IPV should be made available to home visitation providers and collaborations with local legal service agencies may aid in the 
interpretation of these requirements. Collaborations with local domestic violence service organizations can offer additional benefits to home visitation programs as well. Future research is needed to more closely examine state-specific policies that influence the reporting of IPV among home visitation practitioners. The findings of the current study highlight the need to reduce variation among practitioners and establish consistent program practices that are grounded in the program's principals, supported by existing research, and compliant with existing state policies. 
Table 3.1: Nurse Home Visitors' Attitudes towards the Mandatory Reporting of IPV

\begin{tabular}{|c|c|c|c|}
\hline Impact on abused women and their children & $\begin{array}{c}\text { Strongly } \\
\text { Agree or } \\
\text { Agree } \\
(\%)\end{array}$ & $\begin{array}{c}\text { Strongly } \\
\text { Disagree or } \\
\text { Disagree } \\
(\%)\end{array}$ & $\begin{array}{l}\text { Undecided } \\
\quad(\%)\end{array}$ \\
\hline \multicolumn{4}{|l|}{$\begin{array}{l}\text { "I feel that the mandatory reporting of domestic } \\
\text { violence between adults..." }\end{array}$} \\
\hline can damage the relationship between nurse and client & 64.66 & 18.61 & 16.73 \\
\hline can disempower the battered woman & 21.99 & 53.76 & 24.25 \\
\hline can prevent battered women from seeking further help & 32.33 & 46.62 & 21.05 \\
\hline can further traumatize the child(ren) & 20.68 & 60.53 & 18.79 \\
\hline can protect the child(ren) & 88.35 & 3.94 & 7.71 \\
\hline can cause more disruption to the family & 50.19 & 28.76 & 21.05 \\
\hline can damage the battered woman's chances of custody & 7.89 & 78.95 & 13.16 \\
\hline would make it easier for battered women to get help & 64.29 & 12.97 & 22.74 \\
\hline $\begin{array}{l}\text { would put women at greater risk for being abused or } \\
\text { hurt }\end{array}$ & 51.32 & 19.32 & 29.36 \\
\hline $\begin{array}{l}\text { would make it less likely that a client would tell me } \\
\text { about the abuse }\end{array}$ & 62.22 & 18.61 & 19.17 \\
\hline would make my clients resent me for having to report & 41.17 & 23.49 & 35.34 \\
\hline $\begin{array}{l}\text { would help my clients because they would like for } \\
\text { someone else to report the abuse }\end{array}$ & 41.73 & 14.10 & 44.17 \\
\hline Impact on nurse home visitors & $\begin{array}{c}\text { Always } \\
\text { or Often } \\
(\%)\end{array}$ & $\begin{array}{c}\text { Some of } \\
\text { the Time } \\
\text { (\%) }\end{array}$ & $\begin{array}{l}\text { Rarely or } \\
\text { Never } \\
(\%)\end{array}$ \\
\hline $\begin{array}{l}\text { I lack faith in law enforcement to respond appropriately } \\
\text { when reports of domestic violence are made. }\end{array}$ & 23.31 & 50.56 & 26.13 \\
\hline I fear reprisals from reporting domestic violence. & 12.03 & 33.46 & 54.51 \\
\hline $\begin{array}{l}\text { I fear litigation and/or legal liability from reporting } \\
\text { domestic violence. }\end{array}$ & 9.40 & 21.99 & 68.61 \\
\hline $\begin{array}{l}\text { Workload pressures are likely to deter me from } \\
\text { reporting domestic violence. }\end{array}$ & 2.82 & 7.33 & 89.85 \\
\hline
\end{tabular}


Table 3.2: Perceived Awareness of Reporting Requirements and Intended Reporting Behavior

\begin{tabular}{|c|c|c|c|}
\hline & Yes & No & Don’t Know \\
\hline Survey Item & $\% \quad(n)$ & $\% \quad(n)$ & $\% \quad(n)$ \\
\hline Would you report this case? & $44(236)$ & $27(143)$ & $29(153)$ \\
\hline Is there a requirement mandating you to report this case? & 26 (139) & $51(271)$ & $23(122)$ \\
\hline
\end{tabular}

Table 3.3: Logistic Regression Analysis Predicting Support for Mandatory Reporting of IPV

\begin{tabular}{lcc}
\hline \multicolumn{1}{c}{ Variable } & OR & $95 \%$ CI \\
\hline Perceived awareness of reporting requirement & $3.95^{* * *}$ & {$[2.37-6.58]$} \\
Impact on abused women & & {$[0.83-0.90]$} \\
& & \\
Impact on nurse home visitor & $0.85^{* * *}$ & \\
\hline Note. OR $=$ odds ratio; CI $=$ confidence interval & & \\
$* p<.05 . * * p<.01 . * * * p<.001$. &
\end{tabular}


Table 3.4: Logistic Regression Analysis Predicting Intended Reporting Behavior

\begin{tabular}{llc}
\hline \multicolumn{1}{c}{ Variable } & OR & $95 \%$ CI \\
\hline Perceived awareness of reporting requirement & $13.30 * * *$ & {$[7.62-23.23]$} \\
Support for mandatory reporting of IPV & $1.89 * *$ & {$[1.19-3.00]$} \\
Impact on abused women & $0.96 *$ & {$[0.83-1.01]$} \\
Impact on nurse home visitor & & 0.92 \\
\hline Note. OR $=$ odds ratio; $\mathrm{CI}=$ confidence interval & & \\
$* p<.05 . * * p<.01 . * * * p<.001$. & &
\end{tabular}


Chapter 4 


\section{Chapter 4}

\subsection{Introduction}

Although much attention has been given to intimate partner violence (IPV) between adults, only recently have issues related to children who are exposed to IPV but are not victims themselves been extensively studied. ${ }^{109}$ Research has shown that in $30-60 \%$ of homes where IPV is ongoing, child maltreatment is also occurring. ${ }^{31,32}$ However, children in violent homes that are not themselves victims of abuse are often an overlooked piece of the puzzle. ${ }^{110}$ Previous research has referred to these children as “silent” or “invisible” victims. ${ }^{34,111}$ Early research referred to children living in households where IPV was present as child "witnesses"; however, more recent studies have shown that children do not have to actually view violence in the home to experience its negative effects. ${ }^{112}$ This resulted in the adoption of the term "exposure" to encompass the realm of children's experiences living in homes where IPV is perpetrated. ${ }^{34,112}$

Children can be exposed to IPV in a myriad of ways ranging from viewing or hearing the violent incidents, being directly involved (i.e., trying to intervene or placing a call to 911), or experiencing the aftermath of IPV (i.e., seeing destruction of the home or furniture, observing physical or emotional injuries of their parent, such as bruises or depression). ${ }^{42,113}$ Research shows that parents generally underestimate the extent to which children in the home are exposed to this violence. ${ }^{114}$ Studies report that in homes where IPV is perpetrated, $80 \%$ to $90 \%$ of children are aware of the abuse. ${ }^{36}$ A study by Litrownik and colleagues found that $33 \%$ of children reported witnessing IPV, yet only 14\% of parents reported that their children had witnessed this violence. ${ }^{114}$ These children are usually able to give detailed reports of violent episodes in their homes, while their parents assume the violence went unseen. ${ }^{37,43,114}$ 
It is estimated that $10-20 \%$ of children are exposed to IPV annually ${ }^{37,115}$ and anywhere from $25 \%$ to one-third of children exposed to IPV at some point during childhood. ${ }^{37}$ The substantial amount of research dedicated to determining the consequences of children's exposure to IPV suggests that similar psychopathology manifests between children who have been exposed to IPV and those who have been victims of physical abuse. ${ }^{45}$ Just as children who have been victims of child maltreatment, children exposed to IPV between adults experience subsequent negative emotional, psychological, and physical health outcomes. ${ }^{48}$ For example, children exposed to IPV are at a significantly higher risk for developing aggressive behaviors and conduct disorder and have been found to exhibit higher rates of depression, anxiety, and low self-esteem than children not exposed to IPV. ${ }^{48}$ Moreover, children living in homes where IPV is perpetrated are potentially at risk for being physically injured as well. ${ }^{37,116}$ Christian and colleagues reviewed 139 emergency department records of children with injuries as a result of IPV and found that children two years and under were often injured while in the arms of the abused parent and 39\% of the children were injured while trying to intervene in the violent episode. $^{116}$

Due to the deleterious effects that exposure to IPV can have on children, it has been proposed that children's exposure to IPV in and of itself should be classified as a form of child maltreatment. ${ }^{30}$ Recently, there has been movement toward enacting legislation related to IPV committed in the presence of a child. ${ }^{62,87}$ However, current definitions of child maltreatment vary widely between states and only a handful of states include language specific to children's exposure to IPV within their juvenile codes. ${ }^{62}$ Depending on how child maltreatment is defined within the juvenile code, equating children's exposure with child maltreatment may require all 
suspected and verified instances of IPV in homes where children are present to be reported to CPS.

Most research has recommended against considering children's exposure to IPV a form of child maltreatment, calling it a "blunt" $" 117$ or "inappropriate" ${ }^{\prime 60}$ response based on the fact that CPS agencies are usually overwhelmed, underfunded, and understaffed. ${ }^{61,62,118}$ and thus are not equipped to handle the increase in number of children that would be reported if children's exposure would require a maltreatment report and subsequent investigation (See Edelson, 1999). Furthermore, studies have shown that not all children exposed to IPV experience subsequent negative effects; thus, in these cases, reporting all instances of IPV perpetrated in the presence of children might be inappropriate, unnecessary, and potentially damaging. ${ }^{59}$ Though only a few states specifically consider children's exposure to IPV to be a form of child maltreatment, our previous qualitative work with nurses and abused women in a home visitation program revealed that home visitation providers may be under the impression that IPV perpetrated in the presence of a child is reportable to CPS. ${ }^{102}$ Providers might believe that they have an obligation to report because involving CPS in instances of children’s exposure to IPV depends on the local interpretation of a state's child maltreatment statute. ${ }^{61,62}$ Thus, uncertainty regarding this issue may be due to the fact that the boundary between children's exposure to IPV and child maltreatment is often thought of as a "gray area or "gray zone”. ${ }^{60,87}$ Zink and colleagues assert that "from the provider's perspective, it is important to understand when this legislation affects their mandatory reporting obligations”(p. 450) and yet no threshold has been established for what types of exposure should constitute child maltreatment. ${ }^{109,119}$ This lack of clarity can translate into serious ethical and legal implications for those required to report. ${ }^{22}$ 
Even so, most research regarding children's exposure to IPV has focused on the consequences of being exposed to IPV during childhood ${ }^{37}$ or debating the pros and cons of considering children's exposure a form of maltreatment. ${ }^{59}$ There is a paucity of research on reporters' perspectives and practices regarding children's exposure to IPV. Zink and others ${ }^{61}$ examined Ohio family and pediatric physicians' knowledge and management of children exposed to IPV and found that over half of the physicians recognized the signs and symptoms of children's exposure to IPV. Participants in this study were also presented with different scenarios of children exposed to the physical abuse of their mothers and were asked how they would manage the cases. Physicians were more likely to contact CPS when a child was a visual witness to the abuse of their mother as opposed to only hearing the abuse. The authors of this study suggest that research should assess whether or not mandatory reporting of children's exposure to IPV can prevent mothers from disclosing IPV to their health care providers. ${ }^{61}$

Steen ${ }^{103}$ examined the perspectives of domestic violence shelter workers with regard to filing reports of child maltreatment, including reports of children's exposure to IPV. Specifically, Steen assessed shelter workers' perceived impacts of reporting on the mother and child as well as on the relationship between the worker and battered woman. The results of this study revealed that domestic violence shelter workers perceived reporting children's exposure to IPV to have more negative impacts for abused women and children and for the relationship between the worker and abused woman than reporting actual child abuse committed by the batterer. Steen highlights the fact that although a great deal of literature has focused on attitudes toward child abuse reporting, no quantitative studies have been conducted that focus specifically on attitudes toward child maltreatment reporting when IPV is present. Steen recommends that more research is carried out to fill this gap in the literature. ${ }^{103}$ Our previous qualitative work with nurses and 
abused women in a home visitation program focus on attitudes towards reporting children’s exposure to IPV, ${ }^{102}$ but this issue has not been examined within a quantitative framework. The purpose of the current research was to address these gaps by examining the perspectives of nurses within the Nurse-Family Partnership (NFP) home visitation program regarding children's exposure to IPV.

Nurse home visitors within the NFP program provide support and education to lowincome women who are either pregnant or have young infants or children under the age of two. A study of mothers in the NFP program revealed that almost half of the sample reported experiencing IPV since the birth of their child—a rate twice as high as in the general population. ${ }^{2,84}$ As NFP nurses routinely screen for IPV and their clients are either pregnant or have small children, issues related to children's exposure to IPV are likely to emerge when IPV is disclosed within the context of the home visitation program. To the best of our knowledge, no study has examined the perspectives of health care providers in home visitation programs with regard to children's exposure to IPV. Specifically, the purpose of the current study was to examine home visitation providers’ 1) attitudes towards reporting children’s exposure to IPV, 2) perceived awareness of reporting requirements, and 3) intended reporting behaviors after being presented with different scenarios with varying levels of child's exposure to IPV.

\subsection{Method}

\subsubsection{Participants and Procedures}

Recruitment e-mails with information about the study and a link to a web-based questionnaire were sent to 1,119 nurse home visitors whose e-mail addresses were on file with the NFP National Service Office. Twenty six e-mails were returned as “undeliverable” and 534 questionnaires were returned out of the 1,093 that reached valid e-mail addresses (Response Rate 
$=49 \%$ ). Two questionnaires were not used in the final analyses due to large amounts of missing data. This study was approved by the West Virginia University Institutional Review Board (IRB), the Oklahoma State Department of Health IRB, and the NFP Research and Publication Communication Committee.

\subsubsection{Measures}

The questionnaire used in the current study was adapted from previous studies of mandatory reporting of child abuse ${ }^{103,120}$ as well as IPV reporting. ${ }^{16,25,28}$ A reviewer with expertise in the areas of IPV and family violence found the instrument to be acceptable. Furthermore, the survey was pilot-tested for readability and clarity in a small sample of nurses and social workers involved in a home visitation program in West Virginia with a similar mission and goals to that of the NFP program.

It is important to note that although the current study focuses on children's exposure to IPV, the survey refers to this type of violence as "domestic violence" even though it is understood that the term "domestic violence” can encompass violence between individuals other than intimate partners. The decision to include the term "domestic violence" in the language of the survey as opposed to "intimate partner violence” was based on our previous focus groups with nurse home visitors in the NFP program, as nurses revealed that they are most comfortable with using the term "domestic violence" and this is the language that they use with other nurses and clients when discussing violence between adult intimate partners.

Nurse home visitors' support for mandatory reporting of children’s exposure to IPV was assessed by having them respond to the statement, “I should be required to report children’s exposure to domestic violence” with responses choices ranging from 1(never) to 5 (always). 
Home visitors’ attitudes toward reporting children’s exposure to IPV were measured with a 16-item attitudinal scale (Table 3.1) that captured: (a) beliefs about the impact that reporting children's exposure to IPV can have on abused women and children (subscale 1; Cronbach's alpha $=.84)$ and (b) beliefs about the impact that reporting children's exposure can have on nurse home visitors themselves (subscale 2; Cronbach’s alpha $=.65$ ). Participants were asked to respond to each of the twelve statements in the first subscale on a 5-point Likert scale ranging from 1 (strongly agree) to 5 (strongly disagree). The potential range of the first subscale was 12 to 60 , with higher scores indicating that nurse home visitors believe mandatory reporting of children's exposure to IPV can negatively impact abused women and their children. Participants were asked to respond to the four items on the second subscale with responses ranging from 1 (never) to 5 (always). The possible range of the second subscale was 4 to 20, and higher scores indicated the belief that mandated reporting of children's exposure to IPV can negatively impact home visitors. The entire 16-item attitudinal scale (Cronbach's alpha $=.85$ ) had a possible range of 16 to 80, with higher scores representing more negative beliefs about mandated reporting of children's exposure to IPV.

Nurse home visitors' perceived awareness of reporting requirements regarding children’s exposure to IPV and nurses’ intended reporting behavior were examined by presenting participants with four different scenarios that they might encounter during home visitation sessions (See Appendix A). The scenarios describe the abuse of a woman when (1) she is pregnant, (2) she is holding her child in her arms, (3) her child is in the other room and hears but does not visually witness the abuse, and (4) her child is not at home during the violent episode. After reading the first and second scenarios, participants were presented with several questions assessing their perceived awareness of reporting requirements and intended reporting behavior as 
well as whether or not they believed the child's exposure to IPV in the scenario indicated a form of child maltreatment. If home visitors responded that they would report the case presented in the scenario, they were asked about the agencies to which they would send the report. Due to limitations on survey length, for the third and fourth scenarios, participants were only asked whether or not they believed the scenario indicated child maltreatment and whether or not they would report. Home visitors were also asked about demographic characteristics such as their age, number of years working in nursing practice and in the home visitation program, and number of children.

\subsubsection{Data Analysis}

Descriptive statistics were used to describe all demographic and study variables. For logistic regression analyses, responses to the statement measuring support for children's exposure to IPV reporting were dichotomized into "always" and "often" versus "some of the time”, "rarely", and “never”. Responses to the scenario that captured home visitors' perceived awareness of reporting requirements, intended reporting behavior, and whether or not the scenario was indicative of child maltreatment were dichotomized into "yes” versus "no" and "I don’t know”. Logistic regression analyses were conducted in order to predict support for mandatory reporting of children's exposure to IPV and intended reporting behavior for each of the four separate scenarios. Perceived awareness of a reporting requirement and both attitudinal subscales were entered into the regression model predicting support for mandatory reporting of children's exposure to IPV. The independent variables entered into the four separate regression models predicting intended reporting behavior for each of the home visitation scenarios included (a) whether or not the nurse considered the case a form of child maltreatment, (b) nurses' support for mandated reporting of children's exposure to IPV, and (c) both attitudinal subscales. For the 
first and second scenarios, perceived awareness of a reporting requirement was also entered into the regression models. Nurses' age, years as a nurse, years in the home visitation program, and number of children were also entered into each regression model separately in a stepwise fashion to assess for confounding. Any demographic variable that was not significantly predictive of the outcome variable and did not display evidence of confounding was dropped from the regression model. All analyses were conducted using STATA 10.0 software and statistical significance was set to alpha $<.05$.

\subsection{Results}

\subsubsection{Demographic Characteristics}

All home visiting nurses surveyed were female with a mean age of 44 years $(S D=10.30)$. Home visitors reporting being involved in home visitation serves with the NFP program for a mean of 4 years $(S D=3.13)$ and were in nursing practice for a mean of 17.85 years $(S D=$ 10.86). Nurses' reported average number of children was two $(S D=1.17)$.

\subsubsection{Attitudes and Support for Mandatory Reporting of Children's Exposure to IPV}

Over half (295) of nurse home visitors indicated that they should "always” be required to report instances of children's exposure to IPV and 20\% (107) thought they should be required to report "often". An additional 20\% (105) indicated that they should report "some of the time", and almost 5\% of the sample felt they should be required to report children's exposure to IPV "rarely" (13) or "never" (12).

Participants' attitudes towards mandated reporting of children's exposure to IPV are found in Table 4.1. The entire attitudinal subscale had a mean of $43.16(S D=7.83)$ and a range of 17 to 66. The first subscale assessing nurses' beliefs about the impact that reporting can have on abused women and their children had a mean of $34.20(S D=6.51)$ and a range of 13 to 54 . 
The mean of the second subscale measuring the impact that reporting can have on nurse home visitors was $8.96(S D=2.47)$ and the range was 4 to 18 .

As can be seen in Table 4.1, over half of the sample agreed or strongly agreed that reporting children's exposure to IPV can damage the relationship between the nurse and client and over $60 \%$ felt that reporting can limit a woman's disclosure of abuse to her nurse. On the other hand, two-thirds of nurse home visitors felt that reporting children's exposure to IPV can make it easier for battered women to get help and the vast majority (92\%) agreed or strongly agreed that reporting can protect children exposed to IPV. Furthermore, most nurses disagreed that reporting children's exposure to IPV can damage the battered woman's chances of custody or further traumatize the children. It is also important to note that a substantial portion of participants were undecided about their attitudes towards reporting children's exposure to IPV.

\subsubsection{Home Visitation Scenarios}

Nurse home visitors' opinions about whether or not the cases described in the four scenarios were indicative of child maltreatment and their intended reporting behaviors after reading each scenario are shown in Table 4.2. The majority of the sample (87\%) considered the abuse of a woman while her child was in her arms to be a form of child maltreatment and would report this case (78\%). Approximately half of the sample considered the abuse of a woman who is pregnant and a child overhearing the abuse of their mother to be forms of child maltreatment and almost half of the sample indicated that they would report those cases. A smaller percentage of nurses (14\%) considered abuse of a woman when her child was not in the home to be maltreatment, yet $27 \%$ of the sample indicated that they would report this case.

After reading the first and second scenarios, if participants answered that they would report the case described, they were then asked which agencies they would report to. Nurses 
were encouraged to select all answers that applied, and their responses can be seen in Table 4.3. Almost half of the participants who indicated they would report the abuse of a pregnant woman indicated that they would report to police, while 56\% said they would report to CPS and 20\% would report the case to adult protective services. Of those participants who said they would report the abuse of a woman while her child was in her arms, almost one-third would report to the police, the vast majority (92\%) would report to CPS, and 11\% would report to adult protective services. Most of the respondents that would report the cases also indicated that they would report to their supervisor in the home visitation program. Additionally, participants selected "other" agencies that they would report to and wrote in that they would report to the abused woman's health care provider, domestic violence shelters and hotlines, and state health department officials.

With regard to the first, third, and fourth scenarios, $10-20 \%$ of the sample answered that they did not know if they considered these cases to be child maltreatment, and $20-30 \%$ of the sample indicated that they did not know if they would report these cases. However, for the second scenario where the child was in her mother's arms during the violent episode, only 6\% of the sample did not know if they would consider this to be maltreatment and $16 \%$ reported that they did not know if they would report the case.

\subsubsection{Logistic Regression Analyses}

Nurse age, years in nursing practice, years in the home visitation program, and number of children did not significantly predict any outcome variable and did not display evidence of confounding; therefore, they were excluded from the final regression models. Table 4.4 shows the results of logistic regression model predicting support for mandated reporting of children's exposure to IPV. Regression analyses demonstrated that participants who indicated that they 
were aware of a requirement mandating them to report children's exposure to IPV were significantly more likely to support mandated reporting of children's exposure to IPV (OR = 2.43, $p<.001$ ) and participants that held beliefs that reporting children's exposure to IPV can negatively impact abused women and their children were significantly less likely to support reporting children's exposure to IPV $(O R=0.90, p<.001)$.

As can be seen in Table 4.5, nurses’ perceived awareness of a reporting requirement mandating them to report abuse of a pregnant woman was significantly predictive of the intention to report the abuse $(O R=13.35, p<.001)$. Nurses who considered the abuse of a pregnant woman to be a form of child maltreatment were over four times more likely to indicate that they would report the case than nurses who did not believe that this case constituted child maltreatment $(O R=4.43, p<.001)$. Furthermore, home visitors who support mandatory reporting of children's exposure to IPV were almost twice as likely to respond that would report the abuse of a pregnant woman than those participants who held lower levels of support for mandated reporting $(O R=1.77, p<.05)$. Participants who believe reporting children's exposure to IPV can negatively impact nurse home visitors were significantly less likely to indicate that they would report the abuse of a pregnant woman $(O R=0.87, p<.01)$. Home visitors who indicated that reporting children's exposure to abuse can negatively impact abused woman and their children were also less likely indicate that they would report the IPV toward a pregnant woman; however, this result did not achieve statistical significance.

Table 4.5 also shows that home visitors who indicated their perceived awareness of a requirement to report the scenario describing the abuse of a woman with her child in her arms were significantly more likely to respond that they would report the abuse described in this scenario $(O R=19.67, p<.001)$. Home visiting nurses that considered abuse of a woman with a 
child in her arms to be a form of child maltreatment were also significantly more likely to indicate that they would report the case $(O R=14.17, p<.001)$.

Table 4.6 shows that those home visiting nurses who considered a child overhearing the abuse of her mother but not directly witnessing the violence to be child maltreatment were significantly more likely to indicate that they would report the case than those nurses who did not think the scenario described child maltreatment $(O R=10.00, p<.001)$. Additionally, nurses' support for mandatory reporting of children's exposure to IPV was significantly predictive of nurses' intention to report the case where the child is not in the room when the episode of IPV occurs $(O R=2.24, p<.01)$. Table 4.6 also shows that home visiting nurses who thought that the scenario describing the abuse of a woman whose child was not at home during the violent episode to be a form of child maltreatment were significantly more likely indicate their intention to report the case of abuse $(O R=20.40, p<.001)$. Furthermore, nurses' support for mandated reporting of children's exposure to IPV $(O R=5.33, p<.001)$ was significantly predictive of intention to report the case described in the scenario.

\subsection{Discussion}

The results of the current study suggest that most nurse home visitors in our sample support reporting children's exposure to IPV. Overall, nurse home visitors' attitudes and beliefs about the impacts that reporting can have on abused women and children and on home visitors themselves were varied. Most of our sample agreed that mandated reporting of children's exposure to IPV can help abused women and protect children, but the nurses also recognized that reporting may have negative consequences on home visitation practice, such as damaging the relationship between the nurse and client and limiting the client's disclosure of abuse to her nurse. This findings augment the preliminary results found in our prior qualitative work with this 
population, as focus groups revealed that home visitors' duties as mandated reporters often result in a lack of trust from clients and can strain the therapeutic relationship with their clients either temporarily or permanently. ${ }^{102}$ Steen's study of domestic violence shelter workers' attitudes toward reporting children's exposure to IPV found that the workers believed reporting children's exposure to IPV can damage the relationship between the battered woman and worker "about half of the time", ${ }^{103}$ which is consistent with the findings of the current study.

Nurse home visitors' opinions of whether the four different scenarios of children's exposure to IPV were indicative of child maltreatment appeared to depend on the proximity of the child to the violent episode, as most participants considered a mother holding her child while being abused to be child maltreatment, yet only $14 \%$ of the sample considered it child maltreatment when the child was not in the home during the abuse of the mother. The percentage of nurses that would report the four scenarios also decreased the further the child was from the abuse in the scenario. The majority of participants indicated that they would report the scenario where the mother is holding her child during the abuse, suggesting that nurses may be more likely to report cases of children's exposure to IPV when the child is at risk of physical harm.

These findings compare to those found in the previously described study of Ohio physicians' management of children's exposure to IPV ${ }^{61}$ Zink and colleagues found that $54 \%$ of physicians would report to CPS when presented with a scenario of a child who visually witnessed his/her mother being beaten by his/her father resulting in a black eye for the mother and no injury for the child. When responding to a different scenario where the child is an auditory witness to the violence, but does not visually observe the episode, $41 \%$ of physicians indicated that they would contact CPS. ${ }^{61}$ The results of the current study indicate that $45 \%$ of 
nurse home visitors would also report a child who overhears the violence between adults, however, we do not have data on which agency they would send the report to for this scenario.

It is important to note that Alaska is the only state to specifically define children's exposure to IPV as a form of child maltreatment. ${ }^{61}$ As the NFP program is not implemented in Alaska, a substantial proportion of nurses in the current study indicated that they would report children's exposure when it is not included in their state’s child maltreatment statute. However, many states' child maltreatment statutes include language such as "substantial risk of harm” or “imminent danger" in their definitions of child maltreatment. ${ }^{62}$ Thus, it is possible that nurses in the current study consider abuse of a mother when her child is in her arms to pose a "substantial risk” to the child for being physically injured, as over $90 \%$ of those participants that would report this case indicated that they would report to CPS. Christian and others' review of emergency department records provides support for this line of reasoning, as the authors found that children under two years of age were often physically injured while in the arms of the abused parent. ${ }^{116}$ However, it is also possible, that for this scenario as well as the other three situations, participants that indicated they would report were referencing the fact that they would report to their supervisors as part of the protocol within the home visitation program. On the other hand, our previous focus groups with this population suggested that home visiting nurses were under the impression that children's exposure to IPV required a report to both their supervisor and CPS. $^{102}$

Another important outcome of the current study was that almost half of the sample indicated that they would report the abuse of a pregnant woman, and over half of the participants that would report stated that they would report to CPS, indicating that they believe the abuse of a pregnant woman is a form of child maltreatment. Our previous research with community 
stakeholders, many of which who worked for CPS, revealed that most CPS agencies require that a child be born before maltreatment can be reported to the agency. The issue of reporting to CPS when an abused woman was pregnant also emerged in the focus groups home visiting nurses, as they highlighted the uncertainty that they face with regard to their reporting duties when a client is pregnant as well as when her child is exposed to the abuse after birth. The results of the current study also reveal this indecision, as many nurses did not know whether the different types of children's exposure to IPV indicated child maltreatment and if they would report the cases. Logistic regression analyses show that nurses who considered the different types of exposure to constitute child maltreatment were significantly more likely to indicate that they would report the cases. Furthermore, support for mandated reporting of children's exposure to IPV was predictive of intended reporting behavior for all of the scenarios except where the child was in her mother's arms during the abusive episode. Nurses' attitudes about the impact of reporting did not predict intended reporting behavior for this scenario, but attitudes were either significantly predictive or marginally predictive for the other three scenarios. Thus, it is possible that in cases when the child is at greatest risk of being harmed due to IPV between adults, nurses do not consider their own support for and attitudes towards reporting, but are guided by whether or not the child is risk of injury and their perception of this risk may determine their reporting behavior. For the scenarios in which the child is not born, is an auditory witness to the abuse, and is not home during the abusive episode, nurses’ support for mandated reporting of children’s exposure was independently predictive of their intended reporting behavior. It is possible that in situations involving IPV perpetrated in the presence of a child, unless the nurse perceives that the child was at risk for being injured, nurses may consider their own support for mandated reporting when deciding whether or not to report the case. However, in cases where children are at risk for 
harm, nurses may feel that reporting to CPS is in the best interest of the child and the child's safety may override nurses' own support or non-support for reporting and any concerns about the impact that reporting might have on home visitation practice.

\subsubsection{Strengths and Limitations}

One strength of the current research is that, to the best of our knowledge, this is the first study to use a quantitative framework to examine the perspectives of those involved in home visitation services with regard to children's exposure to IPV. Furthermore, we were able to obtain home visitors' perspectives about different types of exposure to IPV. As future research will most likely be geared towards determining a threshold for when exposure to IPV is damaging to children and under which circumstances it should be reported, the perspectives of mandated reporters who closely interact with abused women and their children will be informative.

However, the current study has several limitations. Although we achieved a response rate (49\%) that is typical of internet surveys, ${ }^{107,108}$ our findings are representative of less than half of the overall population of NFP nurse home visitors. Comparisons between the characteristics of the current sample and those of the population of NFP home visitors show that our sample had significantly fewer nurses aged 40 and younger (sample $36 \%$ vs. population $47 \% ; p<.001$ ) and significantly more nurses over age 40 (sample 64\% vs. population 53\%; $p$.001) than in the entire population of NFP nurses (Appendix B). Furthermore, the current sample reporting being in nursing practice for significantly longer than the overall population of nurses (sample 18 years vs. population 14 years; $p<.001$ ). It is important to note that the characteristics of nurses in the entire population of home visitors reflects data collected upon nurses' entry into the home visitation program, and our sample characteristics reflect age and years in nursing practice at the 
time of survey completion. This may account for the difference in age and number of years in nursing practice between our sample and the entire population of home visitors.

In addition, for all logistic regression analyses, “no” and “I don’t know” answers were grouped together, which may have influenced the study’s results, as $10-20 \%$ of the sample responded that they did not know if they would report the abuse described in the scenarios. Table 5.3 and Table 5.4 in Appendix D describe those participants who were undecided about their attitudes towards reporting or who indicated that they did not know if they would report the abuse described in the four scenarios in an attempt to determine if participants who displayed uncertainty differed from respondents who indicated committed responses. Participants that were undecided about whether reporting children’s exposure to IPV can damage the relationship between the nurse and her clients were significantly more likely to support reporting children’s exposure than participants who disagreed with the statement, while participants who were undecided about whether reporting can protect children or make it easier for abused women to get help held significantly lower levels of support for reporting than respondents who agreed or either agreed or disagreed with the beliefs (Table 5.3). Nurse home visitors that indicated "I don't know” after reading the home visitation scenarios where IPV is perpetrated against a pregnant woman, when the child is in another room, and when the child is not home exhibit significantly lower levels of support for reporting children's exposure to IPV than participants who indicated they would report these cases (Table 5.4).

Furthermore, this research was restricted to nurse home visitors in one home visitation program and cannot be generalized to other visitation programs or providers. The data in the current study reflect intended reporting behavior and not actual rates of reporting children's exposure to IPV. Future research on home visitors' actual reporting behaviors with regard to this 
issue is warranted, as national rates of child maltreatment allegations that include children's exposure to IPV are still unknown. ${ }^{87}$ Additionally, it cannot be determined whether nurses’ considerations of whether or not the scenarios were indicative of child maltreatment and whether they would report the cases were motivated by the risk of physical harm to the child or because they are aware of the fact that exposure to IPV can be psychologically damaging for children, or both. Other studies should examine the factors that mandated reporters consider when reporting children's exposure to IPV. Furthermore, we did not include a scenario where a child visually witnesses the incident, but is not being held (as described in Zink et al., 2005) and the perspectives of our sample with regard to this type of scenario would have been useful. Lastly, the current study focuses on home visitors’ perceived awareness of reporting requirements and intended reporting behaviors regarding children's exposure to physical IPV between adults. Research has demonstrated significant associations between psychological or emotional IPV and long-term negative consequences to women's physical and psychological health. ${ }^{88}$ However, this study does not shed light on nurse home visitors’ intended reporting behaviors or perceived awareness of reporting requirements regarding emotional IPV between intimate partners or children's exposure to emotional IPV between adults.

\subsubsection{Conclusion}

The results of the current study quantify the themes that emerged in our previous qualitative work with this population; most notably, that our sample of home visitors exhibits variability and uncertainty with regard to their attitudes about reporting children's exposure to IPV as well as which situations they believe constitute child maltreatment and require a report to CPS agencies. These findings are not unexpected, as research has not yet determined an objective threshold for the severity of exposure to IPV needed for intervention. ${ }^{87,109}$ Even so, it 
is important that health care providers in home visitation programs are fully informed of not only of their states' child maltreatment statutes, but also of the ways in which the language of the statute is interpreted under the law as well as within CPS agencies. We recommend that home visitation programs collaborate with legal agencies and local CPS agencies in order to establish which circumstances are reportable to CPS and which types of exposure to IPV are not appropriate for referrals. In addition, although children exposed to IPV are encountered in a wide variety of health care settings, there is a great deal of untapped potential in examining the home visitation providers' role in responding and intervening with women and children exposed to IPV. Carlson asserts that education on effective parenting can benefit mothers of children exposed to IPV, ${ }^{37}$ and as home visitors are already providing this type of information to clients, they are have a unique opportunity to dialogue with clients and provide education about the effects of exposure to IPV on children. Health care providers in home visitation settings are also appropriate individuals to help link abused women and their children with CPS agencies, local domestic violence service centers, and other mental health services. 
Table 4.1: Nurse Home Visitors' Attitudes toward the Mandatory Reporting of Children's Exposure to IPV

\begin{tabular}{|c|c|c|c|}
\hline Impact on abused women and their children & $\begin{array}{c}\text { Strongly } \\
\text { Agree or } \\
\text { Agree } \\
(\%)\end{array}$ & $\begin{array}{c}\text { Strongly } \\
\text { Disagree or } \\
\text { Disagree } \\
(\%)\end{array}$ & $\begin{array}{l}\text { Undecided } \\
\quad(\%)\end{array}$ \\
\hline \multicolumn{4}{|l|}{$\begin{array}{l}\text { "I feel that the mandatory reporting of children's } \\
\text { exposure to domestic violence..." }\end{array}$} \\
\hline can damage the relationship between nurse and client & 56.20 & 25.19 & 18.61 \\
\hline can disempower the battered woman & 22.18 & 50.38 & 27.44 \\
\hline can prevent battered women from seeking further help & 30.07 & 43.80 & 26.13 \\
\hline can further traumatize the child(ren) & 25.75 & 53.57 & 20.68 \\
\hline can protect the child(ren) & 91.54 & 2.63 & 5.83 \\
\hline can cause more disruption to the family & 53.76 & 22.18 & 24.06 \\
\hline can damage the battered woman's chances of custody & 12.78 & 68.80 & 18.42 \\
\hline would make it easier for battered women to get help & 66.54 & 8.27 & 25.19 \\
\hline would put women at greater risk for being abused or hurt & 50.75 & 14.29 & 34.96 \\
\hline $\begin{array}{l}\text { would make it less likely that a client would tell me } \\
\text { about the abuse }\end{array}$ & 62.21 & 18.05 & 19.74 \\
\hline would make my clients resent me for having to report & 44.93 & 23.87 & 31.20 \\
\hline $\begin{array}{l}\text { would help my clients because they would like for } \\
\text { someone else to report the abuse }\end{array}$ & 45.30 & 12.41 & 42.29 \\
\hline Impact on nurse home visitors & $\begin{array}{c}\text { Always } \\
\text { or Often } \\
(\%)\end{array}$ & $\begin{array}{c}\text { Some of } \\
\text { the Time } \\
(\%)\end{array}$ & $\begin{array}{l}\text { Rarely or } \\
\text { Never } \\
(\%)\end{array}$ \\
\hline $\begin{array}{l}\text { I lack faith in law enforcement to respond appropriately } \\
\text { to reports of children's exposure to domestic violence. }\end{array}$ & 28.20 & 44.17 & 27.63 \\
\hline $\begin{array}{l}\text { I fear reprisals from reporting children’s exposure to } \\
\text { domestic violence. }\end{array}$ & 9.96 & 25.75 & 64.29 \\
\hline $\begin{array}{l}\text { I fear litigation and/or legal liability from reporting } \\
\text { children's exposure to domestic violence. }\end{array}$ & 8.08 & 19.74 & 72.18 \\
\hline $\begin{array}{l}\text { Workload pressures are likely to deter me from reporting } \\
\text { children's exposure to domestic violence. }\end{array}$ & 2.26 & 6.20 & 91.54 \\
\hline
\end{tabular}


Table 4.2: Nurse Home Visitors' Opinions of Whether Child's Exposure to IPV Indicates Child Maltreatment and Intended Reporting Behavior after Reading Four Scenarios

\begin{tabular}{|c|c|c|c|c|}
\hline \multirow[b]{3}{*}{ Survey Item } & \multicolumn{4}{|c|}{ Scenario } \\
\hline & $\begin{array}{l}\text { Client is } \\
\text { Pregnant }\end{array}$ & $\begin{array}{c}\text { Mother is } \\
\text { Holding } \\
\text { Child }\end{array}$ & $\begin{array}{c}\text { Child in } \\
\text { Other } \\
\text { Room }\end{array}$ & $\begin{array}{l}\text { Child Not } \\
\text { at Home }\end{array}$ \\
\hline & $\mathrm{n} \quad(\%)$ & $\mathrm{n} \quad(\%)$ & $\mathrm{n} \quad(\%)$ & $\mathrm{n} \quad(\%)$ \\
\hline Indicates child maltreatment & $288(54.14)$ & $465(87.41)$ & $268(50.38)$ & $75(14.10)$ \\
\hline Would report this case & $236(44.36)$ & 417 (78.38) & $241(45.30)$ & $145(27.26)$ \\
\hline
\end{tabular}

Table 4.3: Responses to Survey Question “If Yes, to Whom?” After Nurse Home Visitors Endorsed Reporting the Cases Described in Scenarios 1 and 2.

\begin{tabular}{|c|c|c|c|c|}
\hline & \multicolumn{4}{|c|}{ Scenario } \\
\hline & \multicolumn{2}{|c|}{ Client is pregnant ${ }^{a}$} & \multicolumn{2}{|c|}{ Child in mother's arms } \\
\hline & $\mathrm{n}$ & $(\%)$ & $\mathrm{n}$ & $(\%)$ \\
\hline Law enforcement & 115 & $(48.73)$ & 128 & $(30.70)$ \\
\hline Child protective services & 131 & $(55.51)$ & 382 & $(91.61)$ \\
\hline Adult protective services & 28 & $(20.34)$ & 44 & $(10.55)$ \\
\hline Supervisor & 211 & $(89.41)$ & 340 & $(81.53)$ \\
\hline Other & 18 & (7.63) & 10 & $(2.40)$ \\
\hline
\end{tabular}

Note. Totals equal more than $100 \%$ because participants were asked to select all that apply.

${ }^{a}$ Out of 236 participants who endorsed reporting the case described in the scenario.

${ }^{\mathrm{b}}$ Out of 417 who endorsed reporting the case described in the scenario. 
Table 4.4: Logistic Regression Analysis Predicting Support for Mandatory Reporting of Children's Exposure to IPV

\begin{tabular}{llc}
\hline Variable $^{\mathrm{a}}$ & OR & $95 \%$ CI \\
\hline Perceived awareness of requirement & $2.43^{* * *}$ & {$[1.58-3.75]$} \\
Impact on abused women & $0.90^{* * *}$ & {$[0.86-0.93]$} \\
Impact on nurse home visitor & 0.93 & {$[0.85-1.02]$}
\end{tabular}

Note. $\mathrm{OR}=$ odds ratio; $\mathrm{CI}=$ confidence interval.

${ }^{\mathrm{a}}$ Three variables entered simultaneously.

${ }^{*} p<.05 .{ }^{* *} p<.01 .{ }^{* * *} p<.001$. 
Table 4.5: Logistic Regression Analysis Predicting Home Visitors' Intention to Report Scenarios 1 \& 2

\begin{tabular}{|c|c|c|c|c|}
\hline \multirow[b]{2}{*}{ Variable $^{a}$} & \multicolumn{2}{|c|}{ Pregnant } & \multicolumn{2}{|c|}{ Child in Arms } \\
\hline & OR & $95 \%$ CI & OR & $95 \% \mathrm{CI}$ \\
\hline Perceived awareness of requirement & $13.35 * * *$ & {$[7.51-23.74]$} & $19.67 * * *$ & {$[10.55-36.66]$} \\
\hline Case is considered child maltreatment & $4.43 * * *$ & {$[2.84-6.91]$} & $14.17 * * *$ & {$[6.50-30.86]$} \\
\hline Support for mandatory reporting & $1.77 *$ & {$[1.03-3.05]$} & 1.40 & {$[0.74-2.68]$} \\
\hline Impact on abused women & 0.96 & {$[0.93-1.00]$} & 0.96 & {$[0.91-1.01]$} \\
\hline Impact on nurse home visitor & $0.87 * *$ & {$[0.79-0.96]$} & 0.93 & {$[0.82-1.06]$} \\
\hline \multicolumn{5}{|c|}{ Note . OR = odds ratio; $\mathrm{CI}=$ confidence interval. } \\
\hline a Five variables entered simultaneously. & & & & \\
\hline
\end{tabular}


Table 4.6: Logistic Regression Analysis Predicting Nurse Home Visitors' Intention to Report Scenarios 3 \& 4

\begin{tabular}{|c|c|c|c|c|}
\hline \multirow[b]{2}{*}{ Variable $^{\text {a }}$} & \multicolumn{2}{|c|}{ Child Overheard Violence } & \multicolumn{2}{|c|}{ Child Not at Home } \\
\hline & OR & $95 \%$ CI & OR & $95 \%$ CI \\
\hline Case is considered child maltreatment & $10.00 * * *$ & {$[6.59-15.16]$} & $20.40 * * *$ & {$[9.61-41.15]$} \\
\hline Support for mandatory IPV reporting & $2.24 * *$ & {$[1.34-3.76]$} & $5.33 * * *$ & {$[2.47-11.50]$} \\
\hline Impact on abused women & 0.97 & {$[0.93-1.00]$} & 0.97 & {$[0.94-1.01]$} \\
\hline Impact on nurse home visitor & 0.92 & {$[0.84-1.01]$} & 0.86 & {$[0.81-1.01]$} \\
\hline \multicolumn{5}{|c|}{ Note. $\mathrm{OR}=$ odds ratio; $\mathrm{CI}=$ confidence interval. } \\
\hline${ }^{\mathrm{a}}$ Four variables entered simultaneously. & & & & \\
\hline
\end{tabular}




\section{Chapter 5}




\section{Chapter 5}

\subsection{Summary}

The main objective of this project was to enhance our understanding of mandatory reporting issues in the context of home visitation programs through the results of three separate but related studies. Previous research about mandatory reporting issues has focused mainly on reporting child abuse ${ }^{64,66}$ Fewer studies have examined mandatory reporting with regard to IPV and children's exposure to IPV, although these issues have gained more attention in recent years. Research focusing on mandatory reporting of IPV and children's exposure to IPV has mainly centered on the current state of legal statutes for reporting requirements ${ }^{17,62}$ and abused victims' perspectives. ${ }^{121}$ Less attention has been given to the perspectives and practices of health care providers' who routinely interact with abused women and their children, yet mandated reporting laws often give rise to serious legal, moral, ethical, and practical questions for those required to report. ${ }^{22}$ The few studies that have given attention to reporting of IPV and children’s exposure to IPV have mainly focused on mandated reporting in clinical settings, such as family or emergency physicians. ${ }^{61,65}$

Health care professionals providing home visitation services are not immune to issues related to mandated reporting of IPV and children's exposure, as they typically support women who are either pregnant or have young children, and because of the same demographic characteristics making them eligible for enrollment in the home visitation program, they are at a greater risk of experiencing abuse ${ }^{83}$ than women in the general population. ${ }^{2,84}$

The qualitative study described in Chapter 2 revealed that issues related to IPV reporting are relevant to providers in home visitation programs and warrant increased attention. Specifically, the sample of nurse home visitors in the NFP program who participated in the 8 
focus groups were in consensus that they were not mandated to report IPV between adults, but were uncertain of their reporting obligations when the abuse was perpetrated in the presence of a child. Nurses also revealed that their duties as mandated reporters can have negative effects on the nurse-client relationship, such as limiting the disclosure of abuse and causing attrition from the NFP program. Furthermore, home visitors perceived that clients' reluctance to interact with mandated reporters was motivated by fear of losing custody of their children. Nurses offered techniques and tactics that help to put abused clients at ease within the home visitation program, such as stressing the confidentiality between nurses and clients and emphasizing the positive impacts that CPS can have in helping abused women and their children. Last, nurses requested up-to-date, state-specific, accurate information about their obligations as mandated reporters within the home visitation program, further highlighting the uncertainty they experience with regard to their reporting duties.

In order to quantify the themes found in the qualitative study described in Chapter 2, a web-based survey was sent to all nurse home visitors within the NFP program who had valid email addresses on file with the NFP National Service Office. The results of the survey provide us with a more comprehensive view of nurse home visitors' perspectives about mandated reporting and their intended reporting behaviors. Results from 532 home visitors (Response Rate $=49 \%$ ) suggest that nurses in the NFP program support both mandated reporting of IPV and children's exposure to IPV and a substantial portion of nurses indicated that they would report these instances to authorities such as law enforcement or CPS.

Attitudinal data demonstrate that home visitors hold multifaceted beliefs about the impacts of mandated reporting. For reporting both IPV between adults and children's exposure, the majority of home visitors agreed that reporting in these situations can make it easier for 
abused women to obtain help and protect their children, but over half also believed that it can disrupt the relationship between nurse and client, limit the abused woman's disclosure of IPV, and importantly, put the woman at greater risk for being abused or hurt by the perpetrator. These findings were alluded to in the focus groups described in Chapter 2, but the quantitative studies employed in Chapters 3 and 4 substantiate home visitors' mixed perceptions about mandated reporting.

Another issue that was referred to in our first study that was more closely examined in the third study was nurses' uncertainty about which types of children's exposure to IPV should be considered forms of child maltreatment and should be referred to CPS. Nurses in the focus groups explained that they did not know if the abuse of a woman with a child in her arms or who visually witnesses abuse between adults constitutes potential harm to the child. Results from the survey described in Chapter 4 demonstrate that home visitors' are more likely to consider situations of IPV to constitute child maltreatment when children are closer to the violent episodes between adults, and are consequently at greater risk for being physically injured themselves.

Last, the findings of this project demonstrate that while home visitation providers' intended reporting behaviors are indeed motivated by their awareness of requirements to report IPV and children's exposure to IPV, their support for reporting in these instances is also influential. Results showed that their attitudes about the impact of reporting on abused women and their children as well as on home visitation practice is predictive of support, and in some instances, their intended reporting behaviors as well.

\subsection{Significance}

The long-term goal of this study was to increase scientific knowledge about mandatory reporting issues within the context of home visitation programs, which, in turn, will help to 
inform the development of intervention strategies and prevention programs for IPV perpetrated towards women and in the presence of children. This study is significant for several reasons. First, these issues have not been specifically studied with this population, and our research shows that mandatory reporting policies have significant consequences for this population of mandated reporters and the clients and children that they support. Furthermore, the fact that over half of nurses sampled in this study agreed that reporting IPV and children's exposure can put the abused woman at greater risk of harm from the perpetrator is especially significant and establishes the importance of conducting in-depth investigations into the impacts of mandated reporting laws before they are enacted. Other researchers that have discovered similar attitudes about reporting laws have cautioned against this type of legislation until more research the risks, benefits, and consequences of mandated reporting laws have been conducted. ${ }^{25}$ Last, the current project demonstrates the need for education and training with home visitation providers about their roles as mandated reporters and the presence or lack of specific state statutes.

\subsection{Strengths and Limitations}

The findings from these three studies should be viewed with regard to their strengths and weaknesses. Given that this was the first major study to examine the issues mandated reporting with regard to IPV in the context of home visitation programs, obtaining a large sample of participants from the most rigorous ${ }^{85}$ and most efficacious ${ }^{86}$ visitation program that is employed in 32 states was a major strength of the current study. Furthermore, the study in Chapter 2 provided rich, detailed narratives of real-life experiences from the perspectives of community stakeholders involved with IPV services as well as nurses and clients within the NFP program. Therefore, the study described in Chapter 2 supplied ample data for a secondary analysis of qualitative data (87 transcripts) and provided a strong foundation for the development of the 
methods described in Chapters 3 and 4. Thus, the triangulation of multiple sources and multiple perspectives results in a more credible and complete understanding of issues related to mandated reporting in home visitation. ${ }^{100}$

The web-based survey described in Chapters 3 and 4 also achieved a response rate typical of internet surveys ${ }^{107,} 108$ and similar to what has been found in previous research with this population of home visitors ${ }^{\text {(M. Gasbarro, personal communication, March 2010) }}$. Furthermore, although the nurses in our sample appear to be significantly older and have more experience in nursing practice (See Appendix B) than NFP nurses in general, it is likely that this finding is explained by the fact that the data for the population of home visitors reflects age and years in nursing practice at hire into the NFP program, while the data for our sample reflect nurses' age and years of nursing experience at the time they completed the survey.

However, the current study is not without limitations. As we only sampled from one home visitation program that employs nurses, the findings from this project cannot be generalized to other home visiting programs or other types of health care professionals, such as paraprofessionals or social workers, who often work in home visitation settings. Another limitation might lie in the way that we measured nurses’ perceived awareness of a reporting requirement and intended reporting behavior for IPV between adults. As nurses only home visit with women who are either pregnant or have young infants and children, it would not have been relevant to present participants with a scenario involving the abuse of a woman without children. Therefore, we used participants' responses to the scenario describing the abuse of a pregnant woman to determine their perspectives about reporting IPV between adults, as described in Chapter 3. Because many participants answered that they would report the abuse of a pregnant woman to both CPS and law enforcement, it is difficult to determine whether they would report 
as a consequence of the abuse towards the woman, the unborn child, or both. The scenario describing the abuse of a woman while her child was not in the home during the abusive episode could have been used to assess nurses’ perspectives about reporting IPV only; but due to length restrictions on the survey, we do not have data on where participants would send the report of abuse, if they indicated that they would report this scenario. The lack of data on participants' perceived awareness of reporting requirements and where they would send the report for the third (child overhears violence) and fourth (child was not in the home during violence) scenarios is also a limitation of the current project.

It is also important to take into account that the findings of the current project are not representative of actual reporting behaviors of home visiting nurses, but are only their responses after being presented with a hypothetical scenario that they might encounter during a home visitation session. In reality, home visitors may rely on other knowledge and details of their clients' situations not included in the scenarios in order to determine whether they would report abuse to an outside agency. Furthermore, it is possible that those participants who indicated that they would report the abuse described in the scenarios believed that informing their supervisor in the program was a form of reporting and this could be an explanation for why a substantial proportion of nurses indicated that they would report IPV and children's exposure to IPV when there states' laws did not require the report. Last, the current project was only able to assess participants' “perceived awareness” of their requirements to report IPV and children’s exposure to IPV, as mandatory reporting requirements for health care professionals in home visitation services have not been adequately delineated. For example, the state of Colorado mandates that physicians are to report "any injury caused by a criminal act, including domestic violence” to the police. ${ }^{15}$ After much debate within the NFP program as to whether or not nurses who provide 
home visitation services should report as well, NFP implementing agencies in Colorado decided that nurses would not be mandated to report instances of violence to the police ${ }^{(K . ~ B l a c k, ~ p e r s o n a l ~}$ communication, December 2009). Thus, although IPV reporting laws may apply to health care professionals in clinical settings, comprehensive guidelines have not been set forth for providers in home visitation settings and laws vary considerably at the state and regional level.

Another concern within the current project is the substantial proportion of respondents that indicated they were undecided about the impacts that reporting IPV and children's exposure to IPV can have on abused women and their children as well the number of participants responding that they did not know whether or not they would report the abuse described in each home visitation scenario. Because participants responding with "I don’t know” were combined with participants answering "no" for logistic regression analyses, the results of the current study may have been influenced by such groupings. It is possible that those participants who exhibited ambivalence or uncertainty with regard to their intended reporting behaviors and attitudes differ on key demographic and study variables from those who chose to respond with "yes" or "no" or who agreed or disagreed with certain items.

Over 50\% (271) of the sample responded that they did not know whether or not they would report for at least one of the home visitation scenarios and 16 participants (3\%) responded with "I don’t know" for all four home visitation scenarios. Logistic regression analyses revealed that if participants indicated "I don't know" for one scenario, they were significantly more likely to respond that they did not know for other scenarios. With regard to participants who were undecided about the impacts that reporting IPV between adults and children's exposure to IPV can have on abused women and their children, an undecided response to one or more items did not significantly predict other undecided responses. Furthermore, 21 (4\%) participants did not 
know if they would report for at least two home visitation scenarios and were undecided on at least three of five attitudinal items regarding children's exposure to IPV; however, this group of participants was not significantly different from the rest of the sample with regard to any demographic characteristics.

Appendix D contains several tables characterizing participants with “undecided” or “I don’t know” responses as a group and examining if these participants are significantly different from participants who gave more committed responses. Table 5.1 in Appendix D shows that participants that were undecided about the perceived impacts that mandatory reporting of IPV can have on abused women and children were not significantly different with regard to demographic variables from the rest of the sample. However, the results in Table 5.2 indicate that those participants who indicated that they were undecided about whether or not mandatory reporting of IPV can damage the relationship between nurse and client held significantly higher levels of support for mandatory reporting of IPV than participants who agreed or strongly agreed with the statement $(p=.0001)$. Furthermore, those participants who were undecided about whether or not mandatory reporting of IPV can protect children held significantly lower levels of support for mandatory reporting of IPV than 1) those who agreed it could protect children $(p=$ $.0000), 2)$ those who disagreed that it could protect children $(p=.0001)$, and 3$)$ those who either agreed or disagreed that it could protect children $(p=.0000)$. In addition, respondents that were undecided about whether or not mandatory reporting of IPV can make it easier for abused women to get help held significantly lower levels of support for reporting IPV than those who agreed with the statement $(p=.0000)$ and those who either agreed or disagreed with the statement. 
With regard to home visitors' attitudes towards the impacts that reporting children's exposure to IPV can have on abused women and their children, the results in Table 5.3 indicate that those participants who were undecided about whether reporting children's exposure to IPV can damage the relationship between the nurse and her clients were significantly more likely to support reporting children's exposure than participants who disagreed with the statement $(p=$ .0000). Nurse home visitors who were undecided about whether reporting children's exposure to IPV can protect the children held significantly lower levels of support for reporting than those who agreed that reporting can protect children $(p=.0000)$ and those who either agreed or disagreed that reporting can protect children $(p=.0000)$. Respondents indicating that they were undecided about whether or not reporting children's exposure to IPV can make it easier for abused women to get help held significantly lower levels of support for mandatory reporting of children's exposure to IPV than participants who agreed with the statement $(p=.0000)$ and those who either agreed or disagreed with the statement $(p=.0001)$.

In terms of intended reporting behaviors for each of the four home visitation scenarios described in Study 3, Table 5.4 shows that those participants who responded with "I don't know" when asked whether or not they would report the IPV perpetrated against a pregnant woman (Scenario $1 ; p=.0000$ ), IPV while the child was in the other room and heard but did not visually witness the violence (Scenario 3; $p=.0000$ ), and IPV when the child was not at home (Scenario $4 ; p=.0001$ ) held significantly lower levels of support for mandatory reporting of children's exposure to IPV than those participants who indicated they would report these cases.

Respondents that indicated they did not know whether or not they would report the four home visitation scenarios did not differ from the rest of the sample with regard to demographic characteristics. 
These analyses reveal that although nurse home visitors that are undecided about their attitudes towards mandatory reporting and their intended reporting behaviors may not significantly differ from the rest of the sample with regard to demographic characteristics, these respondents are significantly different from the rest of the sample with regard to their support for mandatory reporting of IPV and children's exposure to IPV. These results have implications for the current study, as home visitors’ attitudes were used to predict support for mandatory reporting, and this support was used to predict intended reporting behavior in several logistic regression models. These results suggest that undecided participants may represent a third group of respondents that are significantly different from those that definitively agree and/or disagree about the impacts that reporting can have on abused women and children, but they were not treated as such within the current study. Future analyses should focus on treating undecided respondents as a third group as opposed to combining them with participants who committed to an affirmative or negative response.

With regard to intended reporting behaviors, however, results from Table 5.4 in Appendix D suggest that home visitors who responded with “I don’t know” when asked if they would report the IPV in the home visitation scenario are significantly different from those respondents that indicated they would report the abuse, but do not differ from respondents who revealed that they would not report the case.

The differences found with regard to support for mandatory reporting in the participants who responded with “I don’t know” or “undecided” has implications for home visitation practice. The finding that home visitors who did not know if they would report the case for three of the four home visitation scenarios had significantly lower levels of support than participants who indicated they would report these scenarios suggests that lower levels of support for 
reporting and unfavorable attitudes towards reporting may translate into indecision with regard to reporting instances of IPV and children's exposure to IPV in home visitation practice. As home visitors' reporting behaviors should first and foremost be guided by state and local policies and guidelines as opposed to personal support or non-support for reporting, these findings further highlight the need for trainings and information about the pros and cons of mandatory reporting for health care providers in home visitation settings, especially for providers who may be ambivalent about their attitudes and support for mandatory reporting.

\subsection{Future Research}

Future research should work to identify and compile laws and policies for IPV reporting as well as guidelines for which types of children's exposure to IPV constitute child maltreatment and require a report to CPS. Health care providers who interact with abused women and their children, but do not necessarily provide medical treatment are still mandated to report child abuse; thus, considerations about whether or not to report IPV and children's exposure are highly relevant to this population, but they have not been provided with standardized, consistent policies and procedures that are relevant to home visitation practice. The generation of statespecific guidelines for reporting in the context of home visitation programs will also allow hypotheses about home visitors' actual, rather than perceived, knowledge about state laws to be tested, which was a limitation of the current research. In addition, other studies should continue to focus on the perspective of the mandated reporter with regard to reporting IPV and children's exposure to IPV. For example, mental health professionals' and social workers’ views on reporting IPV and children's exposure to IPV might complement the findings from the current project. Furthermore, research centering on home visitation providers' experiences with mandatory reporting in other programs other than the NFP would be useful. In addition, as was 
previously described, the group of home visitors who were undecided about their attitudes towards reporting and/or responded with "I don’t know” when asked if they would report instances of IPV and children’s exposure to IPV warrant further attention and investigation. Preliminary analyses reveal that this group of ambivalent and uncertain nurse home visitors may hold significantly different attitudes towards reporting and hold lower levels of support for reporting than respondents with more committed answers. Future research should treat indecisive respondents as a third group that are separate from participants who respond with affirmative or negative answers.

\subsection{Conclusion}

The findings of the current research have extended our knowledge of mandatory reporting of two controversial issues - mandatory reporting of IPV and children's exposure to IPV—-within the context of home visitation programs. This project has also demonstrated the importance of examining the perspective of the mandated reporter, as our results indicate that mandated reporting issues are highly relevant to home visitors and their clients in home visitation programs. Notably, home visitation providers in our sample exhibited uncertainty and wide variability regarding their attitudes toward reporting, perceived awareness of reporting requirements, and intended reporting behaviors, highlighting the need for consensus among health care providers about reporting practices and policies. Uncertainty with regard to mandatory reporting can result in serious ethical and legal implications for those required to report and can significantly impact the lives of victims of abuse and their children. Thus, education and training about mandated reporting issues and procedures is the next logical step in reducing this variation. However, as this project is only a preliminary glance into the complexities of mandated reporting in home visitation settings, and many issues in the area of 
reporting IPV and children’s exposure are still considerably gray, more research must be carried out and legal statutes may have to be redefined before health care providers in home visitation settings will have clear guidelines for managing IPV and children's exposure to IPV. In the meantime, home visitation programs can benefit from in-depth collaborations with local law enforcement, CPS agencies, domestic violence service organizations, and legal agencies. 
Appendix A: Home Visitation Scenarios

Scenario for Study 2 and 3:

Scenario \#1: You walk into your client's apartment for a home visit and notice that she has a black eye and bruises on her arms. She is 28 weeks pregnant. You talk with your client about how she got the injuries. Your client tells you that she is used to her boyfriend pushing and shoving her, but he has become much more physically violent since the pregnancy. Your client assures you that the situation is "not that bad" and that her boyfriend promised never to hurt her again. She has not revealed to you that her boyfriend was physically abusive prior to this home visit.

Scenario for Study 3:

Scenario \#2: You walk into your client's apartment for a home visit and notice that she has a black eye and bruises on her arms. Her daughter is six months old. You talk with your client about how she got the injuries. Your client tells you that she is used to her boyfriend pushing and shoving her, but he has become much more physically violent since the birth of their daughter. You talk with your client to get details of the incident and learn that the child was in the mother's arms during the violent episode. Your client assures you that her boyfriend has never been physically violent towards her in front of their daughter until now and has never hurt their daughter. She tells you that the situation is "not that bad" and that her boyfriend promised never to hurt her again. She has not revealed to you that her boyfriend was physically abusive prior to this home visit.

Scenario for Study 3:

Scenario \#3: Now imagine a scenario identical to Scenario \#2, except when you talk with your client to get details of the incident you learn that the child was in the next room during the violent episode. Your client assures you that her son only heard the incident, but did not witness the violence.

Scenario for Study 3:

Scenario \#4: In another situation identical to Scenario \#2, imagine when you ask your client for details of the violent episode, she tells you the child was at his grandmother's house. 


\section{Appendix B: Comparisons of Sample Characteristics with Population of Nurse Home}

Visitors

\begin{tabular}{|c|c|c|c|c|c|}
\hline $\begin{array}{l}\text { Characteristic } \\
\text { Age, n (\%) }\end{array}$ & \multicolumn{2}{|c|}{$\begin{array}{l}\text { Sample of Nurse } \\
\text { Home Visitors } \\
(\mathrm{n}=532)\end{array}$} & \multicolumn{2}{|c|}{$\begin{array}{c}\text { Population of Nurse } \\
\text { Home Visitors } \\
(\mathbf{N}=\mathbf{1 , 0 4 8})\end{array}$} & $P$ Value \\
\hline Less than 40 years & 190 & (36) & 493 & (47) & $<0.001$ \\
\hline More than 40 years & 342 & (64) & 555 & (53) & $<0.001$ \\
\hline \multicolumn{6}{|l|}{ Time with NFP } \\
\hline Less than 1 to 5 years & 401 & (75) & 754 & (72) & 0.1636 \\
\hline More than 5 years & 131 & (25) & 294 & (28) & 0.1636 \\
\hline Years as a Nurse, $\mathrm{M}(S D)^{\mathrm{b}}$ & 17.89 & (10.36) & 14 & -- & $<0.001$ \\
\hline \multicolumn{6}{|c|}{ Note. $P$ values for the differences between sample and population characteristics determined by } \\
\hline \multicolumn{6}{|c|}{${ }^{\mathrm{a}}$ For sample, age $=$ nurse age at time of survey; For population, age = nurse age at time of entry } \\
\hline \multicolumn{6}{|c|}{ b For sample, years nursing experiences = number of years at time of survey; For population, } \\
\hline
\end{tabular}




\section{Appendix C: Web-Based Survey}

\section{Home Visiting Nurses' Knowledge, Attitudes and Behaviors Regarding Mandatory Reporting}

Part 1. Mandatory Reporting of Domestic Violence The following sets of questions are going to ask you about domestic violence that occurs between adults_-for example, violence occurring between one of your clients and her current partner. Some states have laws that require health care personnel to report instances of domestic violence to proper authorities, such as the police or adult protective services. We would like to know what you think about the mandatory reporting of domestic violence between adults. Please keep in mind that we are simply interested in your perspectives and there is no right or wrong answer.

\section{A. Please indicate whether you Strongly Agree, Agree, Do Not Know, Disagree, or}

Strongly Disagree with the following statements:

\begin{tabular}{|c|c|c|c|c|c|}
\hline $\begin{array}{l}\text { I feel that mandatory reporting of } \\
\text { domestic violence between adults: }\end{array}$ & $\begin{array}{l}\text { Strongly } \\
\text { Agree }\end{array}$ & Agree & Undecided & Disagree & $\begin{array}{l}\text { Strongly } \\
\text { Disagree }\end{array}$ \\
\hline $\begin{array}{l}\text { 1. can damage the relationship between } \\
\text { nurse and client }\end{array}$ & & & & & \\
\hline 2. can disempower the battered woman & & & & & \\
\hline $\begin{array}{l}\text { 3. can prevent battered women from seeking } \\
\text { further help }\end{array}$ & & & & & \\
\hline 4. can further traumatize the child(ren) & & & & & \\
\hline 5. can protect the child(ren) & & & & & \\
\hline 6. can cause more disruption to the family & & & & & \\
\hline $\begin{array}{l}\text { 7. can damage the battered woman's } \\
\text { chances of custody }\end{array}$ & & & & & \\
\hline $\begin{array}{l}\text { 8. would make it easier for battered women to } \\
\text { get help }\end{array}$ & & & & & \\
\hline $\begin{array}{l}\text { 9. would put women at greater risk for being } \\
\text { abused or hurt }\end{array}$ & & & & & \\
\hline $\begin{array}{l}\text { 10. would make it less likely that a client } \\
\text { would tell me about the abuse }\end{array}$ & & & & & \\
\hline $\begin{array}{l}\text { 11. would make my clients resent me for } \\
\text { having to report }\end{array}$ & & & & & \\
\hline $\begin{array}{l}\text { 12. would help my clients because they would } \\
\text { like for someone else to report the abuse }\end{array}$ & & & & & \\
\hline
\end{tabular}


1B. Please respond with Always, Often, Some of the Time, Rarely, or Never after reading the following statements:

\begin{tabular}{|l|l|l|l|l|l|}
\hline & Always & Often & $\begin{array}{l}\text { Some of } \\
\text { the time }\end{array}$ & Rarely & Never \\
\hline $\begin{array}{l}\text { 13. I lack faith in law enforcement to respond } \\
\text { are made. }\end{array}$ & & & & & \\
\hline $\begin{array}{l}\text { 14. I fear reprisals from reporting domestic violence. } \\
\text { domestic violence }\end{array}$ & & & & & \\
\hline $\begin{array}{l}\text { 15. I fear litigation and/or legal liability from reporting. } \\
\text { reporting domestic violence. }\end{array}$ & & & & & \\
\hline $\begin{array}{l}\text { 16. I should be required to report instances of } \\
\text { domestic violence. }\end{array}$ & & & & & \\
\hline
\end{tabular}


Part 2. Mandatory Reporting of Children's Exposure to Domestic Violence The following sets of questions are going to ask you about children's exposure to domestic violence. This can include children witnessing domestic violence in the home or overhearing violent episodes. Some states have laws that consider children's exposure to domestic violence a form of child maltreatment, making these instances reportable to child protective services. We would like to know what you think about mandatory reporting of children's exposure to domestic violence. Please keep in mind that we are simply interested in your perspectives and there is no right or wrong answer.

2A. Please indicate whether you Strongly Agree, Agree, Do Not Know, Disagree, or Strongly Disagree with the following statements:

\begin{tabular}{|c|c|c|c|c|c|}
\hline $\begin{array}{l}\text { I feel that the mandatory reporting of } \\
\text { children's exposure to domestic } \\
\text { violence: }\end{array}$ & $\begin{array}{c}\text { Strongly } \\
\text { Agree }\end{array}$ & Agree & Undecided & Disagree & $\begin{array}{l}\text { Strongly } \\
\text { Disagree }\end{array}$ \\
\hline $\begin{array}{l}\text { 1. can damage the relationship between } \\
\text { nurse and client }\end{array}$ & & & & & \\
\hline 2. can disempower the battered woman & & & & & \\
\hline $\begin{array}{l}\text { 3. can prevent battered women from seeking } \\
\text { further help }\end{array}$ & & & & & \\
\hline 4. can further traumatize the child(ren) & & & & & \\
\hline 5. can protect the child(ren) & & & & & \\
\hline 6. can cause more disruption to the family & & & & & \\
\hline $\begin{array}{l}\text { 7. can damage the battered woman's } \\
\text { chances of custody }\end{array}$ & & & & & \\
\hline $\begin{array}{l}\text { 8. would make it easier for battered women } \\
\text { to get help }\end{array}$ & & & & & \\
\hline $\begin{array}{l}\text { 9. would put women at greater risk for being } \\
\text { abused or hurt }\end{array}$ & & & & & \\
\hline $\begin{array}{l}\text { 10. would make it less likely that a client } \\
\text { would tell me about the abuse }\end{array}$ & & & & & \\
\hline $\begin{array}{l}\text { 11. would make my clients resent me for } \\
\text { having to report }\end{array}$ & & & & & \\
\hline $\begin{array}{l}\text { 12. would help my clients because they } \\
\text { would like for someone else to report the } \\
\text { abuse }\end{array}$ & & & & & \\
\hline
\end{tabular}


2B. Please respond with Always, Often, Some of the Time, Rarely, or Never after reading the following statements:

\begin{tabular}{|l|l|l|l|l|l|}
\hline & Always & Often & $\begin{array}{c}\text { Some } \\
\text { of the } \\
\text { time }\end{array}$ & Rarely & Never \\
\hline $\begin{array}{l}\text { 17. I lack faith in child protective services to respond } \\
\text { appropriately when reports of children's exposure to } \\
\text { domestic violence are made. }\end{array}$ & & & & & \\
\hline $\begin{array}{l}\text { 18. I fear reprisals from reporting children's } \\
\text { exposure to domestic violence. }\end{array}$ & & & & & \\
\hline $\begin{array}{l}\text { 19. I fear litigation and/or legal liability from reporting } \\
\text { children's exposure to domestic violence. }\end{array}$ & & & & & \\
\hline $\begin{array}{l}\text { 20. Workload pressures are likely to deter me from } \\
\text { reporting children's exposure to domestic violence. }\end{array}$ & & & & & \\
\hline $\begin{array}{l}\text { 21. I should be required to report children's } \\
\text { exposure to domestic violence. }\end{array}$ & & & & & \\
\hline
\end{tabular}


Part 3. Home Visitation Scenarios In this part of the questionnaire, you will be presented with several scenarios that you may face while visiting clients. Please read each scenario carefully and respond to each of the following questions to the best of your ability.

\section{Scenario \#1: You walk into your client's apartment for a home visit and notice that she has a black eye and bruises on her arms. She is 28 weeks pregnant. You talk with your client about how she got the injuries. Your client tells you that she is used to her boyfriend pushing and shoving her, but he has become much more physically violent since the pregnancy. Your client assures you that the situation is "not that bad" and that her boyfriend promised never to hurt her again. She has not revealed to you that her boyfriend was physically abusive prior to this home visit.}

1. In your opinion, do these incidents and facts indicate child maltreatment?

0 Yes 0 No 0 I Don't Know

2. Would you report this case (i.e., to law enforcement, to child protective services)?

\begin{tabular}{|c|c|c|}
\hline 0 Yes & 0 No & 0 I Don't Know \\
\hline 2a. If Yes, to
\end{tabular}

2a. If Yes, to whom?: (Select all that apply)

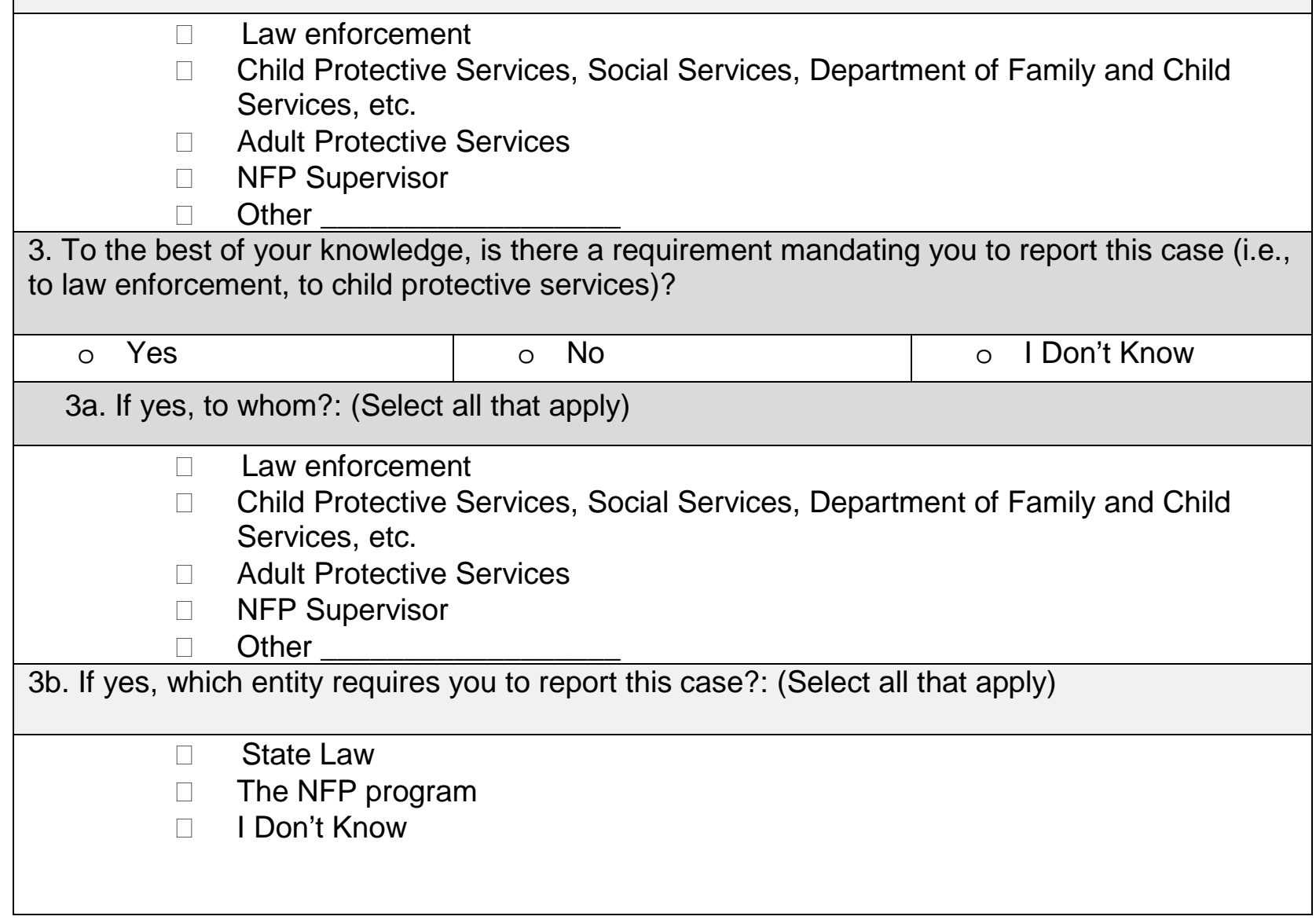




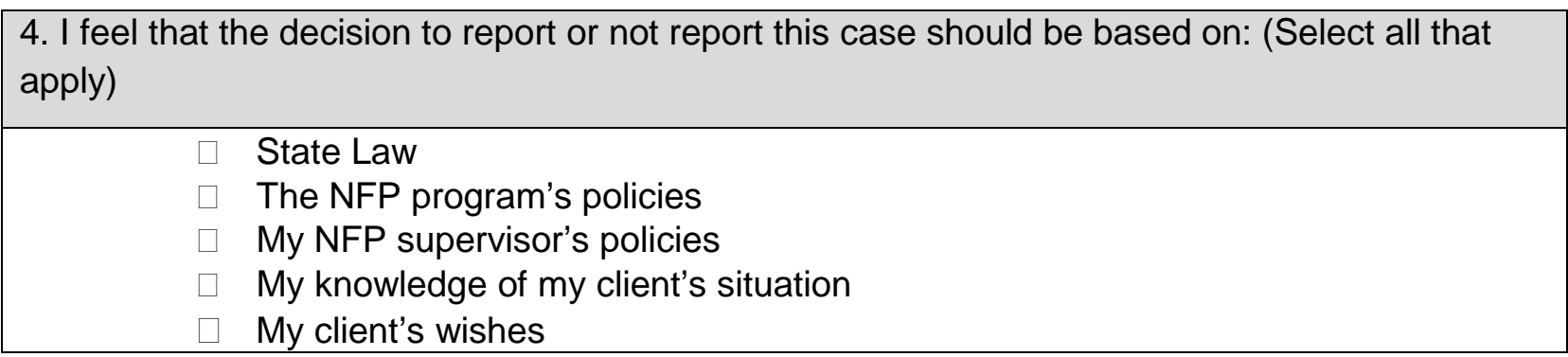

\section{Scenario \#2: You walk into your client's apartment for a home visit and notice that she} has a black eye and bruises on her arms. Her daughter is six months old. You talk with your client about how she got the injuries. Your client tells you that she is used to her boyfriend pushing and shoving her, but he has become much more physically violent since the birth of their daughter. You talk with your client to get details of the incident and learn that the child was in the mother's arms during the violent episode. Your client assures you that her boyfriend has never been physically violent towards her in front of their daughter until now and has never hurt their daughter. She tells you that the situation is "not that bad" and that her boyfriend promised never to hurt her again. She has not revealed to you that her boyfriend was physically abusive prior to this home visit.

1. In your opinion, do these incidents and facts indicate child maltreatment?
o Yes
o No
o I Don't Know

2. Would you report this case (i.e., to law enforcement, to child protective services)?

\begin{tabular}{|c|c|c|}
\hline 0 Yes & 0 No & o I Don't Know \\
\hline 2a. If Yes, to whom?: (Select all that apply)
\end{tabular}

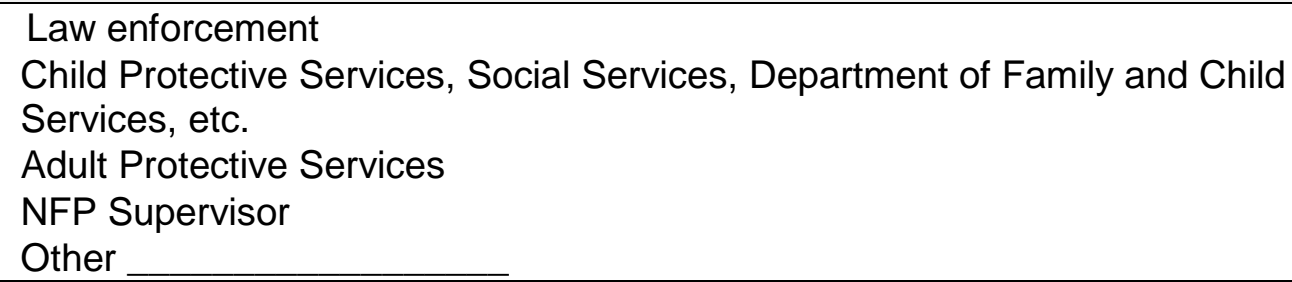

3. To the best of your knowledge, is there a requirement mandating you to report this case (i.e., to law enforcement, to child protective services)?

\begin{tabular}{l|l|l}
\hline o Yes & 0 No & I Don't Know
\end{tabular}


3a. If yes, to whom?: (Select all that apply)

Law enforcement

Child Protective Services, Social Services, Department of Family and Child

Services, etc.

Adult Protective Services

NFP Supervisor

Other

3b. If yes, which entity requires you to report this case?: (Select all that apply)

\section{State Law}

The NFP program

I Don't Know

4. I feel that the decision to report or not report this case should be based on: (Select all that apply)
State Law
The NFP program's policies
My NFP supervisor's policies
My knowledge of my client's situation
My client's wishes

Scenario \#3: Now imagine a scenario identical to Scenario \#2, except when you talk with your client to get details of the incident you learn that the child was in the next room during the violent episode. Your client assures you that her son only heard the incident, but did not witness the violence.

1. In your opinion, do these incidents and facts indicate child maltreatment?

0 Yes $\quad 0$ No $\quad 0$ I Don't Know

2. Would you report this case (i.e., to law enforcement, to child protective services)?

\begin{tabular}{l|l|ll}
\hline Y Yes & 0 No & 0 I Don't Know
\end{tabular}

\section{Scenario \#4: Now imagine a scenario identical to Scenario \#2, imagine when you ask} your client for details of the violent episode, she tells you the child was at his grandmother's house.

1. In your opinion, do these incidents and facts indicate child maltreatment? 


\begin{tabular}{|c|c|c|}
\hline o Yes & o No & o I Don't Know \\
\hline \multicolumn{3}{|c|}{ 2. Would you report this case (i.e., to law enforcement, to child protective services)? } \\
\hline o Yes & $\mathrm{O}$ No & I Don't Know \\
\hline
\end{tabular}

\section{Part 4. Demographic Information}

1. What is your age?

2. In which state are you currently involved in home visitation services for the NFP program?

3. For how many years have you been a nurse?

4. How many years have you been involved in home visitation within the NFP program?

5. How many children do you have? 
Appendix D: Characterizing “Undecided” and “I Don’t Know” Participants

Table 5.1: Associations between Undecided Responses and Demographic Characteristics for the Mandatory Reporting of IPV between Adults

\begin{tabular}{ccccc}
\hline & \multicolumn{4}{c}{ Demographic Characteristic } \\
\cline { 2 - 5 } Attitudinal Scale Item & $\begin{array}{c}\text { Age in } \\
\text { Years }\end{array}$ & $\begin{array}{c}\text { Years as a } \\
\text { Nurse }\end{array}$ & $\begin{array}{c}\text { Years with } \\
\text { NFP }\end{array}$ & $\begin{array}{c}\text { Number of } \\
\text { Children }\end{array}$ \\
\hline & \multicolumn{4}{c}{ P-Value } \\
\hline
\end{tabular}

Can damage relationship with nurse

Agree vs. Undecided

$\begin{array}{llll}.9868 & .6142 & .0540 & .2616 \\ .4112 & .5076 & .6933 & .3375 \\ .8265 & .5962 & .0840 & .5940\end{array}$

Can protect the children

Agree vs. Undecided

$\begin{array}{llll}.6654 & .9637 & .2555 & .7005 \\ .8290 & .8366 & .5286 & .8818 \\ .6866 & .9534 & .2614 & .7251\end{array}$

Makes it easier to get help

Agree vs. Undecided

.1054

.4925

.2516

.0562

Disagree vs. Undecided

.3103

.7713

.6673

.0698

Agree/Disagree vs. Undecided

.1185

.5363

.3819

.0403

Puts women at greater risk for abuse

Agree vs. Undecided

.7418

.6602

.0760

.0248

Disagree vs. Undecided

.4294

.6694

.7480

.1654

Agree/Disagree vs. Undecided

.9743

.6525

.1093

.0249

Can limit the disclosure of abuse

$\begin{array}{lllll}\text { Agree vs. Undecided } & .2908 & .3337 & .0039 & .0479 \\ \text { Disagree vs. Undecided } & .0290 & .3769 & .1699 & .3924 \\ \text { Agree/Disagree vs. Undecided } & .1399 & .3069 & .0072 & .0715\end{array}$

Note. $P$-values determined by $t$-tests. Bonferroni adjustment was used to adjust for multiple

pairwise comparisons; thus, statistical significance was set to $\boldsymbol{p}<\mathbf{. 0 0 0 2}(0.05 / 240$ comparisons). 
Table 5.2: Associations between Undecided Responses and Study Variables for the Mandatory Reporting of IPV between Adults

\begin{tabular}{|c|c|c|c|}
\hline \multirow[b]{2}{*}{ Attitudinal Scale Item } & \multicolumn{3}{|c|}{ Study Variables } \\
\hline & $\begin{array}{c}\text { Support for } \\
\text { Reporting IPV }\end{array}$ & $\begin{array}{c}\text { Intended } \\
\text { Reporting } \\
\text { Behavior } \\
\end{array}$ & $\begin{array}{c}\text { Perception of a } \\
\text { Reporting } \\
\text { Requirement } \\
\end{array}$ \\
\hline & \multicolumn{3}{|c|}{ P-value } \\
\hline \multicolumn{4}{|l|}{ Can damage relationship with nurse } \\
\hline Agree vs. Undecided & .0001 & .3600 & .6940 \\
\hline Disagree vs. Undecided & .0446 & .0050 & .2050 \\
\hline Agree/Disagree vs. Undecided & .0088 & .1300 & .9470 \\
\hline \multicolumn{4}{|l|}{ Can protect the children } \\
\hline Agree vs. Undecided & .0000 & .0010 & .0830 \\
\hline Disagree vs. Undecided & .0001 & .0210 & .1890 \\
\hline Agree/Disagree vs. Undecided & .0000 & .0010 & .0810 \\
\hline \multicolumn{4}{|l|}{ Makes it easier to get help } \\
\hline Agree vs. Undecided & .0000 & .0010 & .0030 \\
\hline Disagree vs. Undecided & .4468 & .4240 & .5150 \\
\hline Agree/Disagree vs. Undecided & .0000 & .0010 & .0060 \\
\hline \multicolumn{4}{|c|}{ Puts women at greater risk for abuse } \\
\hline Agree vs. Undecided & .0007 & .0130 & .0850 \\
\hline Disagree vs. Undecided & .0012 & .0390 & .1410 \\
\hline Agree/Disagree vs. Undecided & .1362 & .2660 & .4820 \\
\hline \multicolumn{4}{|l|}{ Can limit the disclosure of abuse } \\
\hline Agree vs. Undecided & .0021 & .7640 & .8950 \\
\hline Disagree vs. Undecided & .0185 & .0130 & .0660 \\
\hline Agree/Disagree vs. Undecided & .0689 & .6180 & .5060 \\
\hline
\end{tabular}

Note. $P$-values determined by $t$-tests for continuous data and $x^{2}$ for categorical data. Bonferroni adjustment was used to adjust for multiple pairwise comparisons; thus, statistical significance was set to $\boldsymbol{p}<.0002(0.05 / 240$ comparisons). 
Table 5.3: Associations between Undecided Responses and Demographic Characteristics for the Mandatory Reporting of Children's Exposure to IPV

\begin{tabular}{|c|c|c|c|c|c|}
\hline \multirow[b]{2}{*}{ Attitudinal Scale Item } & \multicolumn{5}{|c|}{ Demographic Characteristic } \\
\hline & $\begin{array}{l}\text { Age in } \\
\text { Years }\end{array}$ & $\begin{array}{l}\text { Years as } \\
\text { a Nurse }\end{array}$ & $\begin{array}{l}\text { Years } \\
\text { with } \\
\text { NFP }\end{array}$ & $\begin{array}{l}\text { Number } \\
\text { of } \\
\text { Children }\end{array}$ & $\begin{array}{c}\text { Support } \\
\text { for } \\
\text { Reporting }\end{array}$ \\
\hline & \multicolumn{5}{|c|}{ P-Value } \\
\hline \multicolumn{6}{|l|}{$\begin{array}{l}\text { Can damage relationship with } \\
\text { nurse }\end{array}$} \\
\hline Agree vs. Undecided & .7790 & .3238 & .0058 & .2911 & .7313 \\
\hline Disagree vs. Undecided & .5864 & .1236 & .1752 & .3225 & .0000 \\
\hline Agree/Disagree vs. Undecided & .9966 & .3003 & .0258 & .5729 & .2736 \\
\hline \multicolumn{6}{|l|}{ Can protect the children } \\
\hline Agree vs. Undecided & .4523 & .4760 & .0124 & .3973 & .0000 \\
\hline Disagree vs. Undecided & .5872 & .5403 & 6193 & .8748 & .0197 \\
\hline Agree/Disagree vs. Undecided & .4589 & .4706 & .0278 & .5218 & .0000 \\
\hline \multicolumn{6}{|l|}{ Makes it easier to get help } \\
\hline Agree vs. Undecided & .7224 & .2651 & .4375 & .0188 & .0000 \\
\hline Disagree vs. Undecided & .9182 & .1456 & .2132 & .0810 & .0306 \\
\hline Agree/Disagree vs. Undecided & .7740 & .3218 & .3462 & .0147 & .0001 \\
\hline \multicolumn{6}{|l|}{$\begin{array}{l}\text { Puts women at greater risk for } \\
\text { abuse }\end{array}$} \\
\hline Agree vs. Undecided & .6712 & .4454 & .0446 & .2308 & .8374 \\
\hline Disagree vs. Undecided & 6993 & .7790 & .1405 & .6707 & .0023 \\
\hline Agree/Disagree vs. Undecided & .8612 & .4521 & .0365 & .0269 & .4259 \\
\hline \multicolumn{6}{|l|}{$\begin{array}{l}\text { Can limit the disclosure of } \\
\text { abuse }\end{array}$} \\
\hline Agree vs. Undecided & .4292 & 6198 & .0538 & .4529 & .3331 \\
\hline Disagree vs. Undecided & .0074 & .0516 & .0487 & .6936 & .0024 \\
\hline Agree/Disagree vs. Undecided & .1573 & .3341 & .0389 & .4752 & .9771 \\
\hline
\end{tabular}

Note. $P$-values determined by $t$-tests. Bonferroni adjustment was used to adjust for multiple pairwise comparisons; thus, statistical significance was set to $\boldsymbol{p}<\mathbf{. 0 0 0 2}(0.05 / 240$ comparisons). 
Table 5.4: Associations between I Don't Know Responses and Demographic Characteristics for the Mandatory Reporting of Children's Exposure to IPV

Would You Report this Case?

Would you report?

\begin{tabular}{cllll}
\hline $\begin{array}{c}\text { Age in } \\
\text { Years }\end{array}$ & $\begin{array}{l}\text { Years as } \\
\text { a Nurse }\end{array}$ & $\begin{array}{l}\text { Years } \\
\text { with } \\
\text { NFP }\end{array}$ & $\begin{array}{c}\text { Number } \\
\text { of } \\
\text { Children }\end{array}$ & $\begin{array}{c}\text { Support } \\
\text { for } \\
\text { Reporting }\end{array}$ \\
\hline \multicolumn{3}{c}{ P-value }
\end{tabular}

\section{Scenario 1: Pregnant woman}

Yes vs. I Don’t Know

\begin{tabular}{lllll}
\hline .4577 & .3762 & .0109 & .1908 & $\mathbf{. 0 0 0 0}$ \\
\hline .4378 & .8807 & .9823 & .2769 & .0304 \\
\hline .8469 & .3390 & .0744 & .8608 & .0611 \\
\hline
\end{tabular}

\section{Scenario 2: Child in arms}

Yes vs. I Don’t Know

No vs. I Don’t Know

Yes/No vs. I Don’t Know

\begin{tabular}{lllll}
\hline .4998 & .8247 & .0618 & .2432 & .0179 \\
\hline .9613 & .7921 & .7195 & .4280 & .0833 \\
\hline .6198 & .8106 & .1447 & .9812 & .0573 \\
\hline
\end{tabular}

Scenario 3: Child in other room

Yes vs. I Don’t Know

\begin{tabular}{lllll}
\hline .3297 & .0267 & .0092 & .2222 & $\mathbf{. 0 0 0 0}$ \\
\hline .0799 & .1704 & .2604 & .2637 & .0434 \\
\hline .1526 & .0264 & .0219 & .2129 & .0954 \\
\hline
\end{tabular}

\section{Scenario 4: Child not at home}

Yes vs. I Don’t Know

\begin{tabular}{lllll}
\hline .1526 & .1222 & .5235 & .9755 & $\mathbf{. 0 0 0 1}$ \\
\hline .0276 & .1696 & .7032 & .3137 & .1661 \\
\hline .0452 & .1045 & .7871 & .5055 & .6550
\end{tabular}

No vs. I Don’t Know

Yes/No vs. I Don’t Know

Note. $P$-values determined by $t$-tests. Bonferroni adjustment was used to adjust for multiple pairwise comparisons; thus, statistical significance was set to $\boldsymbol{p}<\mathbf{. 0 0 0 2}(0.05 / 240$ comparisons). 
References 


\section{References}

1. National Center for Injury Prevention and Control, Centers for Disease Control and Prevention. Costs of intimate partner violence against women in the United States; 2003. Available at: http:/www.cdc.gov/violenceprevention/pub/IPV_cost.html. Accessed November 3, 2010.

2. Tjaden P, Thoennes N. Extent, nature, and consequences of intimate partner violence: findings from the national violence against women survey. Report for grant 93-IJ-CX0012, funded by the National Institute of Justice and the Centers for Disease Control. Washington (DC): NIJ; 2000.

3. Campbell JC, Woods AB, Chouaf KL, Parker B. Reproductive health consequences of intimate partner violence. A nursing research review. Clinical Nursing Research. 2000;9(3):217-237.

4. Campbell JC. Health consequences of intimate partner violence. Lancet. 2002;359(9314):1331.

5. Coker AL. Does physical intimate partner violence affect sexual health? Trauma, Violence \& Abuse. 2007;8(2):149-177.

6. Collins RL, Ellickson PL, Orlando M, Klein DJ. Isolating the nexus of substance use, violence and sexual risk for HIV infection among young adults in the United States. AIDS And Behavior. 2005;9(1):73-87.

7. Campbell J, Jones AS, Dienemann J, et ak. Intimate partner violence and physical health consequences. Archives of Internal Medicine. 2002;162(10):1157-1163. 
8. Wingood GM, DiClemente RJ, Raj A. Adverse consequences of intimate partner abuse among women in non-urban domestic violence shelters. American Journal of Preventive Medicine. 2000;19(4):270-275.

9. Pallitto CC, Campbell JC, O'Campo P. Is intimate partner violence associated with unintended pregnancy? Trauma, Violence \& Abuse. 2005;6(3):217-235.

10. Goodwin MM, Gazmararian JE, Johnson CH, Gilbert BC, Saltzman LE. Pregnancy intendedness and physical abuse around the time of pregnancy: findings from the pregnancy risk assessment monitoring system, 1996 - 1997. Maternal \& Child Health Journal. 2000;4(2):85.

11. Leserman J, Drossman DA. Relationship of abuse history to functional gastrointestinal disorders and symptoms. Trauma, Violence \& Abuse. 2007;8(3):331-343.

12. Coker AL, Sanderson M, Fadden MK, Lucia P. Intimate partner violence and cervical neoplasia. Journal of Women's Health \& Gender-Based Medicine. 2000;9(9):1015-1023.

13. Plichta SB. Intimate partner violence and physical health consequences. Journal of Interpersonal Violence. 2004;19(11):1296-1323.

14. Bryant SA, Spencer GA. Domestic violence: What do nurse practitioners think? Journal of the American Academy of Nurse Practitioners. 2002;14(9):421.

15. Iavicoli LG. Mandatory reporting of domestic violence: the law, friend or foe? Mount Sinai Journal of Medicine. 2005;72(4):228-231.

16. Sachs CJ, Koziol-McLain J, Glass N, Webster D, Campbell J. A population-based survey assessing support for mandatory domestic violence reporting by health care personnel. Women \& Health. 2002;35(2-3):121-133. 
17. Hyman A, Schillinger D. Laws mandating reporting of domestic violence. JAMA: Journal of the American Medical Association. 1995;273(22):1781.

18. Bauer HM, Mooney D, Larkin H, et al. California's mandatory reporting of domestic violence injuries: does the law go too far or not far enough? The Western Journal of Medicine. 1999;171(2):118-124.

19. Coulter ML, Chez RA. Domestic violence victims support mandatory reporting: For others. Journal of Family Violence. 1997;12(3):349-356.

20. Houry D, Feldhaus K, Thorson AC, Abbott J. Mandatory reporting laws do not deter patients from seeking medical care. Annals of Emergency Medicine. 1999;34(3):336-341.

21. Family Violence Prevention Fund. National consensus guidelines on identifying and responding to domestic violence victimization in health care settings: State codes on intimate partner violence victimization reporting requirements for health care providers; 2004. Available at: http://www.endabuse.org/userfiles/file/Consensus.pdf. Accessed online November 3, 2010.

22. Freed PE, Drake VK. Mandatory reporting of abuse: practical, moral, and legal issues for psychiatric home healthcare nurses. Issues in Mental Health Nursing. 1999;20(4):423436.

23. Rodriguez MA, McLoughlin E, Nah G, Campbell JC. Mandatory reporting of domestic violence injuries to the police: What do emergency department patients think? JAMA: Journal of the American Medical Association. 2001;286(5):580-583.

24. Hyman A, Chez RA. Mandatory reporting of domestic violence by health care providers: a misguided approach. Women's Health Issues. 1995;5(4):208-213. 
25. Gielen AC, O'Campo PJ, Campbell JC, et al. Women's opinions about domestic violence screening and mandatory reporting. American Journal of Preventive Medicine 2000;19(4):279-285.

26. Glass N, Dearwater S, Campbell J. Intimate partner violence screening and intervention: data from eleven Pennsylvania and California community hospital emergency departments. Journal of Emergency Nursing. 2001;27(2):141-149.

27. Caralis PV, Musialowski R. Women's experiences with domestic violence and their attitudes and expectations regarding medical care of abuse victims. Southern Medical Journal. 1997;90(11):1075.

28. Malecha AT, Lemmey D, McFarlane J, et al. Mandatory reporting of intimate partner violence: safety or retaliatory abuse for women? Journal of Women's Health \& GenderBased Medicine. 2000;9(1):75-78.

29. Rodriguez MA, Craig AM, Mooney DR, et al. Patient attitudes about mandatory reporting of domestic violence: implications for health care professionals. Western Journal of Medicine. 1998;169(6):337-341.

30. Smith KC, Kelleher KJ, Barth RP, et al. Overview of the children and domestic violence services study. Children \& Youth Services Review. 2005;27(11):1243-1258.

31. Edleson JL. The overlap between child maltreatment and woman battering. Violence Against Women. 1999;5(2):134.

32. Appel AE, Holden GW. The co-occurrence of spouse and physical child abuse: A review and appraisal. Journal of Family Psychology. 1998;12(4):578-599.

33. Child Welfare Information Gateway. Definitions of child abuse and neglect state statute series; 2007. Available at: http://www.childwelfare.gov/systemwide/laws_policies/ 
statutes/define.cfm. Accessed November 3, 2010.

34. Holt S, Buckley H, Whelan S. The impact of exposure to domestic violence on children and young people: A review of the literature. Child Abuse \& Neglect. 2008;32(8):797810.

35. McGuigan WM, Pratt CC. The predictive impact of domestic violence on three types of child maltreatment. Child Abuse \& Neglect. 2001;25(7):869-883.

36. Carlson BE, Roberts AR. Children's observations of interparental violence. In Roberts, AR, ed. Battered Women and their Families: Intervention Strategies and Treatment Programs. New York, NY: Springer Publishing; 1984:147-167.

37. Carlson BE. Children Exposed to Intimate Partner Violence. Trauma, Violence \& Abuse. 2000;1(4):321-342.

38. Rudo ZH, Powell DS, Dunlap G. The effects of violence in the home on children's emotional, behavioral, and social functioning. Journal of Emotional \& Behavioral Disorders. 1998;6(2):94.

39. Glass N, Campbell JC. Mandatory reporting of intimate partner violence by health care professionals: a policy review. Nursing Outlook. 1998;46(6):279-283.

40. Strauss MA, Gelles RJ. Physical Violence in American Families: Risk Factors and Adaptations to Family Violence in 8,145 Families. New Brunswick, NJ: Transaction Press; 1990.

41. Dong M, Anda RF, Felitti VJ, et al. The interrelatedness of multiple forms of childhood abuse, neglect, and household dysfunction. Child Abuse \& Neglect. 2004;28(7):771-784. 
42. Kitzmann KM, Gaylord NK, Holt AR, Kenny ED. Child witnesses to domestic violence: A meta-analytic review. Journal of Consulting and Clinical Psychology. 2003;71(2):339352.

43. Kolar KR, Davey D. Silent victims: children exposed to family violence. The Journal of School Nursing. 2007;23(2):86-91.

44. Lundy M, Grossman SF. The mental health service needs of young children exposed to domestic violence: supportive data. Families in Society. 2005;86(1):17-29.

45. Osofsky JD. The impact of violence on children. The Future of Children. 1999;9(3):3349.

46. Knapp JF. The impact of children witnessing violence. Pediatric Clinics of North America 1998;45(2):355-364.

47. Hornor G. Domestic violence and children. Journal of Pediatric Health Care. 2005;19(4):206-212.

48. Sox R. Integrative review of recent child witness to violence research. Clinical Excellence for Nurse Practitioners. 2004;8(2):68-78.

49. Groves BM. Mental health services for children who witness domestic violence. The Future of Children. 1999;9(3):122-132.

50. Osofsky JD. Prevalence of children's exposure to domestic violence and child maltreatment: implications for prevention and intervention. Clinical Child and Family Psychology Review. 2003;6:161 - 171. 
51. Koenen KC, Moffitt TE, Caspi A, et al. Domestic violence is associated with environmental suppression of IQ in young children. Development and Psychopathology. 2003;15(2):297-311.

52. Anda RF, Felitti VJ, Chapman DP, et al. Abused boys, battered mothers, and male involvement in teen pregnancy. Pediatrics. 2001;107(2):E19-E19.

53. Hillis SD, Anda RF, Dube SR, Felitti VJ, Marchbanks PA, Marks JS. The association between childhood experience and adolescent pregnancy, long-term psychosocial consequences, and fetal death. Pediatrics. 2004;113(2):320-327.

54. Dube SR, Anda RF, Croft JB, Edwards VJ, Giles WH, Felitti VJ. Growing up with parental alcohol abuse: exposure to childhood abuse, neglect, and household dysfunction. Child Abuse \& Neglect. 2001;25(12):1627-1640.

55. Anda RF, Croft JB, Felitti VJ, et al. Adverse childhood experiences and smoking during adolescence and adulthood. JAMA: The Journal Of The American Medical Association. 1999;282(17):1652-1658.

56. Dube SR, Anda RF, Felitti VJ, Chapman DP, Williamson DF, Giles WH. Childhood abuse, household dysfunction, and the risk of attempted suicide throughout the life span: findings from the Adverse Childhood Experiences Study. JAMA: The Journal of The American Medical Association. 2001;286(24):3089-3096.

57. Fantuzzo JW, Lindquist CU. The effects of observing conjugal violence on children: A review and analysis of research methodology. Journal of Family Violence. 1989;4(1):7794.

58. Roberts AL, Gilman SE, Fitzmaurice G, Decker MR, Koenen KC. Witness of intimate partner violence in childhood and perpetration of intimate partner violence in adulthood. Epidemiology. 2010;21(6):809-818. 
59. Christian S. Children's exposure to domestic violence: Is it child abuse? National Conference of State Legislatures State Legislative Report; 2002; 27(1): 1 - 9

60. Verhoek-Oftedahl W, Devine A. The gray zone between children witnessing domestic violence and child maltreatment: a call to establish a threshold for intervention. Medicine And Health. 2003;86(12):379-382.

61. Zink T, Siegel R, Chen L, Levin L, Pabst S, Putnam F. Physician knowledge and management of children exposed to domestic violence in Ohio: A comparison of pediatricians and family physicians. Clinical Pediatrics. 2005;44(3):211-219.

62. Zink T, Kamine D, Musk L, Sill M, Field V, Putnam F. What are providers' reporting requirements for children who witness domestic violence? Clinical Pediatrics. 2004;43(5):449-460.

63. Edleson JL, Gassman-Pines J, Hill MB. Defining child exposure to domestic violence as neglect: Minnesota's difficult experience. Social Work. 2006;51(2):167-174.

64. Rodriguez CM. Professionals' attitudes and accuracy on child abuse reporting decisions in New Zealand. Journal of Interpersonal Violence. 2002;17(3):320-342.

65. Rodriguez MA, McLoughlin E, Bauer HM, Paredes V, Grumbach K. Mandatory reporting of intimate partner violence to police: Views of physicians in California. American Journal of Public Health. 1999;89(4):575-578.

66. Mathews B, Fraser J, Walsh K, Dunne M, Kilby S, Chen L. Queensland nurses' attitudes towards and knowledge of the legislative duty to report child abuse and neglect: results of a state-wide survey. Journal of Law and Medicine. 2008;16(2):288-304.

67. Bekemeier B. Public-health nurses and the prevention of and intervention in family violence. Public Health Nursing. 1995;12(4):222-227. 
68. Evanson TA. Addressing domestic violence through maternal-child health home visiting: what we do and do not know. Journal of Community Health Nursing. 2006;23(2):95-111.

69. Shepard MF, Elliott BA, Falk DR, Regal RR. Public health nurses' responses to domestic violence: A report from the enhanced domestic abuse intervention project. Public Health Nursing. 1999;16(5):359-366.

70. Olds D, Henderson CR, Jr., Kitzman H, Cole R. Effects of prenatal and infancy nurse home visitation on surveillance of child maltreatment. Pediatrics. 1995;95(3):365-372.

71. Chaffin M, Bard D. Impact of intervention surveillance bias on analyses of child welfare report outcomes. Child Maltreatment. 2006;11(4):301-312.

72. Nygren P, Nelson HD, Klein J. Screening children for family violence. Annals of Family Medicine. 2004;2(2):161-169.

73. Nurse-Family Partnership. Overview. Available at: http://nursefamilypartnership.org/ assets/PDF/Fact-sheets/NFP_Overview. Accessed November 3, 2010.

74. Nurse-Family Partnership. Nurse-Family Partnership Snapshot. Available at http://www.nursefamilypartnership.org/assets/PDF/Fact-sheets/NFP_Snapshot. Accessed November 3, 2010.

75. Olds DL, Henderson CR Jr, Chamberlin R, Tatelbaum R. Preventing child abuse and neglect: a randomized trial of nurse home visitation. Pediatrics.1986;78(1):65-78.

76. Kitzman H, Olds DL, Henderson CR Jr, et al. Effect of prenatal and infancy home visitation by nurses on pregnancy outcomes, childhood injuries, and repeated childbearing: a randomized controlled trial. JAMA: Journal of the American Medical Association.1997;278(8):644-652. 
77. Olds DL, Kitzman H, Cole R, et al. Effects of nurse home-visiting on maternal life course and child development: age 6 follow-up results of a randomized trial. Pediatrics. 2004;114(6):1550-1559.

78. Olds DL, Robinson J, Pettitt L, et al. Effects of home visits by paraprofessionals and by nurses: age 4 follow-up results of a randomized trial. Pediatrics. 2004;114(6):1560-1568.

79. Olds DL, Eckenrode J, Henderson CR Jr, et al. Long-term effects of home visitation on maternal life course and child abuse and neglect: fifteen-year follow-up of a randomized trial. JAMA: Journal of the American Medical Association. 1997;278(8):637-643.

80. Olds DL, Henderson CR Jr, Tatelbaum R, Chamberlin R. Improving the delivery of prenatal care and outcomes of pregnancy: a randomized trial of nurse home visitation. Pediatrics. 1986;77(1):16-28.

81. Olds DL, Kitzman H, Hanks C, et al. Effects of nurse home visiting on maternal and child functioning: age-9 follow-up of a randomized trial. Pediatrics. 2007;120(4):e832845.

82. Nurse-Family Partnership. Nurses and mothers: Nurse-Family Partnership builds a transformational relationship that benefits multiple generations. Available at: http://www.nursefamilypartnership.org/assets/PDF/Fact-sheets/NFP_Nurses-Mothers. Accessed November 3, 2010.

83. Coker AL, Smith PH, McKeown RE, King MJ. Frequency and correlates of intimate partner violence by type: physical, sexual, and psychological battering. American Journal of Public Health. 2000;90(4):553-559.

84. Eckenrode J, Ganzel B, Henderson CR Jr, et al. Preventing child abuse and neglect with a program of nurse home visitation: The limiting effects of domestic violence. JAMA: Journal of the American Medical Association. 2000;284(11):1385-1391. 
85. Macmillan HL, Wathen CN, Barlow J, Fergusson DM, Leventhal JM, Taussig HN. Interventions to prevent child maltreatment and associated impairment. Lancet. 2009;373(9659):250-266.

86. Mercy JA, Saul J. Creating a healthier future through early interventions for children. JAMA: Journal of the American Medical Association. 2009;301(21):2262-2264.

87. Kantor GK, Little L. Defining the boundaries of child neglect - When does domestic violence equate with parental failure to protect? Journal of Interpersonal Violence. 2003;18(4):338-355.

88. Coker AL, Smith PH, Bethea L, King MR, McKeown RE. Physical health consequences of physical and psychological intimate partner violence. Archives of Family Medicine. 2000;9(5):451-457.

89. Douglas H, Walsh T. Mothers, domestic violence, and child protection. Violence against Women. 2010;16(5):489-508.

90. Olds DL, Kitzman H. Review of research on home visiting for pregnant women and parents of young children. The Future of Children. 1993;3(3):53-92.

91. Jack S, DiCenso A, Lohfeld L. Opening doors: factors influencing the establishment of a working relationship between paraprofessional home visitors and at-risk families. Canadian Journal of Nursing Research. 2002;34(4):59-69.

92. Thorne S. Secondary analysis in qualitative research: Issues and implications. In: Morse J, ed. Critical Issues in Qualitative Research Methods. New York, NY: Sage Publications; 1994: 263-279.

93. Hsiu-Fang H, Shannon SE. Three approaches to qualitative content analysis. Qualitative Health Research. 2005;15(9):1277-1288. 
94. Cohen J. Statistical Power Analysis for the Behavioral Sciences. 2nd ed. New York, NY: Academic Press; 1988.

95. Lincoln Y, \& Guba, E. Naturalistic Inquiry. Thousand Oaks, CA: Sage; 1985.

96. DeVoe ER, Smith EL. Don't take my kids: barriers to service delivery for battered mothers and their children. Journal of Emotional Abuse. 2003;3(3/4):277-294.

97. Sullivan CM, Hagen LA. Survivors' opinions about mandatory reporting of domestic violence and sexual assault by medical professionals. Affilia: The Journal of Women and Social Work. 2005;20(3):346-361.

98. English DJ, Edleson JL, Herrick ME. Domestic violence in one state's child protective caseload: a study of differential case dispositions and outcomes. Children and Youth Services Review. 2005;27(11):1183-1201.

99. Jackson A. Nicholson v. Scoppetta: providing a conceptual framework for noncriminalization of battered mothers and alternatives to removal of their children from the home. Capital University Law Review. 2005;33:821 - 868.

100. Szabo V, Strang VR. Secondary analysis of qualitative data. Advances in Nursing Science. 1997;20(2):66-74.

101. White MD, Marsh EE. Content analysis: a flexible methodology. Library Trends. 2006;55(1):22-45.

102. Fritsch T. Mandatory reporting of intimate partner violence: making it safe and effective. Report prepared and presented for Physicians for a Violence-Free Society; 2004. Available at: http://www.kiprc.uky.edu/projects/ipv/SafeRptg.pdf. Accessed November 3, 2010. 
103. Davidov D, Jack SM, Frost SS, Coben JH. Mandatory reporting in the context of home visitation programs: intimate partner violence and children’s exposure to intimate partner violence. Violence Against Women. In press.

104. Steen JA. The perceived impact of a child maltreatment report from the perspective of the domestic violence shelter worker. Journal of Interpersonal Violence. 2008;24(11): 19061918.

105. Tabachnick BG, Fidell LS. Using Multivariate Statistics. 5th ed. Boston, MA: Allyn \& Bacon/Pearson Education; 2007.

106. Kalichman SC, Brosig CL. Practicing psychologists' interpretations of and compliance with child abuse reporting laws. Law and Human Behavior. 1993;17(1):83-93.

107. Zellman GL. Report decision-making patterns among mandated child abuse reporters. Child Abuse \& Neglect. 1990;14(3):325-336.

108. Archer TM. Response rates to expect from web-based surveys and what to do about it. Journal of Extension. 2008;43(3).

109. Sheehan KB. E-mail survey response rates: a review. Journal of Computer-Mediated Communication. 2001;6(2).

110. Edleson JL. Should childhood exposure to adult domestic violence be defined as child maltreatment under the law? In: Jaffe PG, Baker LL, Cunningham AJ, eds. Protecting Children From Domestic Violence: Strategies for Community Intervention. New York, NY: Guilford Press; 2004: 8-29.

111. Brown T. Should there be laws mandated domestic violence reporting? PRO. American Journal of Maternal Child Nursing. 1999;24(5):224. 
112. Osofsky JD. The effects of domestic violence on children: the invisible victims. Social Policy Reports. 1995; IX(3).

113. Fantuzzo JW, Mohr WK. Prevalence and effects of child exposure to domestic violence. Future of Children. 1999;9(3):21-32.

114. Holden GW, Geffner R, Jouriles EN, Holden GW, Geffner R, Jouriles EN. Children Exposed to Marital violence: theory Research, and Applied Issues. Washington, DC: American Psychological Association; 1998.

115. Litrownik AJ, Newton R, Hunter WM, English D, Everson MD. Exposure to family violence in young at-risk children: A longitudinal look at the effects of victimization and witnessed physical and psychological aggression. Journal of Family Violence. 2003;18(1):59-73.

116. Wolak J, Finkelhor D. Children exposed to partner violence. In: Jasinkski JL \& Williams L, eds. Partner Violence: A Comprehensive Review of 20 Years of Research. Thousand Oaks, CA: Sage Publications; 1998: 73-112.

117. Christian SP, Seidl T, Pinto-Martin J. Pediatric injury resulting from family violence. Pediatrics. 1997;99(2):208 - 212.

118. Humphreys C. Problems in the system of mandatory reporting of children living with domestic violence. Journal of Family Studies. 2008;14(2/3):228-239.

119. Weithorn LA. Protecting children from exposure to domestic violence: The use and abuse of child maltreatment statutes. . Hastings Law Journal. 2001;53(1):1 - 156.

120. Edleson JL. Children's witnessing of adult domestic violence. Journal of Interpersonal Violence. 1999;14(8):839. 
121. Mathews B, Walsh K, Fraser JA. Mandatory reporting by nurses of child abuse and neglect. Journal of Law and Medicine. 2006;13(4):505-517.

122. Rodriguez MA, Sheldon WR, Rao N. Abused patient's attitudes about mandatory reporting of intimate partner abuse injuries to police. Women \& Health. 2002;35(23):135-147.

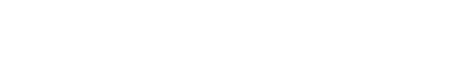

